Review

\title{
Hypervalent Iodine Reagents in High Valent Transition Metal Chemistry
}

\author{
Felipe Cesar Sousa e Silva, Anthony F. Tierno and Sarah E. Wengryniuk* \\ Department of Chemistry, Temple University, 1901 N. 13th St., Philadelphia, PA 19122, USA; \\ tug08706@temple.edu (F.C.S.S.); tuh08431@temple.edu (A.F.T.) \\ * Correspondence: sarahw@temple.edu; Tel.: +1-215-204-0360
}

Academic Editor: Margaret A. Brimble

Received: 29 March 2017; Accepted: 8 May 2017; Published: 12 May 2017

\begin{abstract}
Over the last 20 years, high valent metal complexes have evolved from mere curiosities to being at the forefront of modern catalytic method development. This approach has enabled transformations complimentary to those possible via traditional manifolds, most prominently carbon-heteroatom bond formation. Key to the advancement of this chemistry has been the identification of oxidants that are capable of accessing these high oxidation state complexes. The oxidant has to be both powerful enough to achieve the desired oxidation as well as provide heteroatom ligands for transfer to the metal center; these heteroatoms are often subsequently transferred to the substrate via reductive elimination. Herein we will review the central role that hypervalent iodine reagents have played in this aspect, providing an ideal balance of versatile reactivity, heteroatom ligands, and mild reaction conditions. Furthermore, these reagents are environmentally benign, non-toxic, and relatively inexpensive compared to other inorganic oxidants. We will cover advancements in both catalysis and high valent complex isolation with a key focus on the subtle effects that oxidant choice can have on reaction outcome, as well as limitations of current reagents.
\end{abstract}

Keywords: hypervalent iodine; oxidation; oxidant; redox; high valent; high oxidation state; catalysis

\section{Introduction}

Over the last 20 years, high valent metal complexes have transitioned from mere curiosities to being at the forefront of modern catalytic method development. This approach has enabled transformations complimentary to those possible via traditional manifolds, most prominently carbon-heteroatom bond formation. Key to the advancement of this chemistry has been the identification of oxidants that are capable of accessing these high oxidation state complexes. The oxidant has to be both powerful enough to achieve the desired oxidation as well as provide heteroatom ligands for transfer to the metal center; these heteroatoms are often subsequently transferred to the substrate via reductive elimination. The choice of heteroatom can be critical depending on the application. For example, chloride ligands can aide in the stabilization and isolation of high valent complexes whereas acetate ligands are often more successful in catalytic manifolds. Hypervalent iodine reagents have seen wide application in this field as they are environmentally benign, non-toxic, and relatively inexpensive compared to other inorganic oxidants. Furthermore, they provide an excellent balance of versatile reactivity, heteroatom ligands, and mild reaction conditions. We will cover advancements in the use of hypervalent iodine reagents for both catalysis and high valent complex isolation with a key focus on the subtle effects that oxidant choice can have on reaction outcome, as well as limitations of current reagents. Many of these areas have been covered in the context of more broad reviews and in those cases the discussion will not be comprehensive but focus on the key aspects and most relevant elements for this review. The discussion is organized broadly 
by the metal center being oxidized, including palladium, platinum, gold, nickel, copper, and finally isolated examples with other transition metals. Below a summary graphic has been provided that includes oxidants common to high valent transition metal chemistry that will be discussed in this review as well as common nomenclature and how they will be presented in the text (Figure 1).
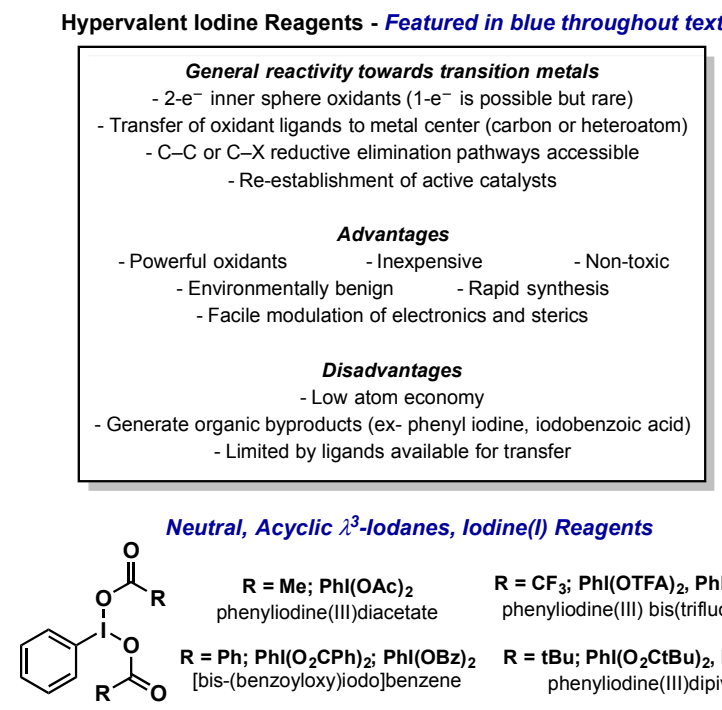

ine(l) Reagents

$\mathrm{R}=\mathrm{CF}_{3} ; \mathrm{Phl}(\mathrm{OTFA})_{2}, \mathrm{Phl}\left(\mathrm{OCOCF}_{3}\right)_{2}$ phenyliodine(III) bis(trifluoroacetate)

$\mathrm{R}=\mathrm{tBu} ; \mathrm{Phl}\left(\mathrm{O}_{2} \mathrm{CtBu}\right)_{2}, \mathrm{Phl}(\mathrm{OPiv})_{2}$ phenyliodine(III)dipivalate

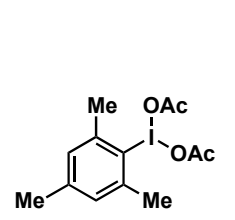

lodomesitylene diacetate $\operatorname{Mes}\left(\right.$ OAc) ${ }_{2}$

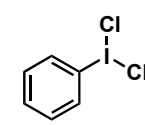

phenyliodine(III)dichloride $\mathrm{Phl}(\mathrm{Cl})_{2}$

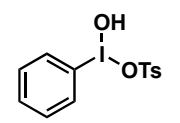

Hydroxo-phenyliodine(III)tosylate Phl(OH)OTs, Koser's reagent

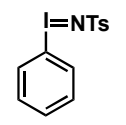

IOAc
lodine monoacetate

[N-(phenylsulfonyl)imino]phenyliodinane PhINTs

Neutral, Cyclic, $\lambda^{3}$-lodanes

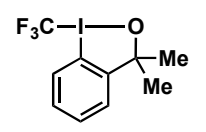

3,3 - Dimethyl-1-(trifluoromethyl)-1,2benziodoxole; Togni's reagent

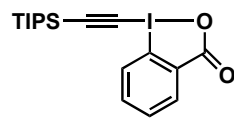

1-[(triisopropylsilyl)ethynyl]-1,2benziodoxol-3(1H)-one;TIPS-EBX

(Poly)cationic, Acyclic $\lambda^{3}$-lodanes

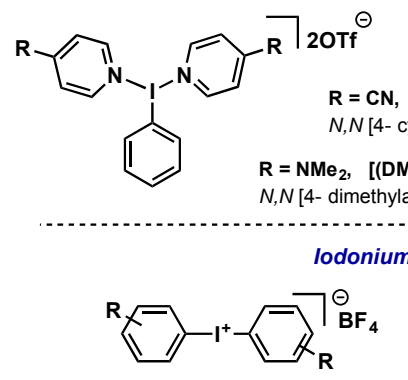

Diaryliodonium tetrafluoroborate $\left[\mathrm{Ph}_{2} \mathrm{IBF}_{4}\right.$
$\mathrm{R}=\mathrm{H} \quad\left[(\mathrm{Py})_{2} \mathrm{Ph}_{\mathrm{Ph}} \mathrm{OOTf}^{-}\right.$

$N, N$ dipyridinium phenyliodine(III) triflate

$\mathrm{R}=\mathrm{CN}, \quad\left[(4 \mathrm{CNPy}){ }_{2} \mathrm{IPh}\right] 2 \mathrm{OTf}^{-}$

$N, N$ [4- cyano]dipyridinium phenyliodine(III) triflate

$=\mathrm{NMe}_{2}, \quad\left[(\mathrm{DMAP})_{2} \mathrm{IPh}_{2} \mathrm{OTf}^{-}\right.$

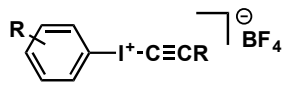

Alkynylliodonium tetrafluoroborate $\left[\mathrm{PhICCR}_{\mathrm{B} F} \mathrm{H}_{4}\right.$

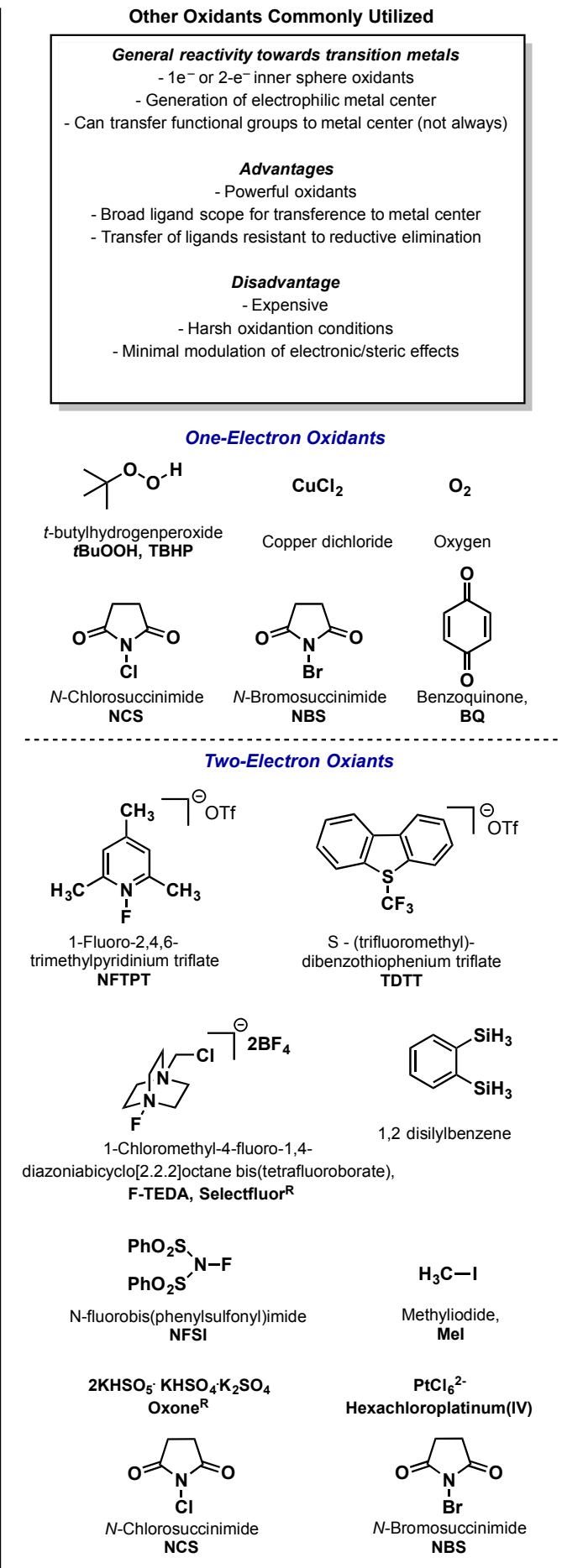

NCS

Figure 1. Common oxidants utilized in high valent metal catalysis. 


\section{Palladium}

\subsection{Introduction}

Palladium has a long and storied history in transition metal catalysis, facilitating such iconic cross coupling reactions as the Heck, Suzuki-Miyara, Negishi, Buchwald-Hartwig, Sonagashira, and others. Its ubiquity stems not only from its excellent reactivity, but also from a detailed understanding of its underlying mechanisms and predictable reactivity, which facilitates novel reaction development. For many years, palladium catalysis relied on the $\mathrm{Pd}(0) / \mathrm{Pd}(\mathrm{II})$ redox couple, however, work in the 21st century has shown the power and promise of the high oxidation state $\mathrm{Pd}(\mathrm{II}) / \mathrm{Pd}(\mathrm{IV})$ manifold, as well as the potential role of Pd(III) species in catalysis (Scheme 1). This chemistry has enabled transformations previously inaccessible via traditional catalytic manifolds, most notably carbon-heteroatom bond forming reductive eliminations, the microscopic reverse of the oxidative addition pathways commonly encountered in low valent palladium catalysis. In this context, hypervalent iodine reagents have emerged as key players, facilitating net two-electron oxidations at the metal center accompanied by transfer of their heteroatom ligands, most commonly acetate or chloride. Arguably the rapid advancements and synthetic applications of high valent palladium chemistry have spurred investigations into more obscure oxidation states with other metals. As both synthetic applications and mechanistic details of this area have been comprehensively discussed in several excellent reviews in recent years [1-8], this section will discuss the key role that hypervalent iodine reagents have played in its development, with special attention paid to recent reports as well as limitations of current methods that could be addressed through continued exploration of novel oxidants. As the body of work in this area is extensive, this section will be organized based on the type of bond formation being targeted, namely $\mathrm{C}-\mathrm{O}, \mathrm{C}-\mathrm{X}, \mathrm{C}-\mathrm{N}$, and $\mathrm{C}-\mathrm{C}$ bonds, and finally studies focusing on $\mathrm{Pd}(\mathrm{III})$ species.

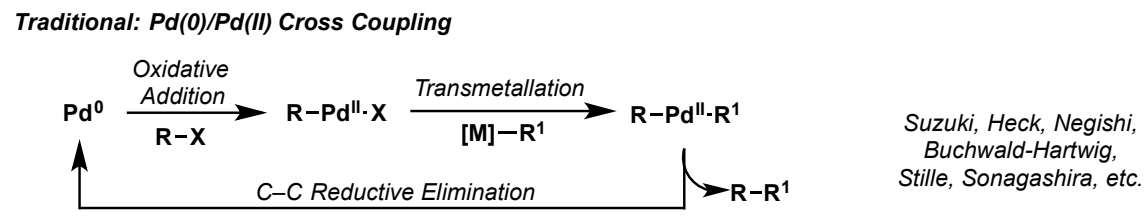

Last 20 years: Pd(II)/Pd(IV) Manifolds: C-H Functionalization, Alkene Difunctionalization, Allylic Oxidation

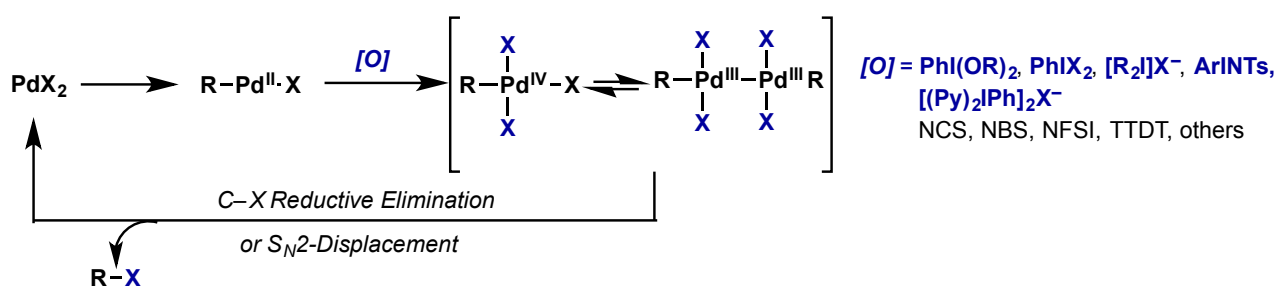

Scheme 1. Manifolds for palladium catalysis. Traditional methods via $\operatorname{Pd}(0) / \operatorname{Pd}(\mathrm{II})$ and recent advances in $\mathrm{Pd}(\mathrm{II}) / \mathrm{Pd}(\mathrm{IV})$ catalysis.

\subsection{Palladium $(I V)$}

\subsubsection{Introduction}

Canty reported the first X-ray structure of an alkyl Pd(IV) organometallic complex in 1986, formed via the oxidative addition of iodomethane to a dimethyl (bpy)Pd(II) complex (1, Scheme 2) [9]. Canty's work revealed the octahedral geometry of $\mathrm{Pd}(\mathrm{IV})$ species 1 , as well as the clean oxidative addition/reductive elimination reactivity and stability of these complexes, which he comments could "suggest that development of a rich organometallic chemistry of palladium(IV) may be possible". This report laid the foundation for the rich chemistry, mechanistic and structural understanding of this high oxidation state redox couple that has emerged over the last 20 years. 


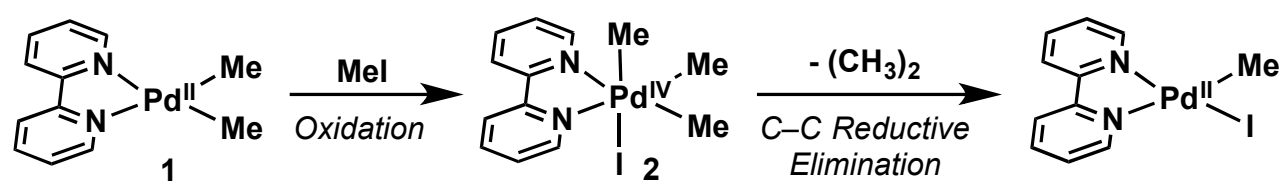

Scheme 2. Canty's report resulting in the first X-ray crystallographic characterization of a $\operatorname{Pd}(\mathrm{IV})$ alkyl species.

$\mathrm{Pd}(\mathrm{II}) / \mathrm{Pd}(\mathrm{IV})$ chemistry has become as a powerful synthetic manifold to facilitate transformations not accessible via traditional $\mathrm{Pd}(0) / \mathrm{Pd}(\mathrm{II})$ catalysis (Scheme 1 ). This field has been pioneered by the Sanford group in the area of $\mathrm{C}-\mathrm{H}$ acetoxylation and halogenation. There have been several comprehensive reviews written on this topic in recent years and the reader is directed there for detailed mechanistic discussion and an exhaustive report of applications [1,4,5]. Building from this work, $\mathrm{Pd}(\mathrm{IV})$ chemistry has been applied to the formation of a diverse array of $\mathrm{C}-\mathrm{N}, \mathrm{C}-\mathrm{O}, \mathrm{C}-\mathrm{X}$, and $\mathrm{C}-\mathrm{C}$ bond forming reactions.

\subsubsection{Carbon-Oxygen Bond Formation}

There has been extensive work in the area of $\mathrm{C}-\mathrm{O}$ bond formation via $\mathrm{Pd}(\mathrm{II}) / \mathrm{Pd}(\mathrm{IV})$ catalysis with hypervalent iodine reagents. This application is particularly well suited as the most common hypervalent iodine oxidants, of the type $\mathrm{PhI}(\mathrm{OR})_{2}$, transfer carboxylate ligands to the metal center that are then engaged in subsequent $\mathrm{C}-\mathrm{O}$ bond forming reductive elimination. These carboxylate ligands are also highly tunable, both sterically and electronically, allowing for control of complex stability, reaction pathway and selectivity. Approaches have expanded to include $\mathrm{C}-\mathrm{H}$ functionalization, allylic oxidation, as well as alkene difunctionalization.

\subsubsection{C-H Functionalization}

The first report of $\mathrm{Pd}$-catalyzed $\mathrm{C}-\mathrm{H}$ acetoxylation using a hypervalent iodine oxidant was by Crabtree, who achieved the acetoxylation of benzene using $\mathrm{Pd}(\mathrm{OAc})_{2}$ with $\mathrm{PhI}(\mathrm{OAc})_{2}$ as the external oxidant and-OAc source (Scheme 3) [10]. This built upon the work of Stock et al., which employed dichromate to perform an analogous transformation [11], however $\mathrm{PhI}(\mathrm{OAc})_{2}$ offered much higher selectivity and did not perform further product oxidations. In what has become a standard mechanistic proposal, Crabtree proposed acetyl assisted $\mathrm{C}-\mathrm{H}$ activation at $\mathrm{Pd}(\mathrm{II})$ (intermediate 3 ) would give intermediate 4, which can then be diverted down one of two pathways. Along the desired pathway (Path B) 5 is then oxidized by $\mathrm{PhI}(\mathrm{OAc})_{2}$ to $\mathrm{Pd}(\mathrm{IV})$ species 5 with introduction of two acetyl groups. Subsequent reductive elimination gives rise to acetoxylated product and regeneration of the $\operatorname{Pd}(\mathrm{OAc})_{2}$. Importantly, Crabtree noted that competitive formation of biphenyl (via Path A) is minimized with $\mathrm{PhI}(\mathrm{OAc})_{2}$, indicating that oxidation to $\mathrm{Pd}(\mathrm{IV})$ in this system is significantly faster than a second $\mathrm{C}-\mathrm{H}$ activation step to give 6 . It was also found that in the absence of oxidant, biphenyl was the only observable product, thus indicating that $\mathrm{Pd}(\mathrm{II})$ intermediate 4 will not undergo direct $\mathrm{C}-\mathrm{X}$ reductive elimination, and emphasizing the significance of $\mathrm{Pd}(\mathrm{IV})$ pathways in facilitating such transformations. While this system displayed only moderate catalytic activity and required solvent quantities of the arene, it laid the foundation for the development of directed $\mathrm{C}-\mathrm{H}$ acetoxylation, which has relied on hypervalent iodine oxidants to efficiently acetoxylate $\mathrm{C}\left(\mathrm{sp}^{2}\right)-\mathrm{H}$ as well as $\mathrm{C}\left(\mathrm{sp}^{3}\right)-\mathrm{H}$ bonds. 


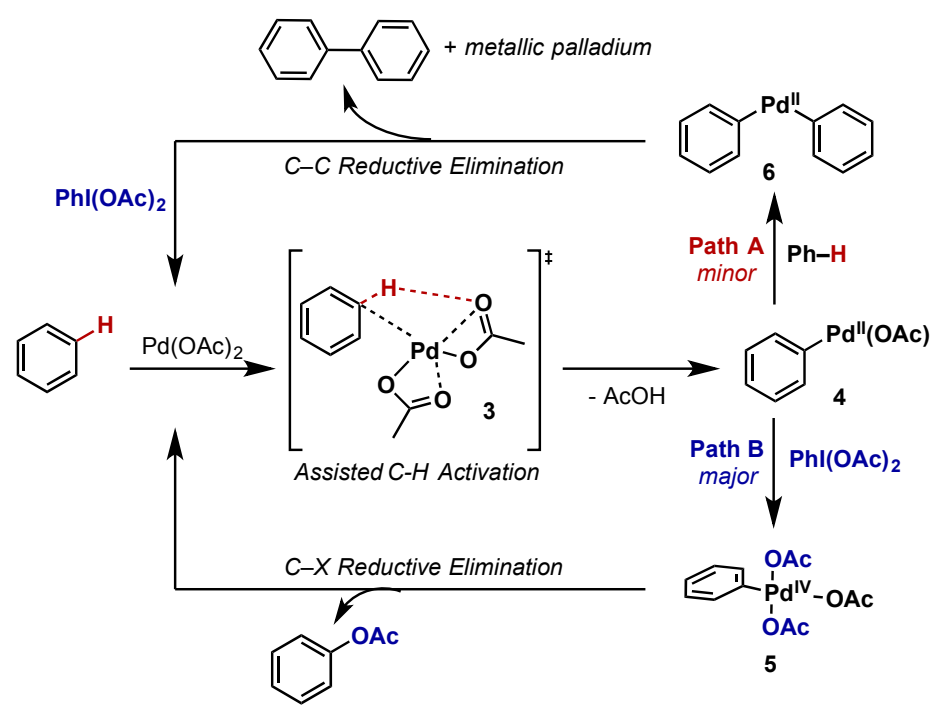

Scheme 3. $\mathrm{Pd}(\mathrm{II}) / \mathrm{Pd}(\mathrm{IV})$ catalyzed acetoxylation of benzene with use of $\mathrm{PhI}(\mathrm{OAc})_{2}$ as external oxidant.

The Sanford group's contributions to this area began in 2004 with their seminal report on the directed $\mathrm{C}-\mathrm{H}$ acetoxylation of 2-phenylpyridine using $\mathrm{Pd}(\mathrm{OAc})_{2} / \mathrm{PhI}(\mathrm{OAc})_{2}$ (Scheme $4 a$ ) [12]. Since then, they have extended this method to include a range of directing groups for $\mathrm{C}\left(\mathrm{sp}^{2}\right)-\mathrm{H}$ acetoxylation and a brief overview is included in Scheme $4 \mathrm{~b}$ [13]. While other oxidants including $\mathrm{Mn}(\mathrm{OAc})_{2}$ and Oxone have been used in this chemistry, $\mathrm{PhI}(\mathrm{OAc})_{2}$ is by far the most common [2]. Sanford also demonstrated a polymer supported variant of this chemistry, which allows for facile recycling of the hypervalent iodine reagent, addressing the issue of iodobenzene byproducts produced in these transformations (Scheme 4c) [14].

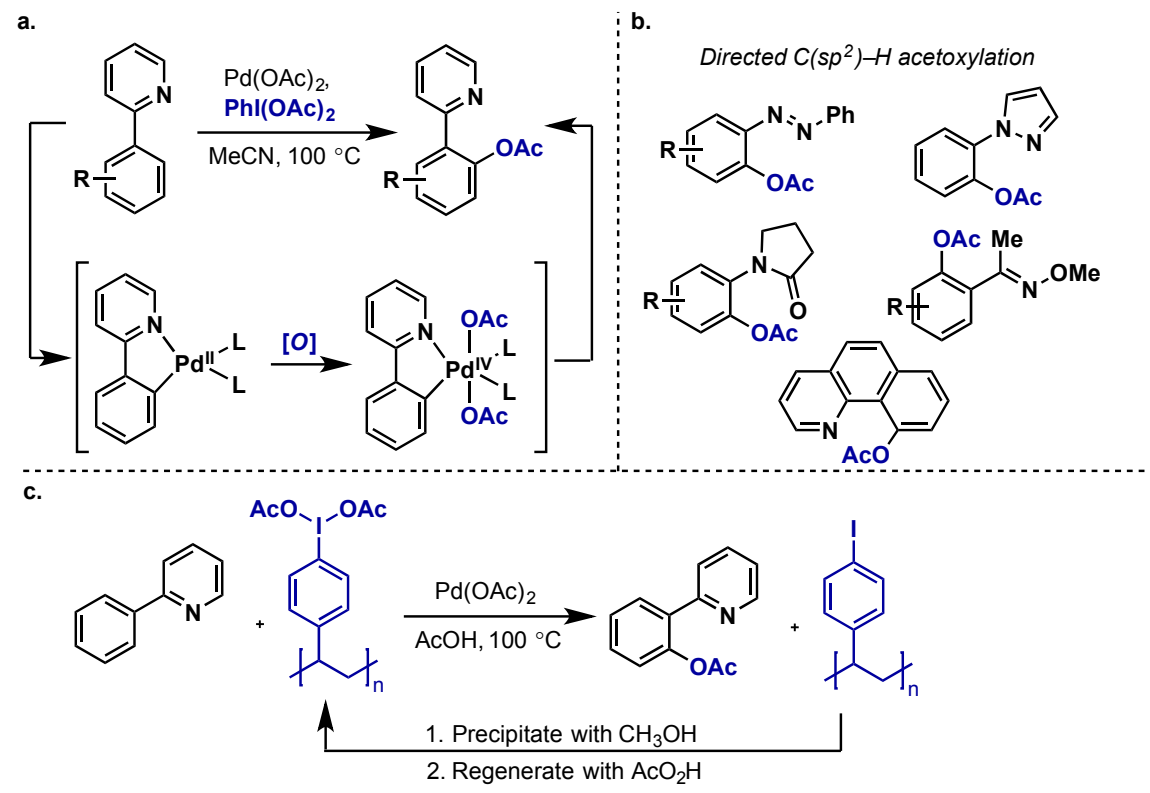

Scheme 4. (a) First report on the directed $\mathrm{C}\left(\mathrm{sp}^{2}\right)-\mathrm{H}$ acetoxylation of 2-phenylpyridine with $\mathrm{Pd}(\mathrm{OAc})_{2} / \mathrm{PhI}(\mathrm{OAc})_{2} ;(\mathbf{b})$ General scope of directing groups used for $\mathrm{C}\left(\mathrm{sp}^{2}\right)-\mathrm{H}$ acetoxylation; (c) Polymer-supported $\lambda^{3}$-iodane allows for facile oxidant recycling.

The acetoxylation of both benzylic and unactivated $\mathrm{C}\left(\mathrm{sp}^{3}\right)-\mathrm{H}$ bonds can also be accomplished with $\mathrm{Pd}(\mathrm{OAc})_{2}$ and $\mathrm{PhI}(\mathrm{OAc})_{2}$ (Scheme 5) $[12,15,16]$. In these reactions, sterics plays a large role in 
dictating regioselectivity, with the less sterically hindered $\mathrm{C}-\mathrm{H}$ bond undergoing $\mathrm{C}-\mathrm{H}$ activation. While the $\mathrm{C}\left(\mathrm{sp}^{3}\right)-\mathrm{H}$ variant often performs most efficiently with $\mathrm{PhI}(\mathrm{OAc})_{2}$ as the oxidant, combinations of Oxone/Mn(OAc) 2 , molecular oxygen, and peroxide oxidants have also been used effectively [2]. Another interesting example used iodine(I) reagent IOAc, which was generated in situ from $\mathrm{PhI}(\mathrm{OAc})_{2}$ and $\mathrm{I}_{2} ; \mathrm{PhI}(\mathrm{OAc})_{2}$ alone was ineffective in this case [17].

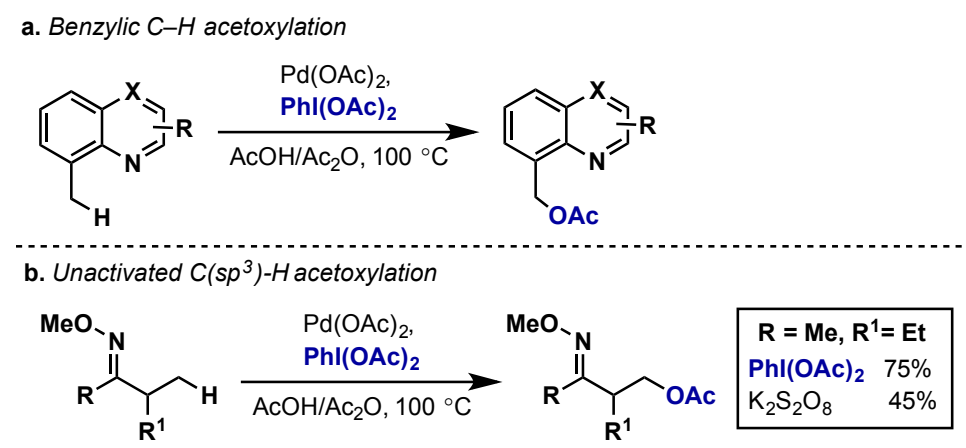

Scheme 5. (a) Directed acetoxylation of benzylic C( $\left.\mathrm{sp}^{3}\right)-\mathrm{H}$ bonds; (b) Directed acetoxylation of unactivated $\mathrm{C}\left(\mathrm{sp}^{3}\right)-\mathrm{H}$ bonds.

The Sanford group has conducted extensive mechanistic studies on these processes, and the reader is directed to some selected full reports for detailed discussion [2,18-20]. Their work has been accompanied by that of Ritter and others, with a key point being whether Pd(IV) species or $\mathrm{Pd}(\mathrm{III})$ dimers are the active catalysts. Key reports detailing the possibility of Pd(III) intermediates are discussed in more detail in Section 2.3. Sanford's seminal report in this area outlines some of the key features of both the ligand scaffolds and hypervalent iodine oxidants that allow for study of reactive Pd(IV) intermediates as well as mechanistic elucidation (Scheme 6) [19]. Two rigid cyclometallated 2-phenylpyridine ligands were incorporated to lend stability to the resultant complexes, and suppress competing ligand exchange and side reactions upon oxidation. Additionally, the acetate ligands of $\mathrm{PhI}(\mathrm{OAc})_{2}$ were exchanged for aryl carboxylates that could be readily derivatized and thus used as facile handles to control the electronic parameters at the metal center. The Pd(IV) complex (7) obtained upon oxidation with $\mathrm{PhI}\left(\mathrm{CO}_{2} p-\mathrm{XAr}\right)_{2}$ where $\mathrm{X}=\mathrm{NO}_{2}$ was able to characterized by $\mathrm{X}$-ray crystallography, revealing cis addition of the two carboxylates ligands. Subsequent Hammett analysis revealed a clear correlation between carboxylate electronics and the rate of reductive elimination, indicating that the carboxylate acted in as a nucleophile in reductive elimination.

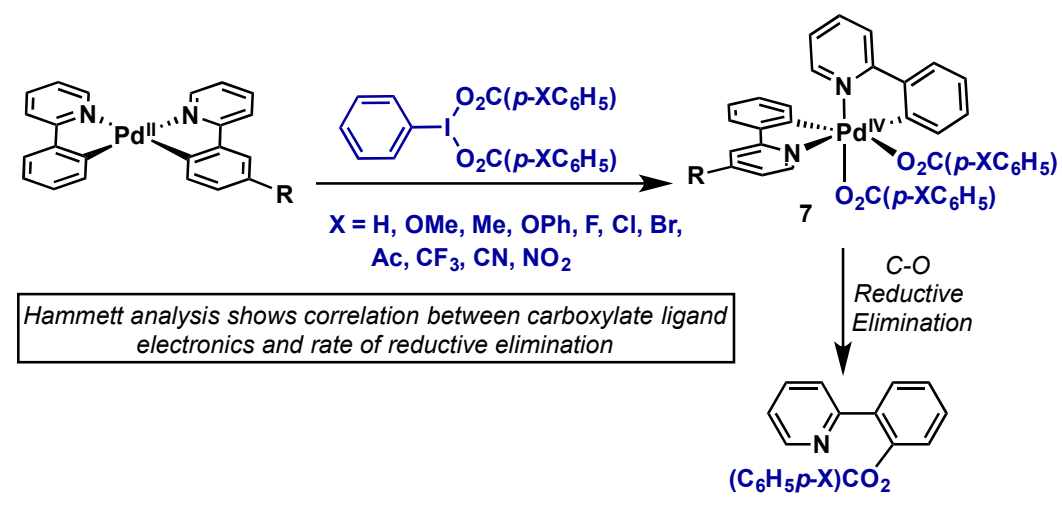

Scheme 6. Seminal mechanistic investigation into Pd(IV)-mediated C-H acetoxylation.

The Yu group reported an intramolecular $\mathrm{C}\left(\mathrm{sp}^{2}\right)-\mathrm{H}$ acetoxylation that could also be rendered asymmetric using a Boc-Ile-OH chiral ligand (Scheme 7) [21]. This report was the first enantioselective application of $\mathrm{Pd}(\mathrm{II}) / \mathrm{Pd}(\mathrm{IV})$ catalysis and gave high yields and enantioselectivities of benzofuranones. 


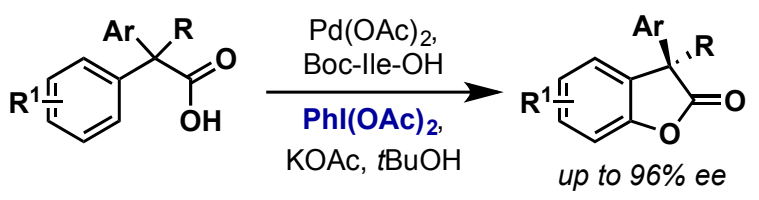

Scheme 7. Enantioselective intramolecular $\mathrm{C}\left(\mathrm{sp}^{2}\right)-\mathrm{H}$ acetoxylation using chiral amino acid ligand.

Sanford demonstrated an impressive example of non-directed $\mathrm{C}\left(\mathrm{sp}^{2}\right)-\mathrm{H}$ acetoxylation through the addition of pyridine to enhance catalytic activity of the palladium catalyst (Scheme 8) [22]. In this system, the ratio of $[\mathrm{Pd}] /$ pyridine proved critical as well as the selection of hypervalent iodine oxidant. Switching to the more sterically hindered MesI $(\mathrm{OAc})_{2}$ from $\mathrm{PhI}(\mathrm{OAc})_{2}$ improved both yield and regioselectivity.

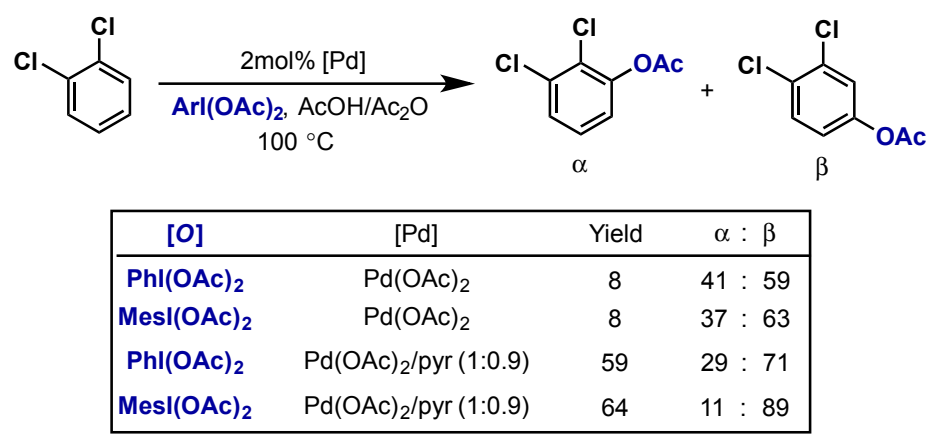

Scheme 8. Non-directed arene $\mathrm{C}-\mathrm{H}$ acetoxylation. Effect of both catalyst and hypervalent iodine oxidant on reactivity.

Chen reported $\mathrm{C}\left(\mathrm{sp}^{3}\right)-\mathrm{H}$ and $\mathrm{C}\left(\mathrm{sp}^{2}\right)-\mathrm{H}$ alkoxylation using a picolinamide directing group (Scheme 9) [23]. The reaction is proposed to proceed via displacement of acetate ligands by alkoxides at a $\mathrm{Pd}(\mathrm{IV})$ intermediate (8). The authors rule out an alternative $\mathrm{S}_{\mathrm{N}}$ 2-displacement of $\mathrm{Pd}(\mathrm{IV})$ by $\mathrm{ROH}$ since $t$ - $\mathrm{BuOH}$ also participates to give $\mathrm{C}-\mathrm{OR}$ bond formation. This reactivity is divergent from their previous reports on $\mathrm{C}-\mathrm{H}$ amination using this same system, where 8 would undergo selective $\mathrm{C}-\mathrm{N}$ reductive elimination in the absence of an external nucleophile (for discussion of $\mathrm{C}-\mathrm{N}$ bond formation, see Section 2.2.4.2, Scheme 27b). It was found that the use of other oxidants including AgOAc, Oxone, $\mathrm{Ce}\left(\mathrm{SO}_{4}\right)_{2}, \mathrm{~K}_{2} \mathrm{~S}_{2} \mathrm{O}_{8}$, " $\mathrm{F}^{+\prime}$ " sources, as well as hypervalent iodine oxidants with other carboxylate ligands all gave inferior conversions. In $\mathrm{C}\left(\mathrm{sp}^{2}\right)-\mathrm{H}$ alkoxylation, either mono- or bisalkoxylation could be achieved by altering the equivalents of $\mathrm{PhI}(\mathrm{OAc})_{2}$.
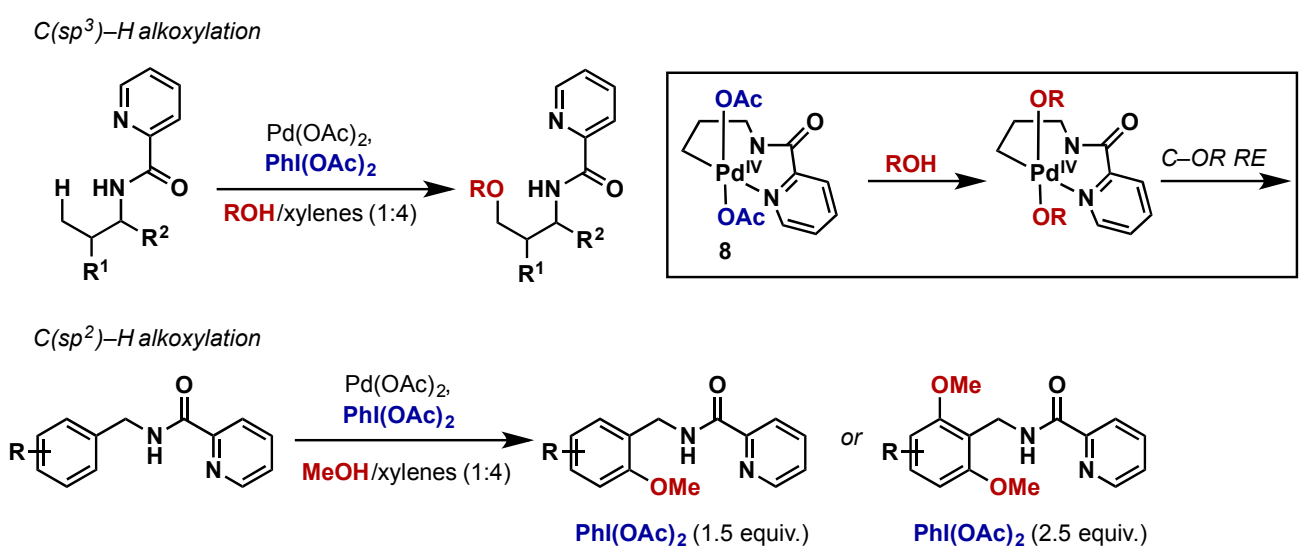

Scheme 9. $\mathrm{C}\left(\mathrm{sp}^{3}\right)-\mathrm{H}$ alkoxylation using picolinamide directing group via ligand exchange at $\mathrm{Pd}(\mathrm{IV})$. 
A similar transformation has also been reported by Rao using an 8-aminoquinoline directing group and the unique choice of $\lambda^{5}$-iodane Dess-Martin Periodinane (DMP, 9) as the oxidant (Scheme 10) [24]. Other oxidants including $\mathrm{PhI}(\mathrm{OAc})_{2}, \mathrm{PhI}(\mathrm{OTFA})_{2}, \mathrm{~K}_{2} \mathrm{~S}_{2} \mathrm{O}_{8}, \mathrm{NaIO}_{4}, \mathrm{NaIO}_{3}$, and Selectfluor all gave little or no conversion to desired products and competing functionalization of the 8-aminoquinoline directing group was also observed. The authors propose that DMP is not the terminal oxidant but rather cyclic $\lambda^{3}$-iodane 10, formed in situ by attack of the alcohol on DMP, which then transfers the alkoxide to the palladium center upon oxidation. However, a similar ligand displacement at a $\mathrm{Pd}(\mathrm{IV})$ intermediate, analogous to Chen's report, cannot be ruled out.
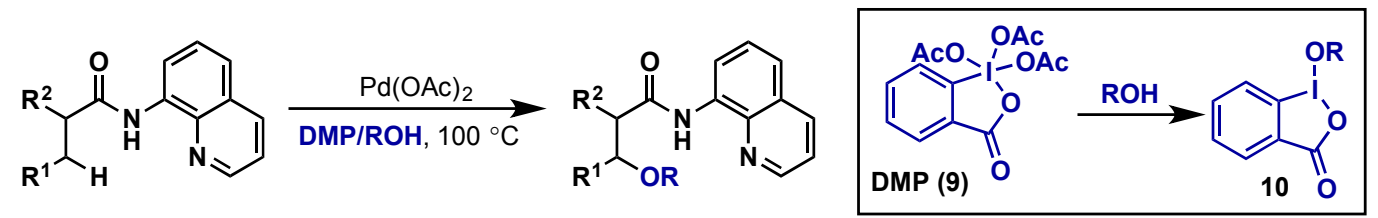

Scheme 10. $\mathrm{C}\left(\mathrm{sp}^{3}\right)-\mathrm{H}$ alkoxylation of methylene positions using an 8-aminoquinoline directing group and DMP as an oxidant.

\subsubsection{Alkene Difunctionalization, Allylic Oxidation}

The difunctionalization of alkenes is also possible employing $\mathrm{Pd}(\mathrm{II}) / \mathrm{Pd}(\mathrm{IV})$ catalysis and hypervalent iodine reagents. Through the traditional $\mathrm{Pd}(0) / \mathrm{Pd}(\mathrm{II})$ catalysis, the $\mathrm{Pd}(\mathrm{II})$ intermediate (11) that arises from initial heteropalladation undergoes rapid $\beta$-hydride elimination to regenerate an alkene (Scheme 11). By introducing an appropriate oxidant, 11 can instead be oxidized to a Pd(IV) species (12), which is set up for subsequent reductive elimination.

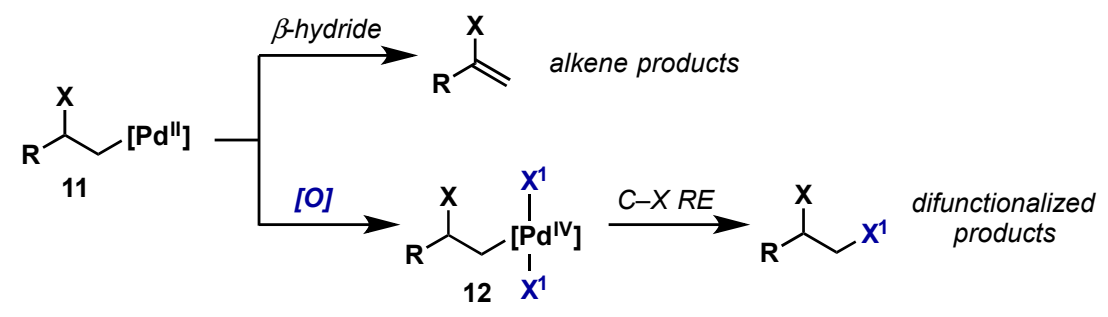

Scheme 11. Alkene difunctionalization enabled via $\mathrm{Pd}(\mathrm{II}) / \mathrm{Pd}(\mathrm{IV})$ catalysis.

There have been several reports on 1,2-aminooxygenation of alkenes via this approach that utilize phthalimide as the nitrogen source. Stahl reported the use of allylic ethers in the diastereoselective aminoalkoxylation of terminal alkenes (Scheme 12a) [25]. Mechanistic studies revealed that an initial cis aminopalladation step and oxidation gave $\mathrm{Pd}(\mathrm{IV})$ intermediate $\mathbf{1 3}$, followed by $\mathrm{C}-\mathrm{O}$ bond formation via an intermolecular $\mathrm{S}_{\mathrm{N}}$ 2-displacement by acetate. Using a similar approach, Sanford employed homoallylic alcohols in the diastereoselective formation of substituted tetrahydrofuran rings (Scheme 12b) [26]. Consistent with Stahl's findings, Sanford reports a cis aminopalladation/oxidation sequence however, in this case, the presence of the homoallylic alcohol results in intramolecular coordination to give palladacycle 14. This leads to preferential direct $\mathrm{C}-\mathrm{O}$ bond forming reductive elimination rather than intermolecular $\mathrm{S}_{\mathrm{N}} 2$ attack on 14 . Consistent with the necessary formation of the six-membered palladacycle, additional substitution on the alcohol backbone results in significantly higher yields. 


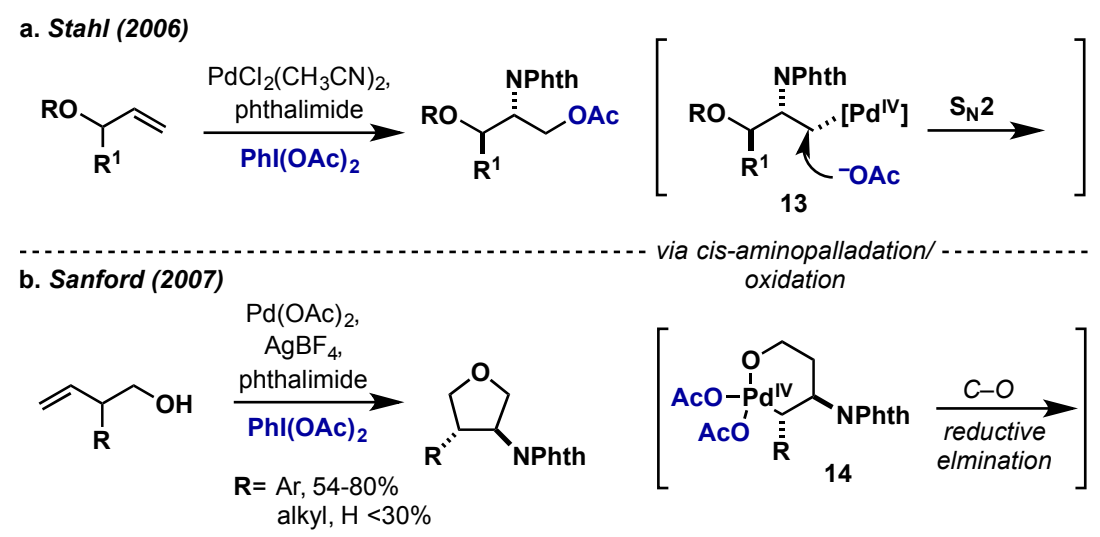

Scheme 12. Two approaches to alkene aminooxygenation via $\mathrm{Pd}(\mathrm{II}) / \mathrm{Pd}(\mathrm{IV})$. Changes in substrate lead to a divergence in mechanism for $\mathrm{C}-\mathrm{O}$ bond formation.

Dong reported the dioxygenation of alkenes with $\left[\mathrm{Pd}(\mathrm{dppp})\left(\mathrm{H}_{2} \mathrm{O}\right)_{2}\right](\mathrm{OTf})_{2}$ and $\mathrm{PhI}(\mathrm{OAc})_{2}$, an attractive alternative to the use of toxic osmium-based reagents (Scheme 13) [27]. Based on labeling studies and the observed cis diastereoselectivity, they propose a mechanism involving a $\mathrm{Pd}(\mathrm{II}) / \mathrm{Pd}(\mathrm{IV})$ cycle and an $\mathrm{S}_{\mathrm{N}} 2$-type displacement of a $\mathrm{Pd}(\mathrm{IV})$ intermediate. Alkene coordination gives $\mathrm{Pd}(\mathrm{II})$ species 15 and promotes intermolecular attack by $\mathrm{AcOH}$ to give 16, which is oxidized by $\mathrm{PhI}(\mathrm{OAc})_{2}$ to give $\mathrm{Pd}(\mathrm{IV})$ species 17. 17 then undergoes intramolecular $\mathrm{S}_{\mathrm{N}} 2$-diplacement by acetate giving cyclic oxonium 18 followed by opening with $\mathrm{H}_{2} \mathrm{O}$ and acylation. This method could also be applied in substrates possessing tethered alcohol and carboxylic acid nucleophiles to give tetrahydrofuran and lactone products.

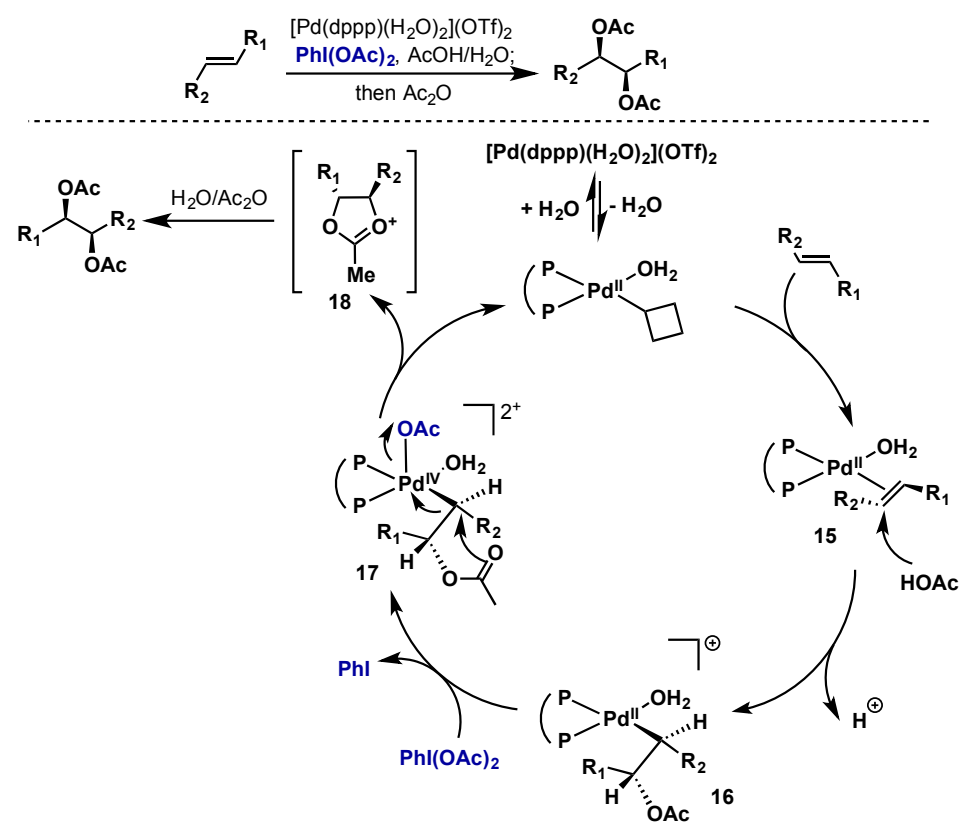

Scheme 13. Diastereoselective catalytic alkene dioxygenation using $\mathrm{Pd}(\mathrm{II}) / \mathrm{Pd}(\mathrm{IV})$ catalysis.

Using $\mathrm{PhI}(\mathrm{OBz})_{2}$ and $\mathrm{PdCl}_{2}(\mathrm{PhCN})_{2}$, Sanford's group was also able to perform asymmetric alkene dioxygenation by tethering of a chiral oxime directing group (Scheme 14) [28]. They were able to achieve moderate to high levels of diastereoselectivity on a wide range of oxime substrates possessing different chiral elements. A control experiment using both a cis and trans alkene showed that both gave rise to their respective syn dioxygenated products, shedding some light on the potential mechanism. 
While the exact pathway was not elucidated, they propose that an initial oxypalladation could occur in either a trans or cis fashion to give $\mathbf{1 9}$ or $\mathbf{2 0}$, each of which can converge to the syn product by either an $\mathrm{S}_{\mathrm{N}} 2$-type displacement or direct reductive elimination respectively.

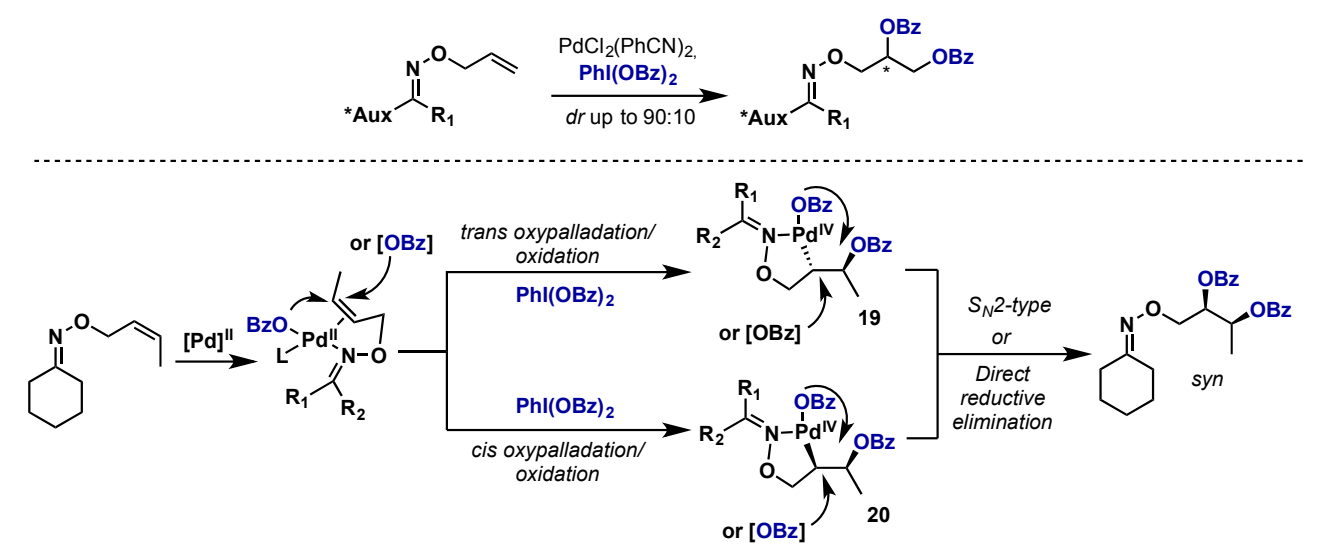

Scheme 14. Asymmetric alkene dioxygenation using a chiral oxime directing group.

Using a palladium NCN-pincer complex (21) or $\mathrm{Pd}(\mathrm{OAc})_{2}$, Szabo's group was able to perform allylic acetoxylation, benzoxylation, or trifluoroacetoxylation using $\mathrm{PhI}(\mathrm{OAc})_{2}, \mathrm{PhI}(\mathrm{OBz})_{2}$, or PhI(OTFA) 2 (Scheme 15) $[29,30]$. This offers a complimentary approach to traditional methods of allylic functionalization proceeding via $\mathrm{Pd}(0) / \mathrm{Pd}(\mathrm{II})$ catalysis. $\mathrm{Pd}(0) / \mathrm{Pd}(\mathrm{II})$ methods require stoichiometric benzoquinone as an essential additive to activate the allyl $\mathrm{Pd}(\mathrm{II})$ species for nucleophilic attack and the use of a more electrophilic $\operatorname{Pd}(\mathrm{IV})$ intermediate obviates the need for this activation. The proposed catalytic cycle is shown in the context of acetoxylation, beginning with oxidation of $\operatorname{Pd}(\mathrm{II})$ to $\mathrm{Pd}(\mathrm{IV})$ and subsequent alkene coordination to give complex 22. Pi-allyl formation gives 23 , which can then undergo reductive elimination to give desired product 24. It should be noted that White has reported a Wacker oxidation employing a combination of $\mathrm{Pd}(\mathrm{OAc})_{2}$ and catalytic $\mathrm{PhI}(\mathrm{OAc})_{2}$, however mechanistic studies indicate that this does not involve direct oxidation to a Pd(IV) intermediate as no ArI byproducts were observed [31].

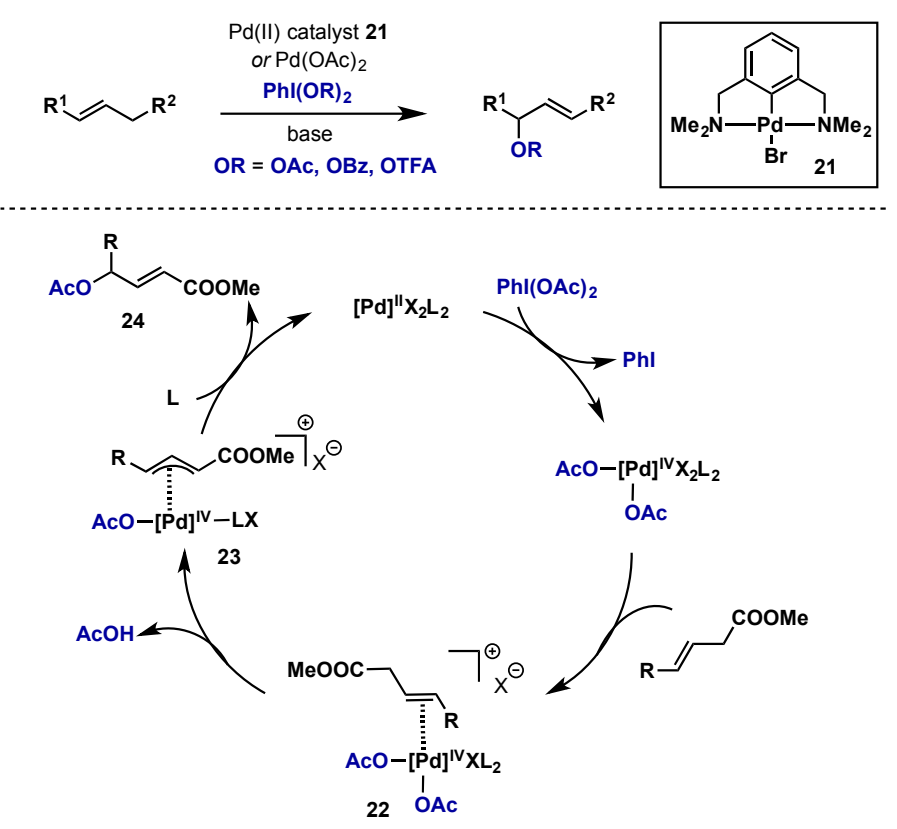

Scheme 15. Allylic acetoxylation, benzoxylation, or trifluoroacetoxylation via $\mathrm{Pd}(\mathrm{II}) / \mathrm{Pd}(\mathrm{IV})$ catalysis. 


\subsubsection{Carbon-Halogen, Carbon-Boron Bond Formation}

One of the most interesting transformations enabled by high valent palladium catalysis is in carbon-halogen and carbon-boron bond formation. $\operatorname{In} \mathrm{Pd}(0) / \mathrm{Pd}(\mathrm{II})$ catalysis, these groups represent functional handles that undergo facile oxidative addition and the reverse process is highly disfavored. $\mathrm{Pd}(\mathrm{II}) / \mathrm{Pd}(\mathrm{IV})$ manifolds offer the perfect compliment, allowing the installation of these valuable atoms into carbon scaffolds via $\mathrm{C}-\mathrm{H}$ functionalization. The application of hypervalent iodine reagents in this area is limited by the relatively low stability and high reactivity of these reagents that possess halogen ligands. $\mathrm{PhICl}_{2}$ is the most common reagent of this type and has seen the most use, more often in high valent complex isolation, whereas $N$-halosuccinimides have dominated synthetic transformations [2].

\subsubsection{Carbon-Halogen Bond Formation}

In her 2004 report, Sanford shows that the use of $N$-chloro or N-bromosuccinimide (NCS, NBS) for the chlorination or bromination of benzoquinoline give rise to the directed halogenation products in good yield (25, 26, Scheme 16) [12]. In contrast, the use of $\mathrm{PhICl}_{2}$ gave C5-chlorinated products both in the presence and absence of palladium, indicating a direct electrophilic chlorination mechanism as opposed to a $\mathrm{C}-\mathrm{H}$ activation pathway. This highlights the disadvantages of using such a highly reactive hypervalent iodine reagent for arene halogenation.

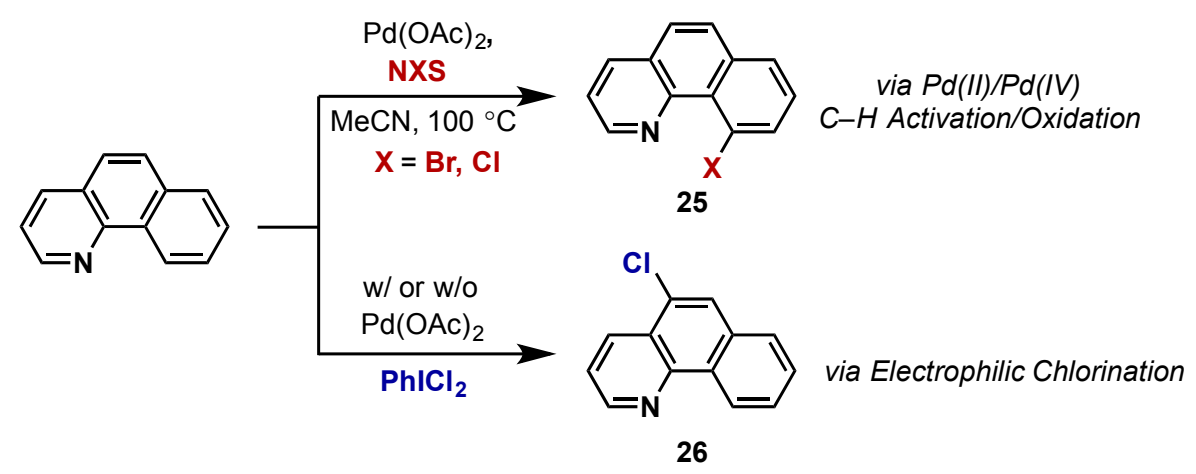

Scheme 16. $\mathrm{N}$-halosuccinimide oxidants give rise to directed $\mathrm{C}-\mathrm{H}$ halogenation whereas $\mathrm{PhICl}_{2}$ gives product of direct electrophilic chlorination.

There have been several reports of C-I bond formation using the Suarez-type iodine reagent IOAc, often generated via reaction of $\mathrm{PhI}(\mathrm{OAc})_{2}$ and $\mathrm{I}_{2}$ in situ. $\mathrm{Yu}$ initially demonstrated this approach in the directed iodination of unactivated primary $\mathrm{C}\left(\mathrm{sp}^{3}\right)-\mathrm{H}$ bonds using an oxazoline directing group (Scheme 17a) [32,33]. The use of a chiral oxazoline gave good to excellent levels of diastereoselectivity (91:9 to 99:1) in prochiral substrates. A subsequent report from Yu showed the directed $\alpha$-iodination of benzoic acids under similar conditions giving rise to predominantly diiodinated products (Scheme 17b) [34]. It was found that DMF was essential for high conversion and the use of tetrabutylammonium iodide as an additive could help control mono- vs. bisiodination products. While the mechanism of Pd(II) oxidation with IOAc has not been fully elucidated, KIE indicate that $\mathrm{C}-\mathrm{H}$ bond cleavage is proceeding via an electrophilic mechanism in these cases and thus a $\mathrm{Pd}(\mathrm{II}) / \mathrm{Pd}(\mathrm{IV})$ catalytic cycle is proposed.

Kraft demonstrated the use of a $\mathrm{Pd}(\mathrm{II})-\mathrm{NHC}$ complex for stoichiometric dichlorination of linear alkenes and monochlorination of benzylic $\mathrm{C}-\mathrm{H}$ bonds (Scheme 18) [35]. $\mathrm{PhICl}_{2}$ oxidizes $\mathrm{Pd}(\mathrm{II})$ species 27 to $\mathrm{Pd}(\mathrm{IV})$ (28), and subsequent loss of chloride generates a cationic, pentacoordinated $\mathrm{Pd}(\mathrm{IV})$ species that is active for $\mathrm{C}-\mathrm{H}$ chlorination. 
a. $\mathrm{Yu}(2005)$

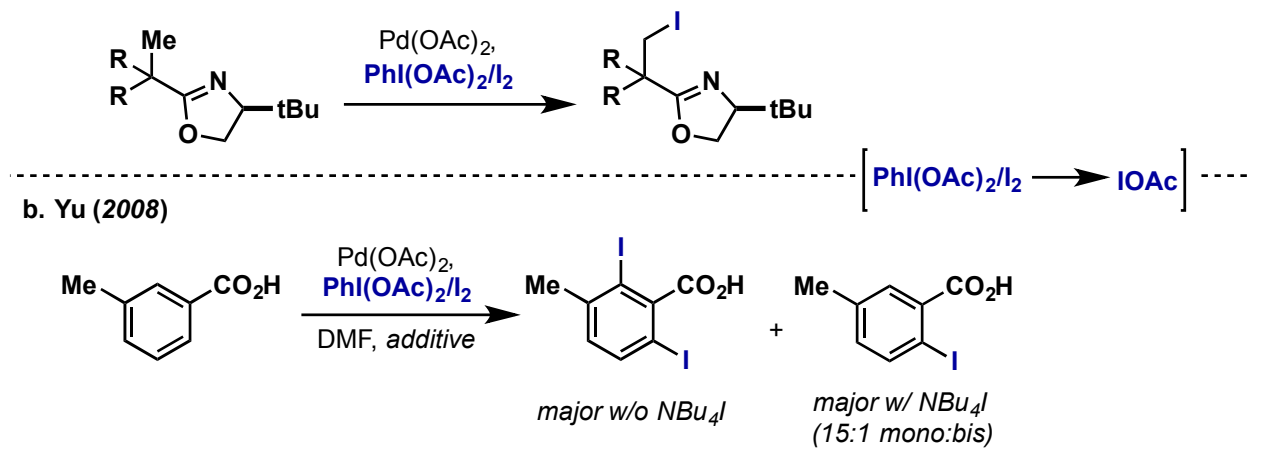

Scheme 17. Directed iodination of $(\mathbf{a}) \mathrm{C}\left(\mathrm{sp}^{3}\right)-\mathrm{H}$ and (b) $\mathrm{C}\left(\mathrm{sp}^{2}\right)-\mathrm{H}$ bonds using in situ generated IOAc.

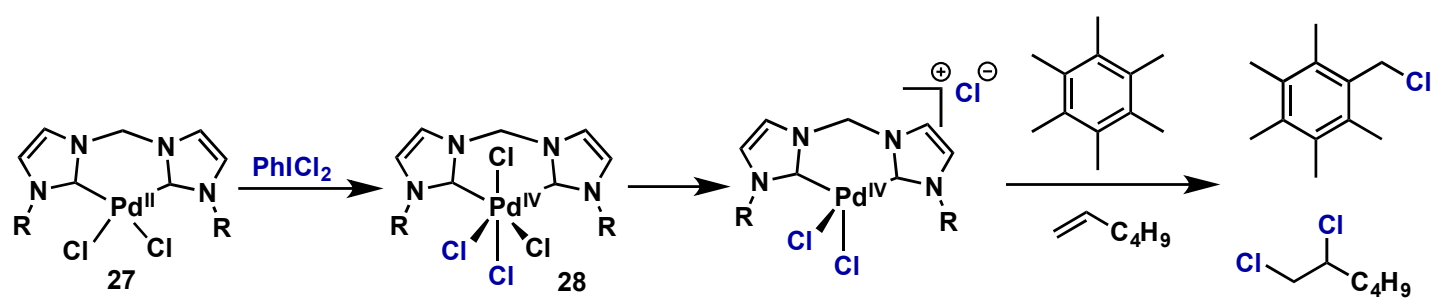

Scheme 18. Stoichiometric chlorination of linear alkenes or benzylic positions with a cationic $\operatorname{Pd}(\mathrm{IV})$ generated upon oxidation with $\mathrm{PhICl}_{2}$.

Direct $\mathrm{C}-\mathrm{H}$ fluorination is challenging for transition metal catalysis due to the low reactivity of metal-fluorine bonds towards reductive elimination. Several attempts have been made using $\mathrm{Pd}(\mathrm{II}) / \mathrm{Pd}(\mathrm{IV})$ catalysis, however the use of hypervalent iodine oxidants has been met with challenges. This is due to the high reactivity of the most common $\lambda^{3}$-iodane $\mathrm{X}$-ligands, namely acetates or halogens, to undergo competitive reductive elimination. In this area, Ritter has been successful in the radiofluorination of $\mathrm{C}\left(\mathrm{sp}^{2}\right)-\mathrm{H}$ bonds using stoichiometric $\mathrm{Pd}(\mathrm{II})$ complexes as fluorinating agents and a (poly)cationic $\lambda^{3}$-iodane (29) as the oxidant (Scheme 19) [36]. These (poly)cationic $\lambda^{3}$-iodane reagents are relatively underutilized in the synthetic literature, however Dutton has also used these complexes to study high valent palladium and platinum complexes and this work is discussed in Section 2.1. Ritter's report is an extension of his prior work which utilized the " $\mathrm{F}^{+}$" source Selectfluor in the two step fluorination of arylboronic acids with a similar complex, however the use of electrophilic fluorinating agents are not readily translatable to radiolabeling applications [37]. They therefore designed a system employing a highly electrophilic $\mathrm{Pd}(\mathrm{IV})$ complex (30), could then undergo ligand exchange with a source of nucleophilic ${ }^{18} \mathrm{~F}^{-}$. Pd(IV) complex 30 was accessed via oxidation of 31 with (poly)cationic $\lambda^{3}$-iodane 29; the key feature of this oxidant is the donation of a labile heterocyclic ligand which can undergo facile ligand exchange, first with 4-picoline to give 32, and subsequently with fluoride upon exposure to a nucleophilic ${ }^{18} \mathrm{~F}$-source in the reaction conditions. This complex then serves as a highly electrophilic source of ${ }^{18} \mathrm{~F}$ for a second $\mathrm{Pd}(\mathrm{II})$ species (33) which then undergoes $\mathrm{C}-\mathrm{F}$ bond reductive elimination to give desired product. In a later report they also report the use of an analogous nickel-mediated process under similar conditions (see Section 5.2). 


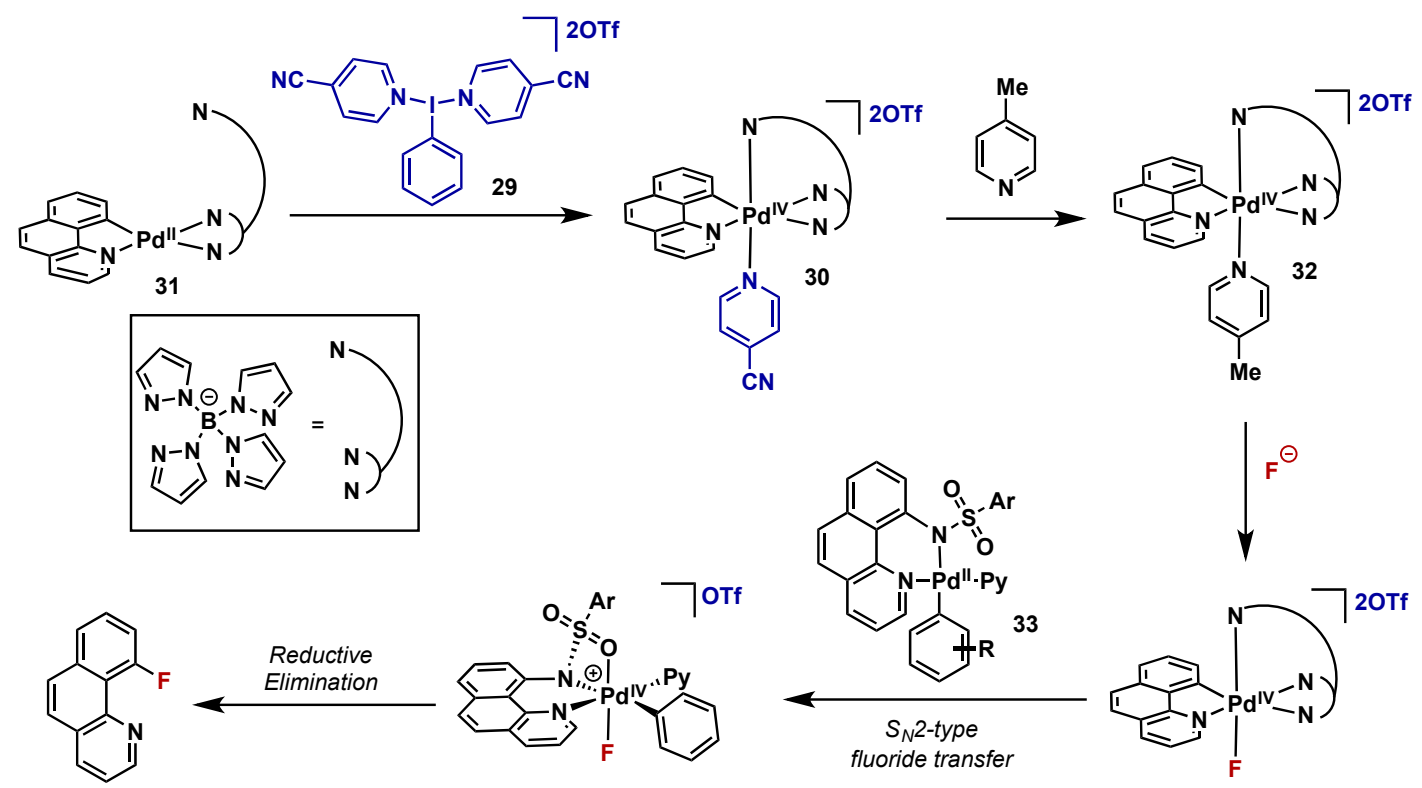

Scheme 19. Ritter's approach to radiofluorination using nucleophilic ${ }^{18} \mathrm{~F}$ and a (poly)cationic $\lambda^{3}$-iodane.

In catalytic $\mathrm{Pd}(\mathrm{II}) / \mathrm{Pd}(\mathrm{IV})$ approaches to $\mathrm{C}-\mathrm{H}$ fluorination, electrophilic $\mathrm{N}$-fluoropyridinium reagents $(35,36)$ have been much more successful than the analogous hypervalent iodine reagent $\mathrm{PhIF}_{2}$ (34), as both the oxidant and fluoride source (Scheme 20a) [38,39]. Sanford has attempted to utilize a nucleophilic fluoride source in combination with a hypervalent iodine oxidant achieve catalytic benzylic fluorination (Scheme 20b) [40]. This is a much more economical approach as nucleophilic fluoride sources are considerably less expensive than electrophilic reagents (e.g., 36- $\$ 88,295 / \mathrm{mol}$ vs. KF $\$ 3.95 / \mathrm{mol}$ ). A critical challenge to this approach is the relative rates of competitive $\mathrm{C}-\mathrm{O}$ bond forming reductive elimination at $\mathrm{Pd}(\mathrm{IV})$ (39) relative to displacement of the carboxylate ligands by $\mathrm{F}^{-}$ to give 40. The use of $\mathrm{AgF}$ as the nucleophilic fluoride source proved critical as well as the use of a sterically hindered oxidant $\mathrm{PhI}(\mathrm{OPiv})_{2}$ to suppress $\mathrm{C}-\mathrm{O}$ bond formation, however this pathway could never be completely eliminated. Therefore, while the combination of oxidant and nucleophilic fluoride source is certainly attractive, the choice of oxidant remains challenging and continued research in this area is required.

a. $C-H$ fluorination with $F^{+}$oxidants
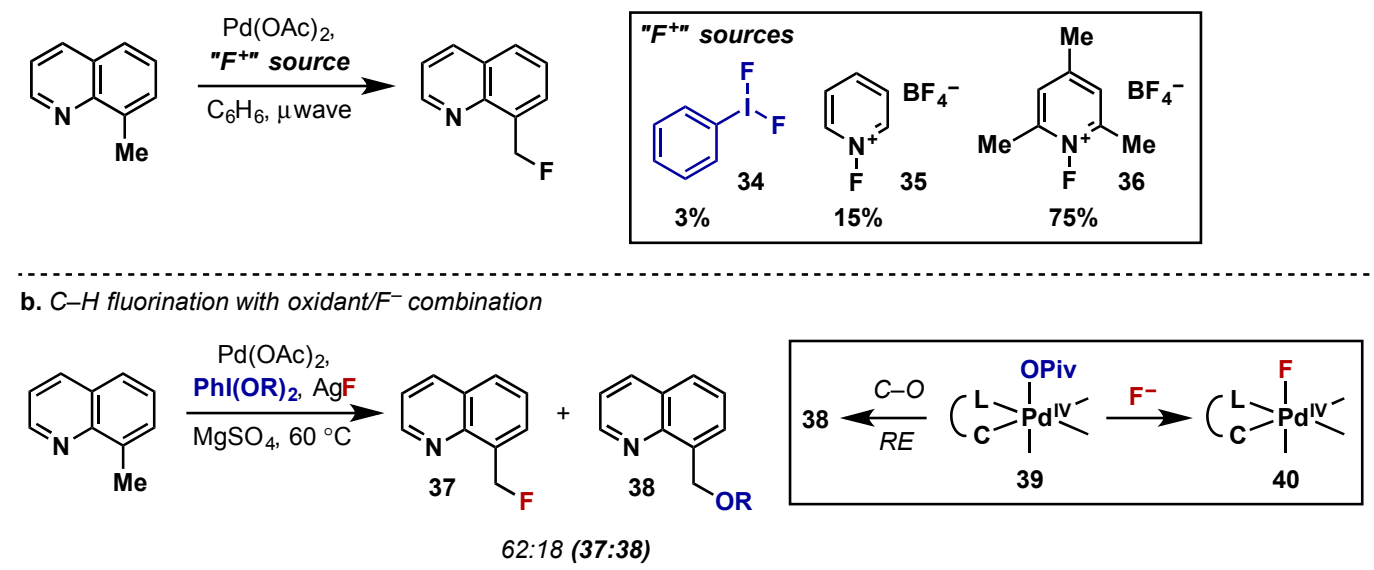

Scheme 20. Complimentary approaches to C-H fluorination with $\mathrm{Pd}(\mathrm{II}) / \mathrm{Pd}(\mathrm{IV})$ catalysis via (a) electrophilic fluorine sources and (b) nucleophilic fluorine sources. 


\subsubsection{Carbon-Boron Bond Formation}

The selective C-H borylation of alkenes under oxidative conditions was reported by Szabo in 2010, giving rise to valuable alkenyl boronates (Scheme 21) [41]. Using an NCN-pincer Pd(II) catalyst (21), $\mathrm{PhI}(\mathrm{OTFA})_{2}$ as an oxidant, and $\mathrm{B}_{2} \mathrm{pin}_{2}$, the borylation of simple alkenes could be accomplished in good yield. It is noted that a particular advantage of this method is that the oxidizing conditions produce TFAO-BPin upon transmetallation rather than borohydrides, which avoids competitive hydroboration of the resultant alkene products. While the authors could not fully elucidate the mechanism of this process, they propose that initial oxidation of catalyst $\mathbf{2 1}$ generates a highly electrophilic $\mathrm{Pd}(\mathrm{IV})$ species 41 which then undergoes facile transmetallation with $\mathrm{B}_{2} \mathrm{pin}_{2}$ to give 42 . Alkene coordination, insertion, and finally elimination and decomplexation give the desired products and regenerate 21 . The method is limited by the need to use solvent quantities of the alkene, and internal alkenes react very poorly.

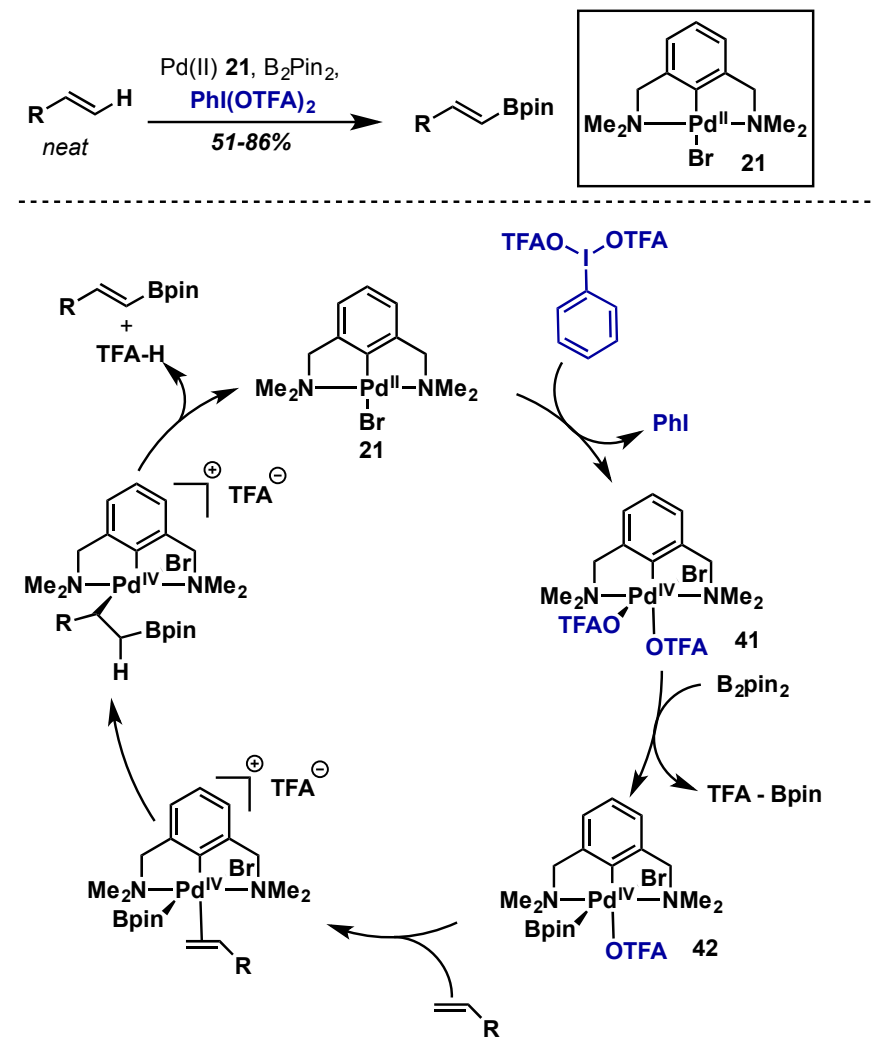

Scheme 21. C-H borylation of olefins under oxidative conditions with $\mathrm{PhI}(\mathrm{OTFA})_{2}$.

\subsubsection{Carbon-Nitrogen Bond Formation}

Carbon-nitrogen $(\mathrm{C}-\mathrm{N})$ bond formation is a valuable synthetic transformation as nitrogen atoms are ubiquitous is bioactive molecules. $\mathrm{Pd}(0) / \mathrm{Pd}(\mathrm{II})$ catalysis has served as a valuable approach for the formation of $\mathrm{C}\left(\mathrm{sp}^{2}\right)-\mathrm{N}$ bonds via the venerable Buchwald-Hartwig amination of aryl halides. Unfortunately wide spread approaches to $\mathrm{C}-\mathrm{N}$ bond formation, via either $\mathrm{C}-\mathrm{H}$ activation, alkene functionalization, or others, remains a challenge in palladium catalysis. This is due both to the high activation barrier for $\mathrm{C}-\mathrm{N}$ bond reductive elimination from $\mathrm{Pd}(\mathrm{II})$ species and the fact that many amine substrates will coordinate to palladium, leading to rapid catalyst deactivation. Innovative approaches relying on $\mathrm{Pd}(\mathrm{II}) / \mathrm{Pd}(\mathrm{IV})$ catalysis have emerged to address these challenges and this area has been recently reviewed by Muniz [42]. Hypervalent iodine reagents have played a key role in this area, with careful tuning of oxidant sterics and electronics playing a role in the success a given method. 


\subsubsection{Alkene Diamination}

The Muniz group has been a leader in the development of both intra- and intermolecular approaches to alkene diamination via $\mathrm{Pd}(\mathrm{II}) / \mathrm{Pd}(\mathrm{IV})$ catalysis [42]. Their first report in this area involved the intramolecular diamination of terminal alkenes with urea derivatives, a particularly challenging transformation due to the high coordinating ability of these substrates to palladium (Scheme 22) [43]. Their method had broad scope and gave the bicyclic 1,2-diamine products in excellent yields. They note that the choice of oxidant was critical and only $\mathrm{PhI}(\mathrm{OAc})_{2}$ was able to promote the reaction with high efficiency. A subsequent mechanistic investigation showed the reaction proceeds via rate limiting aminopalladation, followed by oxidation to give $\mathrm{Pd}(\mathrm{IV})$ intermediate 43 , which then undergoes $\mathrm{S}_{\mathrm{N}} 2$-type displacement by the second amine [44]. This catalytic cycle is supported by stoichiometric studies conducted in their group (employing $\mathrm{PhI}(\mathrm{OAc})_{2}$ as the oxidant), which showed that $\mathrm{C}-\mathrm{N}$ bond formation proceeded via ligand ionization and subsequent $\mathrm{S}_{\mathrm{N}} 2$-displacement rather than a concerted reductive elimination from Pd(IV) [45]. This general catalytic cycle is invoked for their subsequent applications in both intra- and intermolecular amination reactions.

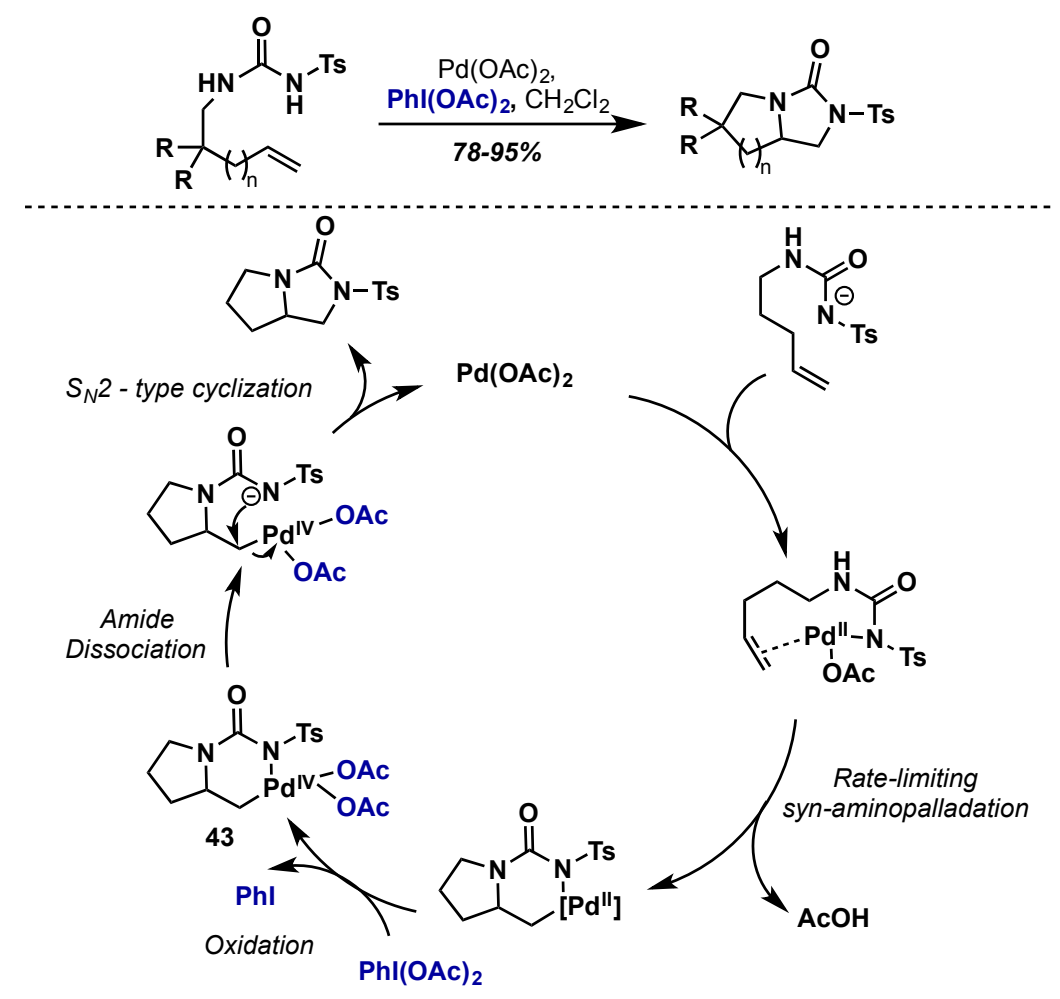

Scheme 22. Intramolecular diamination of alkenes via a $S_{N}$ 2-type displacement of a $\mathrm{Pd}(\mathrm{IV})$ intermediate.

Muniz extended this approach to Boc-protected guanidine substrates, which required a change in oxidant from $\mathrm{PhI}(\mathrm{OAc})_{2}$ to stoichiometric $\mathrm{CuCl}_{2}$ (Scheme 23a) [46]. In this case, the use of $\mathrm{PhI}(\mathrm{OAc})_{2}$, a more powerful oxidant than $\mathrm{CuCl}_{2}$, gives rise to exclusively the aminoacetoxylated product as a result of competitive $\mathrm{C}-\mathrm{O}$ reductive elimination (Scheme 23b). Furthermore, reducing the nucleophilicity of the terminal amine in the presence of $\mathrm{CuCl}_{2}$ led to aminochlorinated products (Scheme 23c). This $\mathrm{S}_{\mathrm{N}} 2$ cyclization mechanism is also analogous to Sanford's $\mathrm{Pd}(\mathrm{IV})$ mediated cyclopropanation and these results clearly indicate that the further development of $S_{N} 2$ based methods with $\mathrm{Pd}(\mathrm{IV})$ will depend on careful tuning of both oxidant and nucleophile [47]. A final report of intramolecular diamination from Muniz involved the intramolecular diamination of stilbene derivatives to yield bisindoline substrates employing $\mathrm{Pd}(\mathrm{OAc})_{2}$ and $\mathrm{PhI}(\mathrm{OAc})_{2}$ (not shown) [48]. 
a. Standard conditions

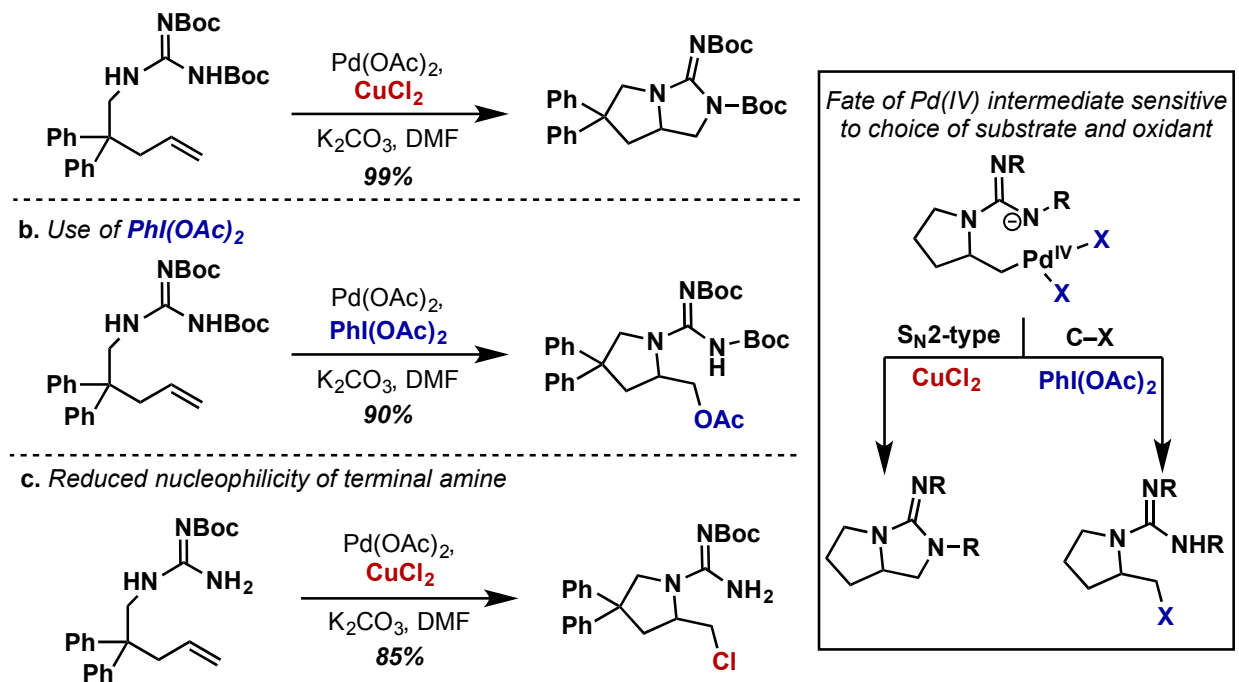

Scheme 23. Intramolecular alkene diamination with guanidines. Reactivity of $\mathrm{Pd}(\mathrm{IV})$ intermediate sensitive to both substrate and oxidant selection. (a) Standard conditions with $\mathrm{CuCl}_{2}$ as oxidant (b) Use of $\mathrm{PhI}(\mathrm{OAc})_{2}$ as oxidant (c) Terminal amine with $\mathrm{CuCl}_{2}$.

Extending this approach to intermolecular diamination was challenging as $\mathrm{C}-\mathrm{O}$ bond forming reductive elimination formation would be more competitive relative to a slower intermolecular $\mathrm{S}_{\mathrm{N}} 2$ amine displacement. In three reports, the Muniz group succeeded in addressing this challenge in the intermolecular diamination of terminal alkenes, allyl ethers, and finally internal styrene derivatives with phthalimide, saccharide or N-fluoro-bis(phenylsulfonyl)imide (NFSI) as the amine sources (Scheme 24) [49-51]. In all cases, $\mathrm{PhI}(\mathrm{OPiv})_{2}$ was employed as the hypervalent iodine oxidant as $\mathrm{PhI}(\mathrm{OAc})_{2}$ gave very low yields with a range of palladium catalysts. The use of the more sterically encumbered $\mathrm{PhI}(\mathrm{OPiv})_{2}$ is presumably critical to address the issue of competitive $\mathrm{C}-\mathrm{O}$ reductive elimination as the-OPiv group will undergo this process much slower than the corresponding-OAc, allowing intermolecular $\mathrm{S}_{\mathrm{N}} 2$ displacement to occur. It is noteworthy than a similar approach from Michael utilized NFSI as both the amine source and external oxidant, circumventing competitive $\mathrm{C}-\mathrm{X}$ reductive elimination $[52,53]$.
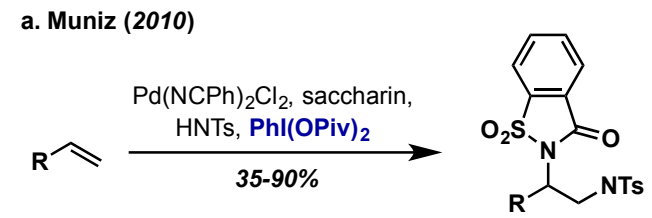

b. Muniz (2011)

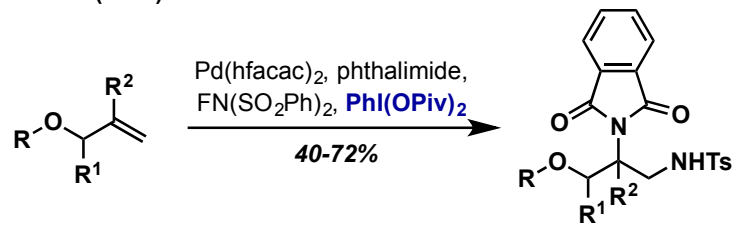

c. Muniz (2012)

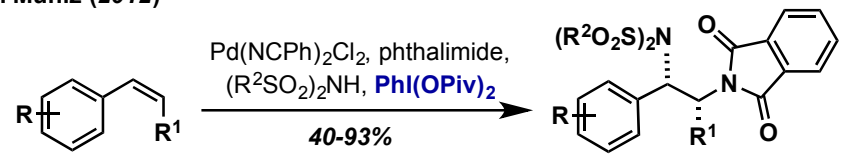

Scheme 24. Reports from the Muniz group on intermolecular alkene diamination with $\mathrm{PhI}(\mathrm{OPiv})_{2}$ as the oxidant. (a) Diamination of terminal alkenes (b) Diamination of allyl ethers (c) Diamination of styrene derivatives.

\subsubsection{C-H Amination}

Sanford reported a study of $\mathrm{C}\left(\mathrm{sp}^{2}\right)$ and $\mathrm{C}\left(\mathrm{sp}^{3}\right)-\mathrm{H}$ bond amination using $\mathrm{Pd}(\mathrm{II})$ catalysts and $\mathrm{PhI}=\mathrm{NTs}$ as the oxidant in a stoichiometric context (Scheme 25) [54]. Using various palladacyclic 
species 44,45 , generated via directed $\mathrm{C}-\mathrm{H}$ activation, they found that $\mathrm{C}-\mathrm{H}$ insertion happens readily upon oxidation with $\mathrm{PhI}=\mathrm{NTs}$. In both cases, byproducts arising from competitive $\mathrm{C}-\mathrm{X}$ bond forming reductive elimination were observed in up to $18 \%$ yield (compounds 46,47 ), and this was highly dependent on reaction conditions. Oxidant electronics were found to play a role in the rate of $\mathrm{C}-\mathrm{H}$ insertion; altering the substituents on the benzylsulfonamide $\mathrm{PhINSO}_{2} \mathrm{C}_{5} \mathrm{H}_{4} \mathrm{X}\left(\mathrm{X}=\mathrm{OMe} / \mathrm{NO}_{2}\right)$ led to prolonged reaction times. The authors refrain from drawing mechanistic conclusions from this data due to the highly varied solubility and hydrolytic instability of the hypervalent iodine reagents under the reaction conditions. A general mechanism is shown in Scheme $25 \mathrm{c}$, and the intermediacy of $\mathrm{Pd}(\mathrm{IV})$ is supported by the observation of $\mathrm{C}-\mathrm{X}$ reductive elimination products. Direct $\mathrm{C}-\mathrm{H}$ activation/amination could also be achieved at $\mathrm{sp}^{3} \mathrm{C}-\mathrm{H}$ bonds, however isolated yields upon protolysis were lower relative to $\mathrm{sp}^{2}$ analogues. It should be noted that a catalytic approach to $\mathrm{C}-\mathrm{H}$ bond amination has been reported using $\mathrm{K}_{2} \mathrm{~S}_{2} \mathrm{O}_{8}$ as a stoichiometric oxidant [55].

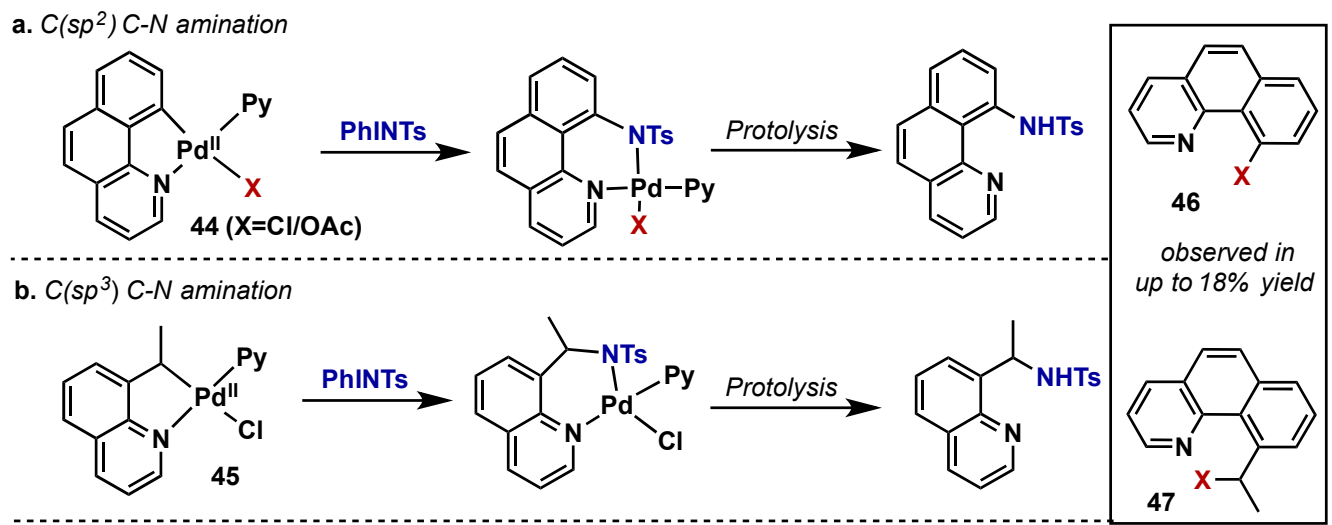

c. Proposed general mechanism

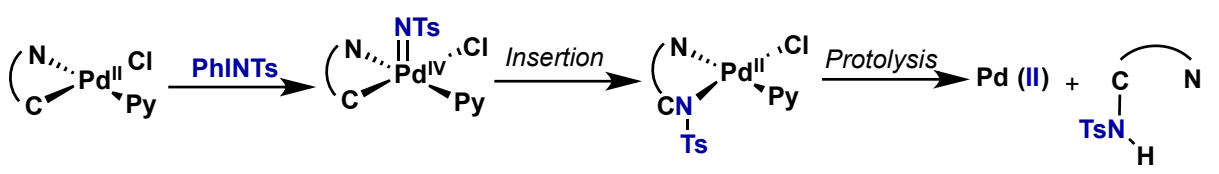

Scheme 25. Stoichiometric study of directed $\mathrm{C}-\mathrm{H}$ bond amination with $\mathrm{Pd}(\mathrm{II})$ and $\mathrm{PhI}=\mathrm{NTs}$ as oxidant and N-source. Insert: Byproducts observed as a result of competitive $\mathrm{C}-\mathrm{X}$ bond formation.

Daugulis provided the first report of catalytic alkyl-nitrogen coupling via $\mathrm{C}-\mathrm{H}$ activation with $\mathrm{Pd}(\mathrm{II}) / \mathrm{Pd}(\mathrm{IV})$, which relied on oxidation with $\mathrm{PhI}(\mathrm{OAc})_{2}$ (Scheme 26a) [56]. Other oxidants screened included more electron-deficient $\lambda^{3}$-iodanes $\mathrm{PhI}(\mathrm{OTFA})_{2}, \mathrm{PhI}\left(p-\mathrm{NO}_{2} \mathrm{C}_{6} \mathrm{H}_{4} \mathrm{O}_{2} \mathrm{C}\right)_{2}$, as well as AgOAc, all of which gave very low or no conversion. The net intramolecular $\mathrm{C}-\mathrm{H}$ amination proceeded via consecutive $\mathrm{N}-\mathrm{H} / \mathrm{C}-\mathrm{H}$ activation, oxidation of complex 48 to give $\mathrm{Pd}(\mathrm{IV})$ intermediate 49 , and final $\mathrm{C}-\mathrm{N}$ bond forming reductive elimination. Mechanistic insights into the $\mathrm{C}-\mathrm{N}$ bond forming step were not provided. This work was followed closely by that of Chen who used the picolinamide directing group for the construction of diverse 4 - and 5-membered nitrogen heterocycles via $\mathrm{C}\left(\mathrm{sp}^{3}\right)-\mathrm{H}$ amination (Scheme 26b) [57]. 
a. Daugulis (2012)
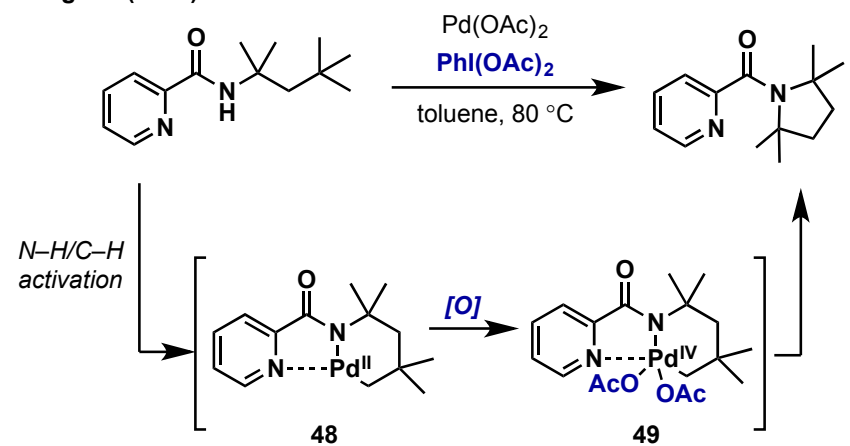

b. Chen (2012)<smiles>[R]C(CC)NC(=O)c1ccccn1</smiles><smiles>[R]C(CC)C([R])NC(=O)c1ccccn1</smiles><smiles>[R]C(Cc1ccccc1)NC(=O)c1ccccn1</smiles>

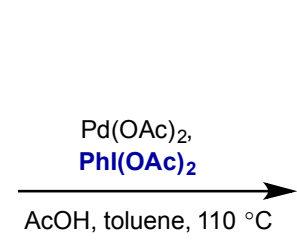<smiles>[R]C1CN([R17])C1[R]</smiles><smiles>[R]C1Cc2ccccc2N1P(=O)=O</smiles>

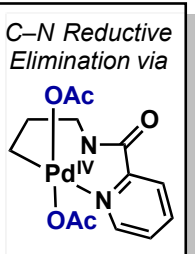

Scheme 26. Intramolecular $\mathrm{C}-\mathrm{H}$ amination via $\mathrm{Pd}(\mathrm{II}) / \mathrm{Pd}(\mathrm{IV})$ catalysis with $\mathrm{PhI}(\mathrm{OAc})_{2}$. (a) Daugulis report on direct $\mathrm{C}\left(\mathrm{sp}^{3}\right)$-amination $(\mathbf{b})$ Chen's $\mathrm{C}\left(\mathrm{sp}^{3}\right)$ and $\mathrm{C}\left(\mathrm{sp}^{2}\right)-\mathrm{H}$ amination.

The Muniz group reported a benzylic $\mathrm{C}-\mathrm{H}$ amidation via a directed $\mathrm{C}-\mathrm{H}$ bond activation and subsequent $\mathrm{S}_{\mathrm{N}}$ 2-type displacement at Pd(IV) (Scheme 27) [58]. In this reaction it was more effective to have the oxidant also serve the source of nitrogen and hypervalent iodine reagents therefore proved to be less efficient than NFSI. A more electron deficient bidentate hexafluoroacetylacetonate (hfacac) ligand on palladium also improved efficiency. This reaction could be extended to anisole and pyridine directing groups, giving a rather versatile method for $\mathrm{C}-\mathrm{H}$ bond amidation. Despite its utility, the use of NFSI as the oxidant does lead to generation of an equivalent of $\mathrm{HF}$, and thus discovery of more environmentally friendly alternatives would be a significant advancement for large-scale applications.
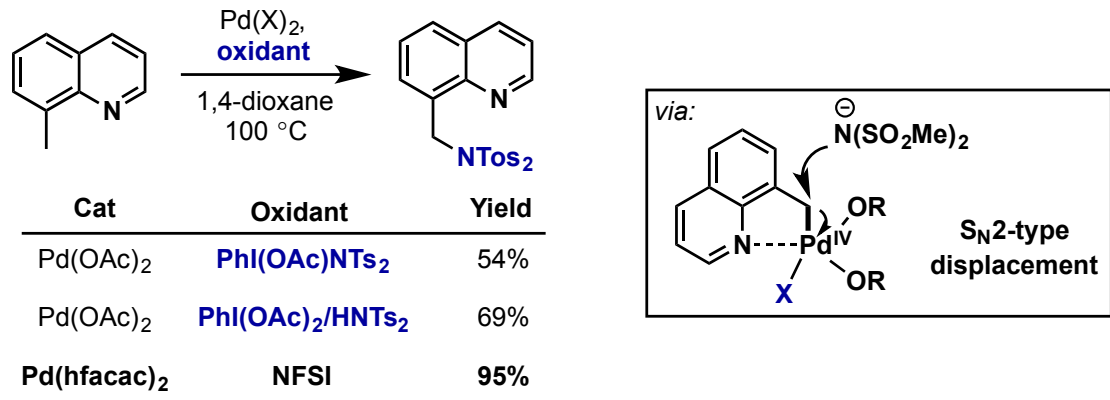

Scheme 27. Directed $\mathrm{C}\left(\mathrm{sp}^{3}\right)$-amidation of benzylic $\mathrm{C}-\mathrm{H}$ bonds via $\mathrm{S}_{\mathrm{N}}$ 2-displacement of $\mathrm{Pd}(\mathrm{IV})$.

Li reported the synthesis of oxindole derivatives via a intermolecular aminopalladation/C-H activation cascade employing $\mathrm{Pd}(\mathrm{OAc})_{2}$ and $\mathrm{PhI}(\mathrm{OAc})_{2}$ (Scheme 28) [59]. In this case, other oxidants such as oxone, $\mathrm{K}_{2} \mathrm{~S}_{2} \mathrm{O}_{8}, \mathrm{Cu}(\mathrm{OAc})_{2}$, benzoquinone, and $\mathrm{O}_{2}$ were ineffective, giving little or no conversion to products. The authors propose either terminal $\mathrm{C}-\mathrm{N}$ reductive elimination from $\mathrm{Pd}(\mathrm{IV})$ or $\mathrm{Pd}(\mathrm{IV})$ $\mathrm{C}-\mathrm{H}$ activation, however further mechanistic investigation is required. 


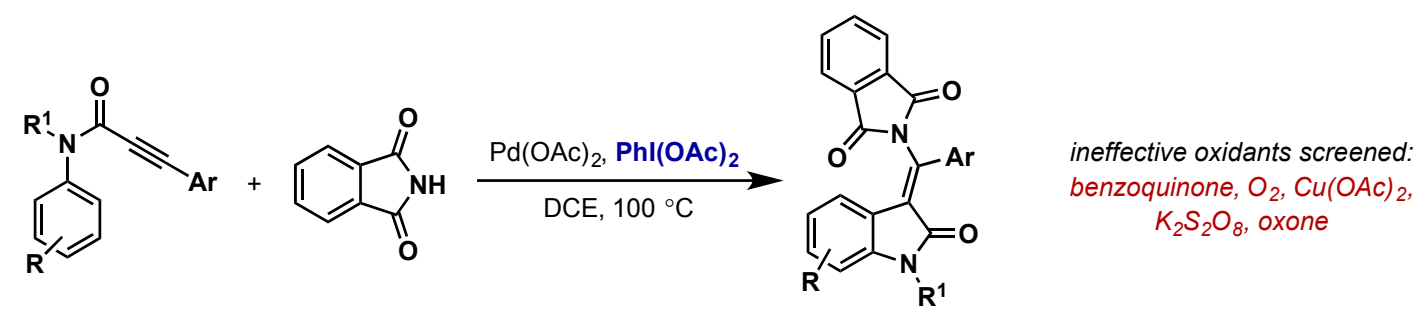

Scheme 28. Synthesis of substituted oxindoles via sequential aminopalladation/C-H activation.

The synthesis of carbazole derivatives via an oxidative $\mathrm{C}-\mathrm{H}$ amidation procedure with $\mathrm{Pd}(\mathrm{OAc})_{2}$ and $\mathrm{PhI}(\mathrm{OAc})_{2}$ at ambient temperature was reported by Gaunt in 2008 (Scheme 29) [60]. This protocol offers an alternative to Ulmann and Buchwald-Hartwig coupling reactions and obviates the need for prefunctionalization. The reaction mechanism should proceed as the other examples demonstrated in this review. The isolation of a trinuclear $\mathrm{Pd}(\mathrm{II})$ complex (50) having two cyclopalladated aminobiphenyl connected through bridging acetates to a third Pd(II) suggests the oxidation pathways leads to a $\mathrm{Pd}(\mathrm{IV})$ that promotes the reductive elimination. However it is also possible that the trimeric complex dissociates into monomeric species prior to the oxidation.

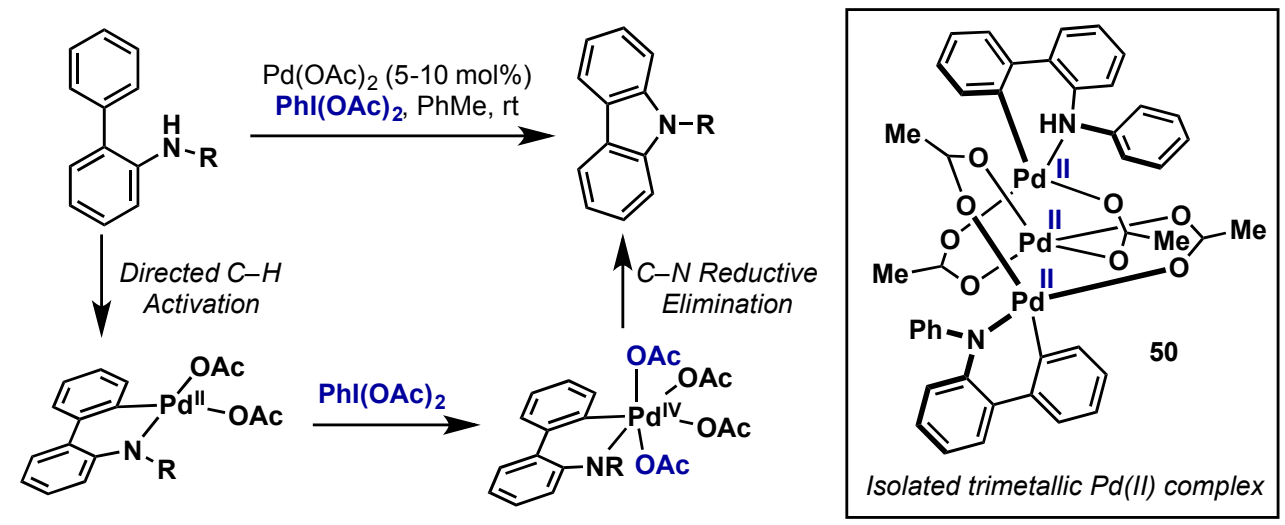

Scheme 29. Direct $\mathrm{C}\left(\mathrm{sp}^{2}\right)$-amination at ambient temperature via $\mathrm{Pd}(\mathrm{II}) / \mathrm{Pd}(\mathrm{IV})$.

Gaunt also reported the synthesis of aziridines through $\mathrm{C}-\mathrm{H}$ activation with $\mathrm{Pd}(\mathrm{OAc})_{2}$ and $\mathrm{PhI}(\mathrm{OAc})_{2}$ (Scheme 30). Mechanistic experiments demonstrated that the reaction proceeds through formation of a relatively rare four-membered palladacycle (51), which further reductively eliminates to generate the $\mathrm{C}-\mathrm{N}$ bond. Those experiments also suggest that cyclopalladation is the rate-determining step, followed by fast oxidation by $\mathrm{PhI}(\mathrm{OAc})_{2}$. They subsequently translated this to a flow process providing an elegant and efficient approach to the synthesis of challenging strained nitrogen heterocycles [61].

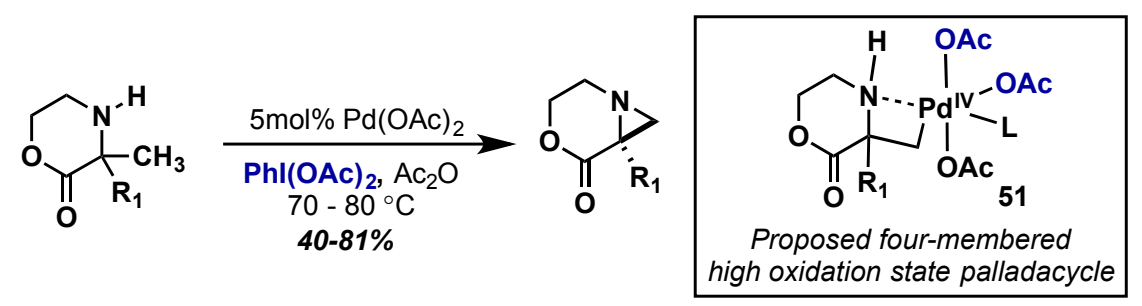

Scheme 30. C-H activation approach to aziridines through high oxidation $\mathrm{Pd}(\mathrm{IV})$. 


\subsection{5. $\mathrm{C}-\mathrm{C}$ bond Formation}

\subsubsection{Diaryliodonium Salts}

For many years, diorganoiodine (III) compounds, represented [Ar-I-R]X ${ }^{-}$, have been utilized for catalytic $\mathrm{C}-\mathrm{C}$ bond formation via oxidative transfer of " $\mathrm{R}^{+ \text {" }}$ to a $\mathrm{Pd}(0)$ catalyst and subsequent reductive elimination [62]. In recent years, these reagents have been extended to $\mathrm{Pd}(\mathrm{II})$ catalysis, in both stoichiometric and catalytic studies, proceeding via either $\mathrm{Pd}(\mathrm{III})$ or $\mathrm{Pd}(\mathrm{IV})$ intermediates. From this work, a variety of $\mathrm{C}\left(\mathrm{sp}^{2}-\mathrm{sp}^{2}\right)$ and $\mathrm{C}\left(\mathrm{sp}^{3}-\mathrm{sp}^{2}\right)$ bond formations have been reported.

\section{Stoichiometric Studies}

Canty has conducted many of the seminal reports on the isolation of various $\mathrm{Pd}(\mathrm{IV})$ and $\mathrm{Pt}(\mathrm{IV})$ complexes via oxidation with both aryl and alkynyliodonium salts (Scheme 31) [63-66]. The iodonium salts were able to cleanly oxidize Pd(II) complexes with a variety of ligand scaffolds, giving rise to varying degrees of cis/trans isomers (52-cis or 52-trans) and a Pd(III) dimer (53), at low temperature. For characterization purposes these complexes were then treated with $\mathrm{NaI}$ resulting in triflate displacement or addition into the cationic Pd(III) species (54-cis or 54-trans), and a summary of the complexes synthesized via this approach is provided below (55-59, Scheme 32). Throughout these reports, Canty notes that the palladium complexes are significantly less stable than the corresponding platinum species meaning isolation and characterization were much more challenging. For a further discussion of the analogous platinum components to Canty's studies, see Section 3.1.

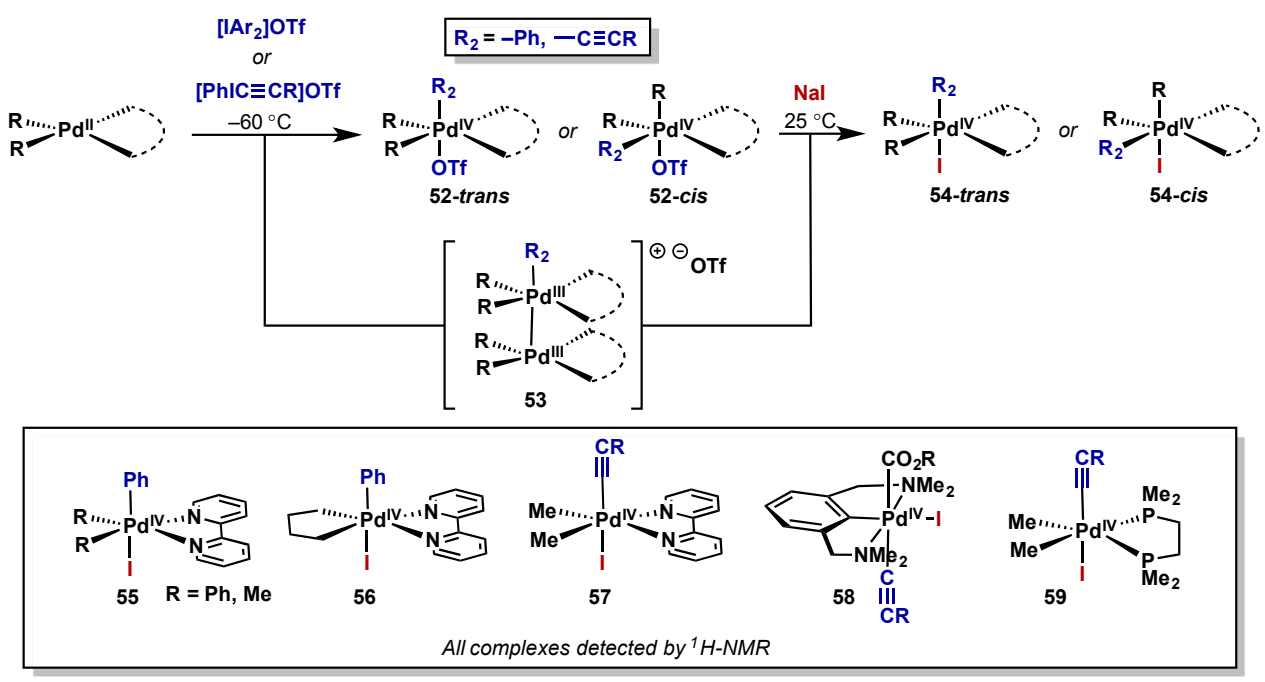

Scheme 31. Synthesis of $\operatorname{Pd}(\mathrm{IV})$ species upon oxidation with diaryl- and alkynyl iodonium salts.

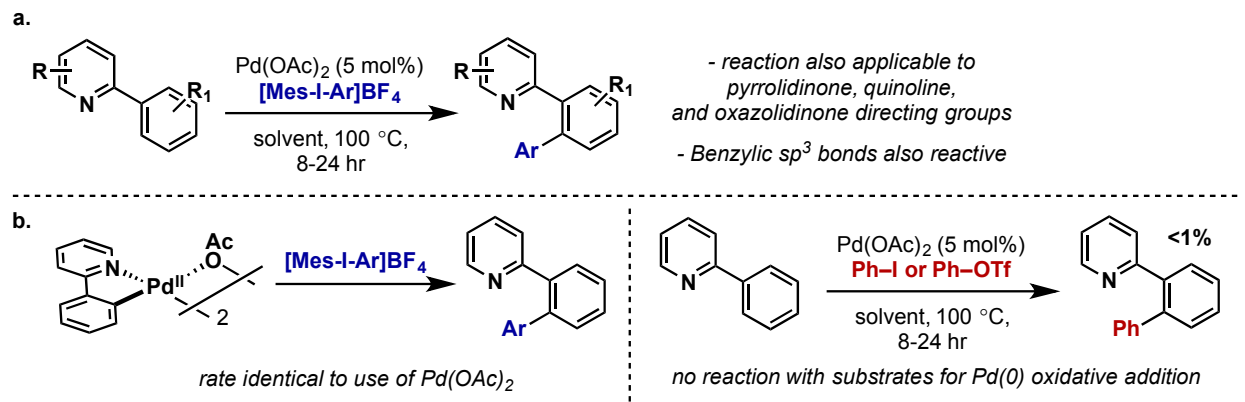

Scheme 32. (a) Directed C-H arylation with diaryliodonium salts and $\mathrm{Pd}(\mathrm{OAc})_{2}$; (b) Evidence for $\mathrm{Pd}(\mathrm{II}) / \mathrm{Pd}(\mathrm{IV})$ pathway. 


\section{Catalytic Applications}

In 2005, Sanford reported a directed $\mathrm{C}-\mathrm{H}$ arylation using diaryliodonium salts and $\mathrm{Pd}(\mathrm{OAc})_{2}$, the first report of $\mathrm{C}-\mathrm{H}$ arylation invoking a $\mathrm{Pd}(\mathrm{II}) / \mathrm{Pd}(\mathrm{IV})$ catalytic manifold (Scheme 32a) [67]. The reaction was applicable to a wide range of heterocyclic directing groups and a range of electron-deficient and electron-rich aryl rings could be transferred in good yields. This method was further extended to benzylic $\mathrm{C}\left(\mathrm{sp}^{3}\right)-\mathrm{H}$ arylation on $\mathrm{C} 8$-methylquinoline as well as the regioselective arylation of 2,5-disubstituted pyrroles (not shown) [68]. This group subsequently reported a variant using polymer-supported iodonium salts that gave equally high yields and the hypervalent iodine reagent could be readily recycled [14]. The reaction was proposed to proceeded via a $\mathrm{Pd}(\mathrm{IV})$ intermediate by analogy to their work with $\mathrm{C}-\mathrm{H}$ acetoxylation (see Section 2.2.2.1), and preliminary mechanistic investigations supported this hypothesis (Scheme 32b). A subsequent study revealed further mechanistic insights, including that oxidation by the diaryliodonium salt was turnover limiting [69]. This is particularly interesting since analogous acetoxylation reaction with $\mathrm{PhI}(\mathrm{OAc})_{2}$ are found to be zero-order in $\mathrm{PhI}(\mathrm{OAc})_{2}$ and that cyclopalladation is turnover limiting. This implies that oxidation by diaryliodonium salts is much slower than by $\mathrm{Ph}(\mathrm{OAc})_{2}$ and this could be significant in the further development of this chemistry as undesirable side reactions could begin to compete with oxidation. A complete, detailed mechanistic study was later conducted between the groups of Sanford, Canty, and Yates, incorporating computational studies, and readers are directed to that report for further discussion [70].

In 2006, Sanford reported of the C2-arylation of indoles using diaryliodonium salts (Scheme 33) [71]. The proposed mechanism invoked a $\mathrm{Pd}(\mathrm{II}) / \mathrm{Pd}(\mathrm{IV})$ catalytic cycle beginning with rate-determining cyclopalladation, followed by oxidative addition to give $\mathrm{Pd}(\mathrm{IV})$ species 60 and subsequent $\mathrm{C}-\mathrm{C}$ reductive elimination. This approach improved upon prior reports using $\mathrm{Pd}(0) / \mathrm{Pd}(\mathrm{II})$, which required long reaction times and high temperatures $\left(12-24 \mathrm{~h},>125^{\circ} \mathrm{C}\right)$, by accelerating rate-determining cyclopalladation through use of a $\mathrm{Pd}(\mathrm{II})$ catalyst. The use of IMes (61) as an ancillary ligand improved conversion by stabilizing the $\operatorname{Pd}(\mathrm{IV})$ intermediate, but slowed reaction times, supporting a mechanism wherein electrophilic palladation is rate-limiting.

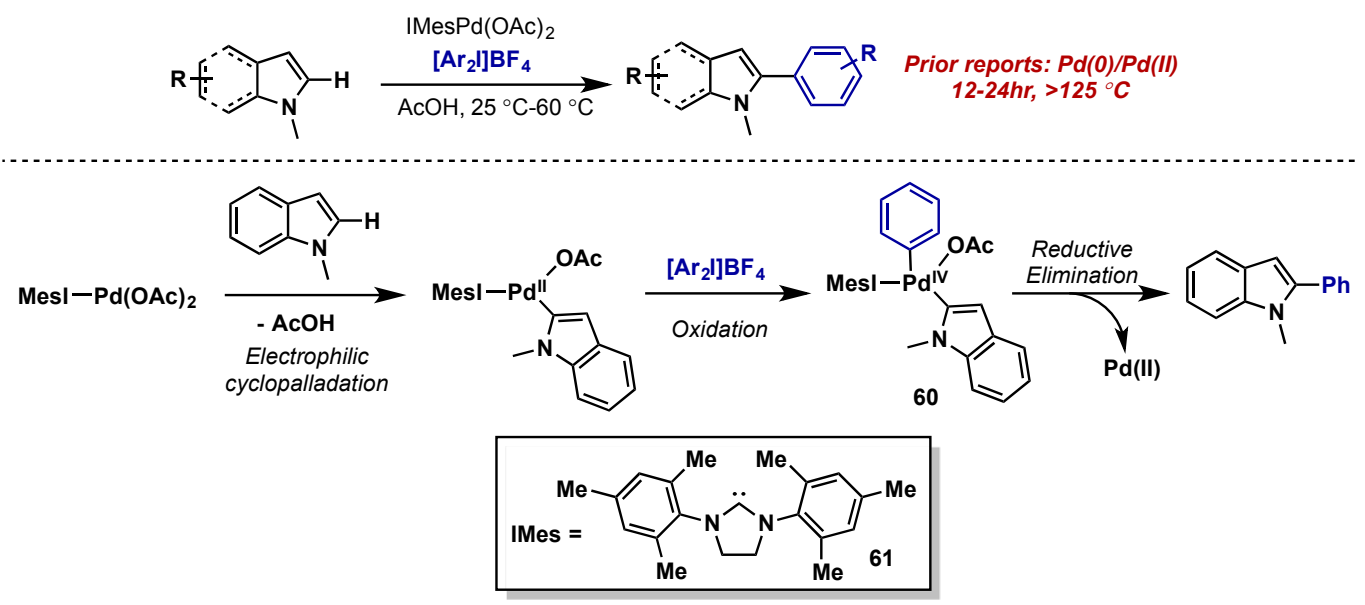

Scheme 33. Facile C2-arylation of indoles with diaryliodonium salts through $\mathrm{Pd}(\mathrm{II}) / \mathrm{Pd}(\mathrm{IV})$ catalytic cycle.

In a systematic study of ligand effects on regiocontrol in non-directed $\mathrm{C}-\mathrm{H}$ activation, Sanford examined the $\mathrm{C}-\mathrm{H}$ arylation of naphthalene with $\mathrm{Pd}(\mathrm{II})$ and diaryliodonium salts (Scheme 34) [72]. It was found that subtle changes to ligand sterics had dramatic effects on the regioselectivity of arylation using a range of bidentate diamine ligands. Similar to previous reports, mechanistic investigations revealed oxidation was rate-limiting, however in this case it precedes $\mathrm{C}-\mathrm{H}$ activation, which then occurs at a $\mathrm{Pd}(\mathrm{IV})$ center. 


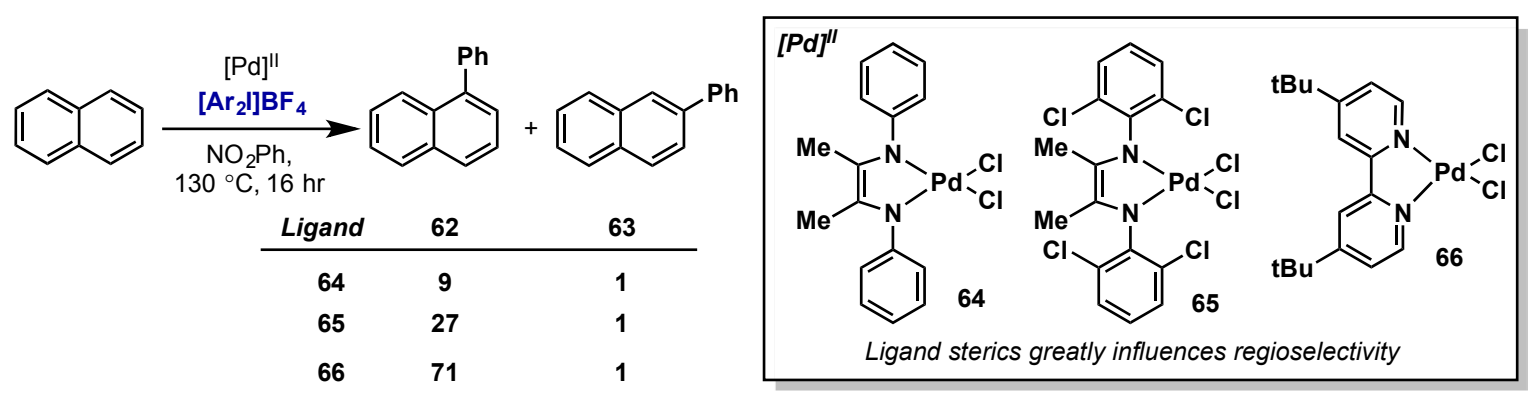

Scheme 34. Ligand-controlled regioselectivity in non-directed C-H arylation with diaryliodonium salts.

\subsubsection{Benzoiodoxolones}

In 2013, Waser reported the direct C2-alkynylation of indoles using 1-[(triisopropylsilyl) ethynyl]-1 $\lambda^{3}, 2$-benziodoxol-3(1H)-one (TIPS-EBX, 67) as both an alkynyl transfer reagent and oxidant (Scheme 35) [73]. The authors have worked extensively with this reagent with further applications in $\mathrm{Au}(\mathrm{I}) / \mathrm{Au}(\mathrm{III})$ catalysis (see Section 4.3). This method is proposed to proceed through a $\mathrm{Pd}(\mathrm{II}) / \mathrm{Pd}(\mathrm{IV})$ catalytic cycle highly analogous to that proposed for $\mathrm{C}-\mathrm{H}$ arylation (see previous discussion). This approach addresses issues of $\mathrm{C} 2 / \mathrm{C} 3$ selectivity in prior methods and products are obtained in moderate to good yield.

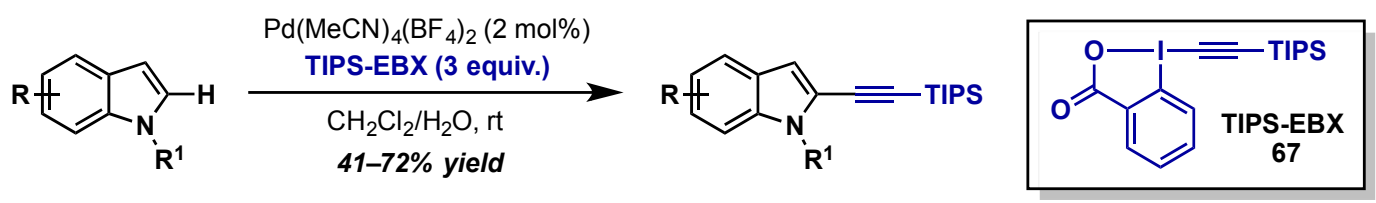

Scheme 35. Direct C2-alkynylation of indoles via Pd(II)/Pd(IV) using alkynyl benzoiodoxolone 67.

\subsubsection{Trifluoromethylation}

Palladium-catalyzed approaches to arene trifluoromethylation are rare, largely because most palladium (II) species are inert to $\mathrm{Ar}-\mathrm{CF}_{3}$ bonding forming reductive elimination [74-76]. Methods involving a $\mathrm{Pd}(\mathrm{II}) / \mathrm{Pd}(\mathrm{IV})$ cycle are an attractive alternative due to more facile reductive eliminations from high oxidation state $\mathrm{Pd}(\mathrm{IV})$. Unfortunately, a limiting factor of most common $\mathrm{Pd}(\mathrm{IV})$ oxidants, including hypervalent iodine reagents, is the transfer of X-groups to the metal center that will readily outcompete a $-\mathrm{CF}_{3}$ group for reductive elimination. This problem was exemplified in studies by Sanford, wherein the synthesis and stoichiometric reactivity of a $\mathrm{Pd}(\mathrm{IV})-\mathrm{CF}_{3}$ complex was examined with a range of common oxidants (Scheme 36) [77,78]. Upon oxidation of complex 68, high oxidation state $\mathrm{Pd}(\mathrm{IV})$ intermediate 69 could undergo two possible reductive elimination pathways to form with an $\mathrm{Ar}-\mathrm{CF}_{3}$ or $\mathrm{Ar}-\mathrm{X}$ bond. Employing $\mathrm{PhI}(\mathrm{OAc})_{2}$ or $\mathrm{N}$-halosuccinimides exclusive $\mathrm{C}-\mathrm{X}$ bond formation was observed, in varying yields. Only upon use of a " $\mathrm{F}^{+}$" source as an oxidant, the optimal being NFTPT (70), was Ar- $\mathrm{CF}_{3}$ bond formation observed in high yield (71). This landmark study shows the feasibility of $\mathrm{Ar}-\mathrm{CF}_{3}$ bond formation via a $\mathrm{Pd}(\mathrm{IV})$ intermediate, however it also exposes the limitations of current oxidants. Common " $\mathrm{F}^{+1}$ sources are expensive relative to hypervalent iodine reagents or $\mathrm{N}$-halosuccinimides and their use in catalytic reaction manifolds of this type is not proven. Therefore, the identification of suitable oxidant/ligand combinations that will facilitate selective $-\mathrm{CF}_{3}$ reductive elimination from $\mathrm{Pd}(\mathrm{IV})$ is of critical importance to the advancement of this area. 


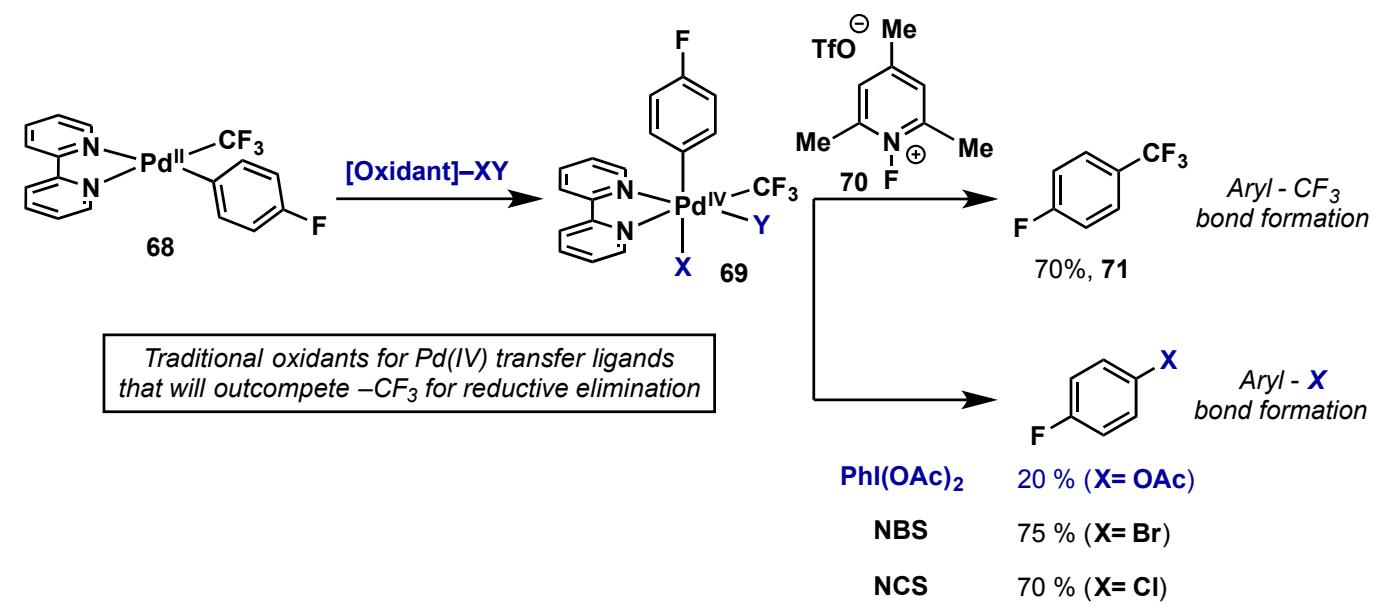

Scheme 36. Isolation and study of $-\mathrm{CF}_{3}$ reductive elmination from $\mathrm{Pd}(\mathrm{IV})$ complexes.

In a significant report, the catalytic trifluoromethylation of indoles was reported by Liu, utilizing $\mathrm{TMSCF}_{3}$ as the trifluoromethyl source and $\mathrm{PhI}(\mathrm{OAc})_{2}$ as a stoichiometric oxidant (Scheme 37) [79]. The authors propose a $\mathrm{Pd}(\mathrm{II}) / \mathrm{Pd}(\mathrm{IV})$ catalytic cycle, involving electrophilic palladation at $\mathrm{Pd}(\mathrm{II})$, followed by oxidation by $\mathrm{PhI}(\mathrm{OAc})_{2} / \mathrm{TMSCF}_{3}$ and reductive elimination. However, detailed mechanistic support is not provided and this result is perhaps surprising given Sanford's previous reports detailing competitive $-\mathrm{OAc}$ vs. $-\mathrm{CF}_{3}$ reductive elimination at $\mathrm{Pd}(\mathrm{IV})[77,78]$. Given the complex set of reaction conditions employed, a more detailed mechanistic study is required to definitively prove the intermediacy of $\mathrm{Pd}(\mathrm{IV})$, and such a study could provide valuable insights for further development of $\mathrm{Pd}(\mathrm{IV})$ trifluoromethylation with $\mathrm{PhI}(\mathrm{OAc})_{2}$ as an oxidant.
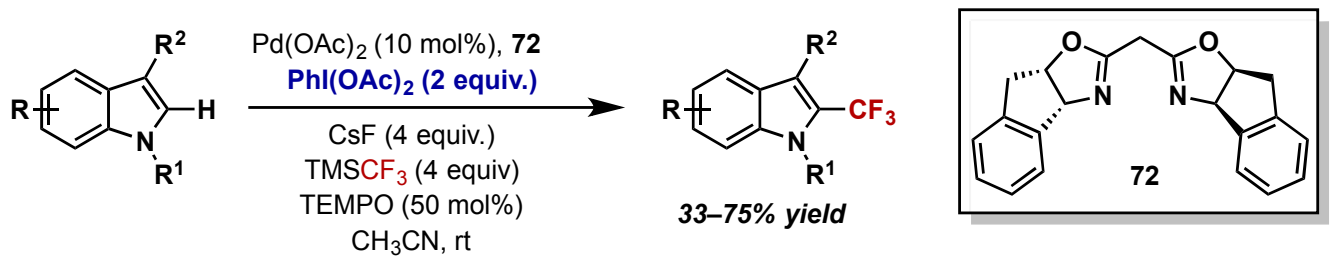

Scheme 37. Catalytic trifluoromethylation of indoles with $\mathrm{PhI}(\mathrm{OAc})_{2}$ as the oxidant and $\mathrm{TMSCF}_{3}$ as the trifluoromethyl source.

Due to the low reactivity towards reductive elimination, trifluoromethyl palladium complexes have been used as tools to probe mechanistic details and oxidation states of proposed catalytic intermediates. There is an ongoing discussion in the literature whether $\operatorname{Pd}(\mathrm{IV})$ monomeric species or $\mathrm{Pd}(\mathrm{III})-\mathrm{Pd}(\mathrm{III})$ dimers are the intermediates arising from hypervalent iodine oxidation of a Pd(II) species (see Section 2.3.2 for further discussion). Ritter has reported that oxidation of palladium complex 73 with $\mathrm{PhI}(\mathrm{OAc})_{2}$ and $\mathrm{PhICl}_{2}$ results in the formation of $\mathrm{Pd}(\mathrm{III})$ dimers [80]. In contrast, Sanford showed that oxidation of $\mathbf{7 3}$ with Togni's reagent (74) gave rise to an isolable $\mathrm{Pd}(\mathrm{IV})$ species (76) (Scheme 38) [81]. In this study, Togni's reagent gave the best yield of complex 76, as compared to other electrophilic " $\mathrm{CF}_{3}{ }^{+}$" sources. A subsequent study between the groups of Ritter, Yates, Canty, in collaboration with Sanford, showed that monomeric $\mathrm{Pd}(\mathrm{IV})$ complex $\mathbf{7 6}$ is likely formed through a two-step oxidation/disproportionation sequence, through the intermediacy of bimetallic intermediate 75 [82]. It is suggested that formation of the $\mathrm{Pd}-\mathrm{Pd}$ bond that occurs during initial oxidation to $\mathrm{Pd}(\mathrm{III})$ lowers the activation barrier to oxidation en route to 76 . 

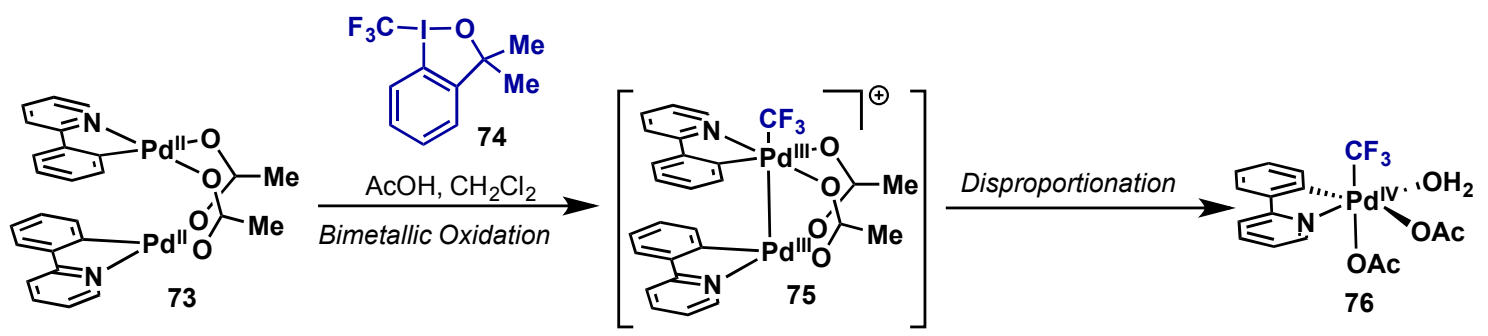

Scheme 38. Evidence for intermediacy of bimetallic $\mathrm{Pd}(\mathrm{III})$ species en route to monomeric $\mathrm{Pd}(\mathrm{IV})$ upon oxidation with Togni's reagent.

\subsubsection{Miscellaneous}

Sanford has reported an interesting transformation wherein enynes are converted to highly substituted cyclopropanes via a cyclization cascade employing $\mathrm{Pd}(\mathrm{OAc})_{2}$ and $\mathrm{PhI}(\mathrm{OAc})_{2}$ (Scheme 39) [47]. In this case, the high-oxidation state of Pd(IV) intermediate (77) undergoes nucleophilic displacement by an internal enol ether to generate the cyclopropane moiety via an $\mathrm{S}_{\mathrm{N}}$ 2-type pathway, analogous to Muniz's reports on Pd(IV)-mediated amination (see Section 2.2.4.1). Key to success is that the rate of intramolecular cyclization is faster than that of $\mathrm{C}-\mathrm{O}$ bond forming reductive elimination from 77 and trace amounts of $\mathrm{C}-\mathrm{O}$ products (78) are observed.

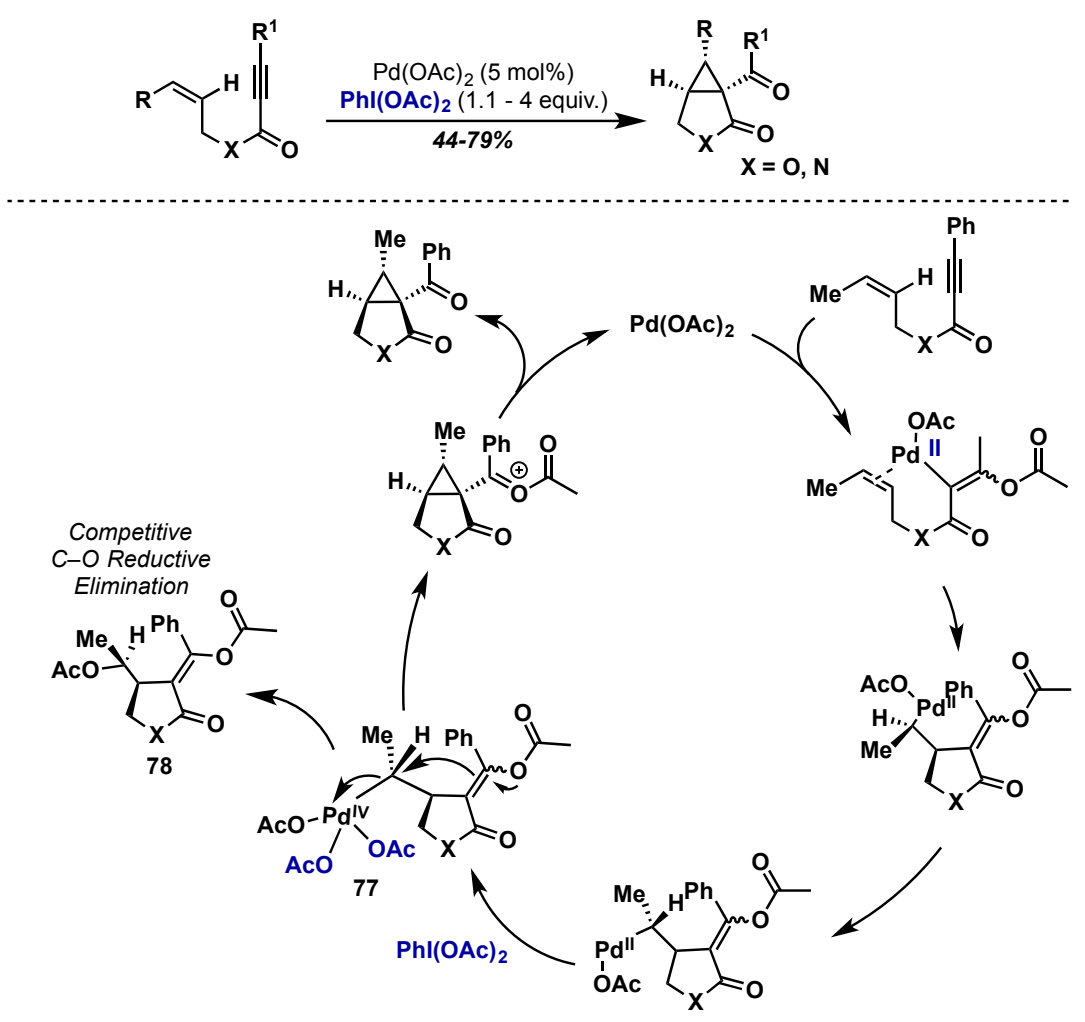

Scheme 39. Cyclopropane synthesis via $\mathrm{Pd}(\mathrm{II}) / \mathrm{Pd}(\mathrm{IV})$ catalysis with $\mathrm{S}_{\mathrm{N}}$ 2-type displacement of $\mathrm{Pd}(\mathrm{IV})$.

\subsection{Palladium(III)}

\subsubsection{Introduction}

In contrast to reactions with palladium in its $0,+1,+2$, and +4 oxidation states, little is known about the chemistry of $\mathrm{Pd}(\mathrm{III})$ dimers or their potential role in catalysis. This has been due to the low stability of these compounds, hindering their isolation and characterization, and a lack of examples 
employing Pd(III) organometallic species in catalytic manifolds. Over the last 10 years, hypervalent iodine reagents have emerged as excellent oxidants for the isolation of $\mathrm{Pd}(\mathrm{III})$ dimers and these studies have provided key insights into the role that $\mathrm{Pd}(\mathrm{III})$ intermediates could play in carbo-heteroatom bond forming transformations. In this section we will highlight some of the more significant studies in this area, with an emphasis on those that relate to the previously discussed $\mathrm{Pd}(\mathrm{II}) / \mathrm{Pd}(\mathrm{IV})$ carbon-halogen and carbon-oxygen bond forming reactions.

\subsubsection{Complex Isolation}

Cotton reported the isolation and characterization of several dimeric Pd(III) species possessing a Pd-Pd single bond, all accessed via two, one-electron oxidations of dimeric Pd(II) precursors with $\mathrm{PhICl}_{2}$ (Scheme 40) [83,84]. In their initial report, cyclic voltammetry measurements revealed that Pd(II) species 79, with a bridging hpp (1,3,4,6,7,8-hexahydro-2H-pyrimido[1,2- $\alpha$ ]pyrimidine) ligand, possessed a quasi-reversible oxidation at $-0.12 \mathrm{~V}$ and an irreversible oxidation at $+0.82 \mathrm{~V}$ hinting at the low stability of the products. Indeed, while they were able to achieve oxidation with $\mathrm{PhICl}_{2}$, products were isolated in low yield via manual selection of crystals amongst numerous decomposition products. A subsequent study improved on the oxidation by exploring other bridging ligands and found that while it was possible to oxidize Pd(II) dimers with a variety of electron-rich and electron-deficient carboxylate ligands (80); oxidation became inaccessible upon introduction of an electron-deficient perfluorinated aryl backbone on the phosphine ligand.
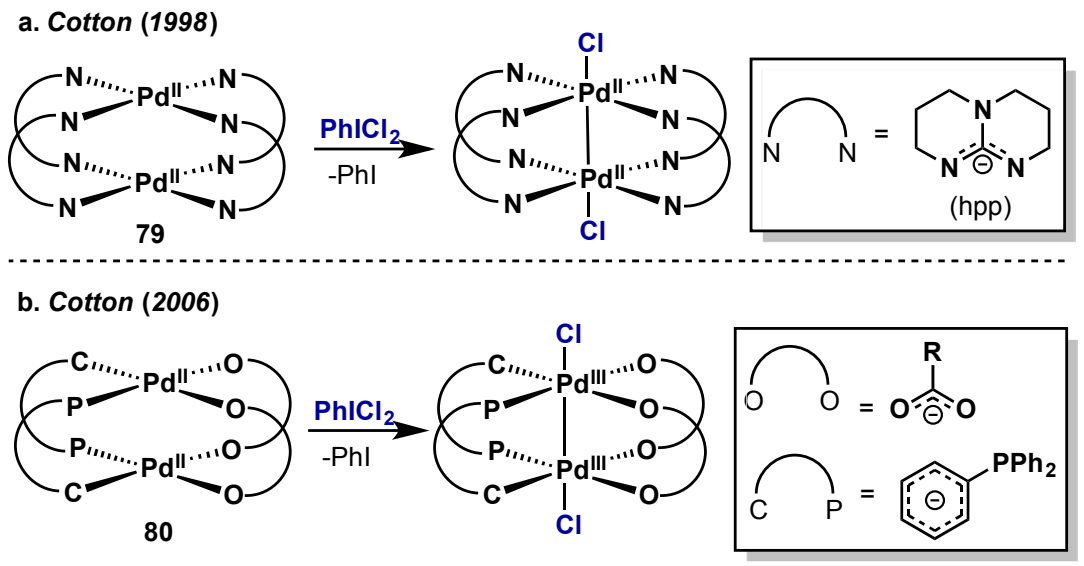

Scheme 40. Formation of $\mathrm{Pd}(\mathrm{III})$ dimers upon oxidation with $\mathrm{PhICl}_{2}$. (a) Use of an hpp bridging ligand (b) Use of bridging carboxylate and arylphosphine ligands.

Ritter has conducted extensive studies on the potential role that bimetallic Pd(III) dimers could play in what had been widely proposed to be Pd(II)/Pd(IV) catalytic cycles (Scheme 41) $[80,82,85]$. The first definitive report for the presence of $\mathrm{Pd}(\mathrm{III})$ intermediates was in 2009. The oxidation of a dimeric Pd(II) complex (81) was examined employing oxidants common to Pd(II)/Pd(IV) C-X bond forming reactions, including $\mathrm{PhI}(\mathrm{OAc})_{2}, \mathrm{PhICl}_{2}$, or $\mathrm{N}$-halosuccinimides. Oxidation of 81 with $\mathrm{PhICl}_{2}$ gave rise to $\mathrm{Pd}(\mathrm{III})$ intermediate $\mathbf{8 2}$, which was characterized by $\mathrm{X}$-ray crystallography. $\mathrm{The} \mathrm{Pd}-\mathrm{Pd}$ bond length in 82 is $2.84 \AA$, which strongly suggests a metal-metal single bond and bond order of zero. Therefore, in a net two-electron oxidation, $\mathrm{PhICl}_{2}$ oxidizes each palladium center by one electron $\left(\mathrm{d}^{8} \rightarrow \mathrm{d}^{7}\right)$, which results in formation of a metal-metal single bond. Detailed mechanistic and computational studies support that $\mathbf{8 2}$ is then able to undergo a concerted reductive elimination event wherein both components of the new $\mathrm{C}-\mathrm{X}$ bond arise from a single palladium center. A subsequent report from Ritter provides additional evidence that a $\mathrm{Pd}$ (III) dimer is the kinetically competent species in the acetoxylation of 2-phenylpyridine with $\mathrm{Pd}(\mathrm{OAc})_{2} / \mathrm{PhI}(\mathrm{OAc})_{2}$ [85]. 


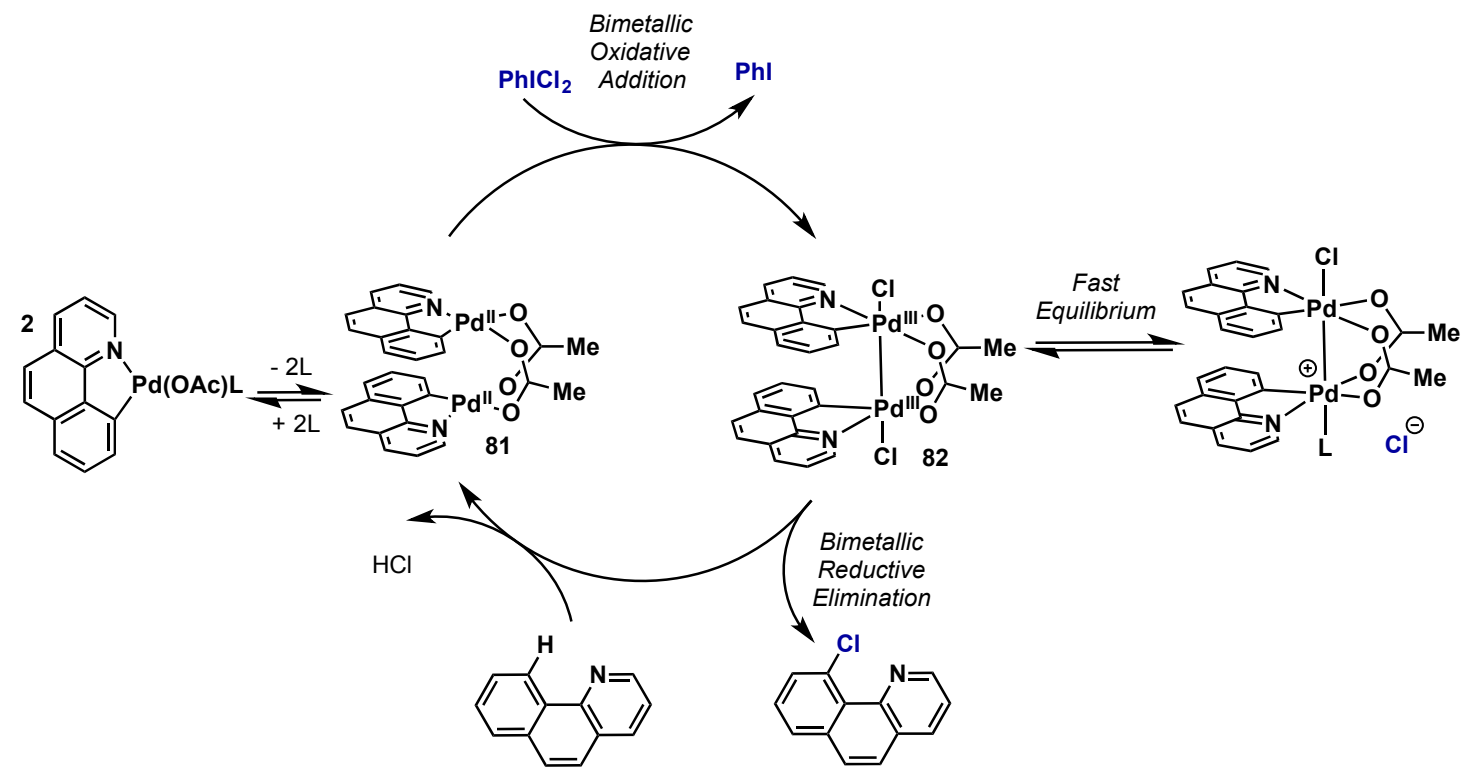

Scheme 41. First evidence for the role of bimetallic Pd(III) dimers in catalysis.

Together, these reports are the first to show the catalytic competence of $\mathrm{Pd}(\mathrm{III})$ dimers in $\mathrm{C}-\mathrm{X}$ bond forming reactions and could fuel further investigations in the area of bimetallic $\mathrm{Pd}(\mathrm{III})$ catalysis. Furthermore it supports the consideration of $\mathrm{Pd}(\mathrm{III})$ dimers along $\mathrm{Pd}(\mathrm{II}) / \mathrm{Pd}(\mathrm{IV})$ catalytic cycles employing hypervalent iodine oxidants.

\subsubsection{Conclusions}

High valent palladium chemistry represents one of the most well developed areas of high oxidation state metal catalysis. Advancements in the formation of a wide range of carbon-heteroatom bonds including $\mathrm{C}-\mathrm{O}, \mathrm{C}-\mathrm{X}, \mathrm{C}-\mathrm{N}$, as well as $\mathrm{C}-\mathrm{C}$ bonds via this manifold have been reported. $\mathrm{PhI}(\mathrm{OAc})_{2}$ and diaryliodonium salts have been the most widely applied hypervalent iodine reagents in catalytic method development and $\mathrm{PhICl}_{2}$ has been successfully used for high valent complex isolation. Detailed mechanistic studies have revealed clear evidence for $\mathrm{Pd}(\mathrm{II}) / \mathrm{Pd}(\mathrm{IV})$ redox couples in these processes, however the role of $\mathrm{Pd}(\mathrm{III})$-dimers along the catalytic cycles is becoming more evident. Current limitations remain in the reductive elimination of challenging groups such as fluoride or trifluoromethyl groups, and development of oxidants that do not possess competitive ligands for reductive elimination would significantly contribute to this area.

\section{Platinum}

Platinum has played a pivotal role in the evolution of oxidative couplings. Arguably, the "Shilov system" was the first significant example of an intermolecular $\mathrm{C}-\mathrm{H}$ functionalization, wherein the oxidation of alkanes to a mixture alcohols and alkyl chlorides was mediated by an aqueous solution of $\left[\mathrm{PtCl}_{4}{ }^{2-}\right]$ and $\left[\mathrm{PtCl}_{6}{ }^{2-}\right]$ (Scheme 42a) [86]. Since this seminal discovery, extensive studies have been conducted on the $\mathrm{Pt}(\mathrm{II}) / \mathrm{Pt}(\mathrm{IV})$ redox couple, as well as the potential formation of $\mathrm{Pt}(\mathrm{III})$ dimeric species. Oxidation of square planar $\mathrm{Pt}(\mathrm{II})$ to octahedral $\mathrm{Pt}(\mathrm{IV})$ is significantly more facile than palladium (standard reduction potentials of $\left[\mathrm{PtCl}_{6}{ }^{2-}\right]$ and $\left[\mathrm{PdCl}_{6}{ }^{2-}\right]$ are $+0.68 \mathrm{~V}$ and $+1.29 \mathrm{~V}$, respectively) [86], however, $\mathrm{Pt}(\mathrm{II}) / \mathrm{Pt}(\mathrm{IV})$ mediated oxidative couplings are comparatively rare. This is due to the significantly higher barrier to reductive elimination for $\mathrm{Pt}(\mathrm{IV})$ relative to $\mathrm{Pd}(\mathrm{IV})$ [87]. The enhanced stability of $\mathrm{Pt}(\mathrm{IV})$ complexes has been exploited in their use as isolable model systems for the study of more elusive $\mathrm{Pd}(\mathrm{II}) / \mathrm{Pd}(\mathrm{IV})$ redox couples [88]. Mechanistic insights provided by these studies have been recently reviewed $[88,89]$ and this section will cover recent advancements in $\mathrm{Pt}(\mathrm{IV})$ chemistry as they relate to hypervalent iodine reagents. 

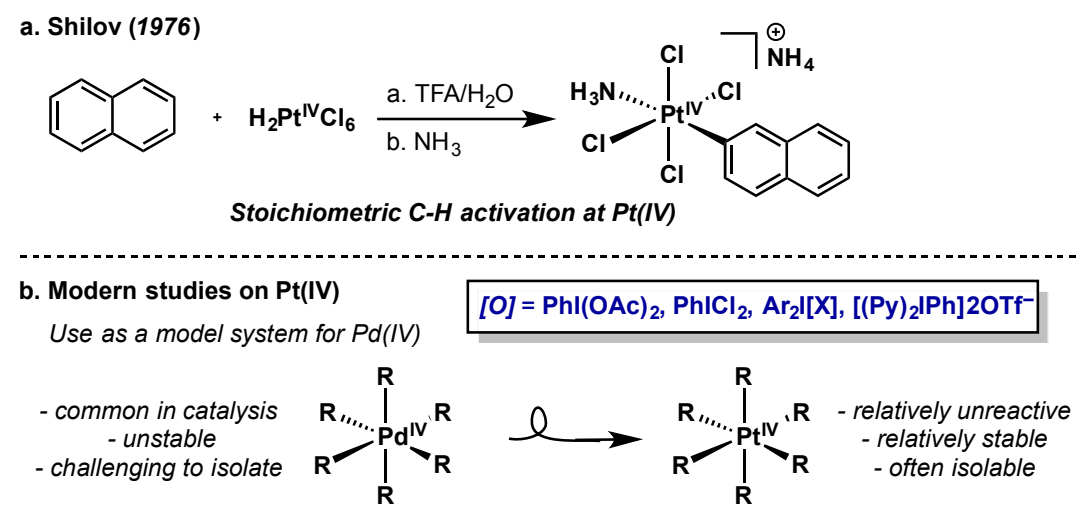

Development of Pt(II)/Pt(IV) C-H activation

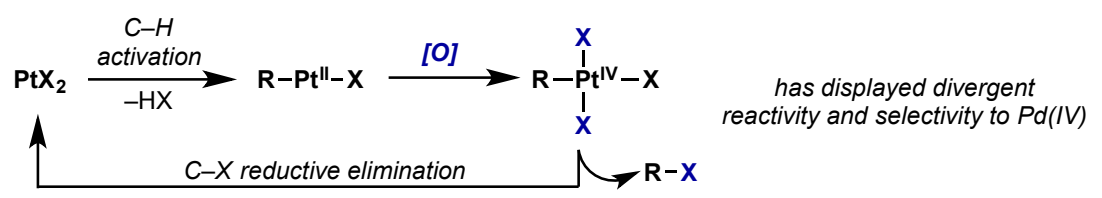

Scheme 42. (a) Stoichiometric C-H functionalization of naphthalene by Shilov; (b) General scheme for modern applications $\mathrm{Pt}(\mathrm{II}) / \mathrm{Pt}(\mathrm{IV})$ redox couples with hypervalent iodine oxidants.

\subsection{Complex Isolation}

Canty has conducted many of the seminal reports on the isolation of various $\mathrm{Pt}(\mathrm{IV})$ and $\mathrm{Pd}(\mathrm{IV})$ complexes via oxidation with both aryl and alkynyliodonium salts (Scheme 43) [63-66]. The iodonium salts were able to cleanly oxidize Pt(II) complexes with a variety of ligand scaffolds, giving rise to varying degrees of cis/trans isomers (83-cis or 83-trans), at low temperature. For characterization purposes these complexes were then treated with $\mathrm{NaI}$ resulting in triflate displacement, and a summary of the complexes synthesized via this approach is provided below (compounds 84-88). Throughout these reports, Canty notes the higher stability of the resultant platinum complexes relative to palladium, facilitating isolation and structural characterization that was not possible with the corresponding palladium species. For a further discussion of the analogous palladium components to Canty's studies, see Section 2.2.5.1.

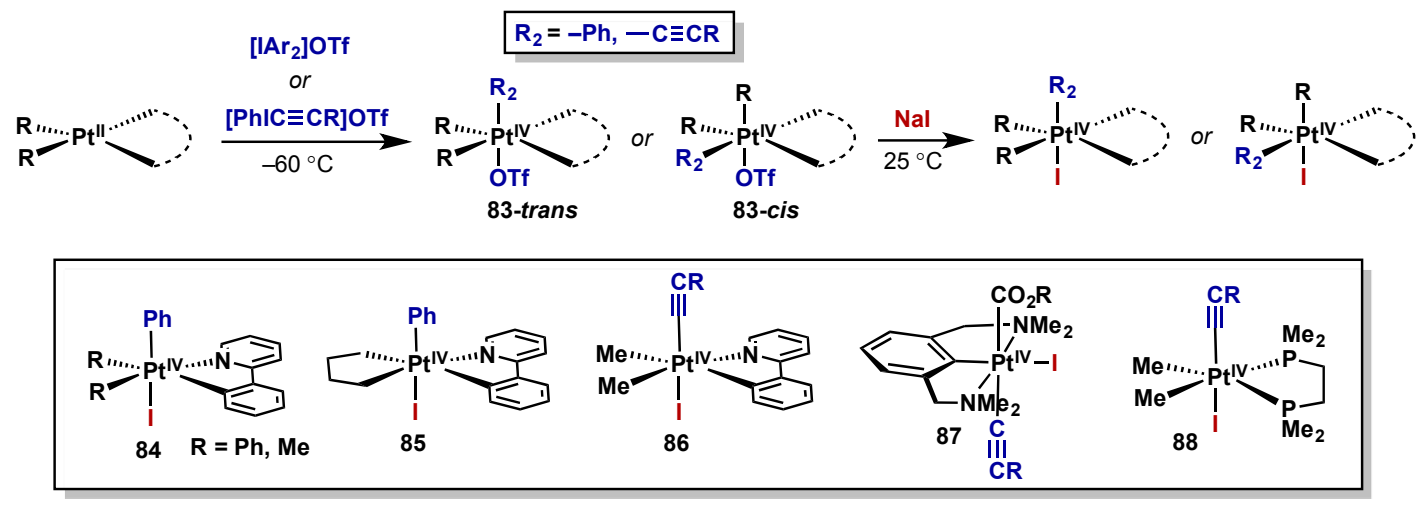

Scheme 43. Characterization of Pt(IV) upon oxidation with diaryl and alkynyliodonium salts.

In 2005, Sanford reported the oxidation of benzo[ $h$ ]quinoline supported $\mathrm{Pt}(\mathrm{II})$ acac complex 89 with $\mathrm{PhI}(\mathrm{OAc})_{2}$ in an effort to gain mechanistic insights into the analogous $\mathrm{Pd}(\mathrm{II}) / \mathrm{Pd}(\mathrm{IV})$ system (Scheme 44) [90]. Interestingly, it was found that solvent had a pronounced effect on product distribution. In $\mathrm{AcOH}, \mathrm{Pt}(\mathrm{III})-\mathrm{Pt}(\mathrm{III})$ dimer 90 was obtained, while a mixture of $\mathrm{Pt}(\mathrm{IV})$ alkoxides $(91,92)$ were obtained in the alcoholic solvents, with ratios dependent on the steric bulk of the 
alcohol. Alcoholic solvents are not able to serve as bridging ligands, thus resulting in preferential formation of the monomeric species $(\mathbf{9 1}, 92)$ and such complexes were hypothesized to be analogous to intermediates in $\mathrm{Pd}(\mathrm{II}) / \mathrm{Pd}(\mathrm{IV}) \mathrm{C}-\mathrm{H}$ oxygenations. In contrast, isolation of $\mathrm{Pt}(\mathrm{III})-\mathrm{Pt}(\mathrm{III}) 90$ was surprising as these intermediates had not been invoked in $\mathrm{Pd}(\mathrm{II}) / \mathrm{Pd}(\mathrm{IV})$-catalyzed processes, however subsequent studies from Ritter, Sanford, and others have shown the viability of Pd(III) dimers in these processes (see Section 2.3). Only 0.5 equivalents of $\mathrm{PhI}(\mathrm{OAc})_{2}$ were needed for formation of either the monomeric or bimetallic species, providing strong evidence that both pathways proceed via two-electron oxidation.

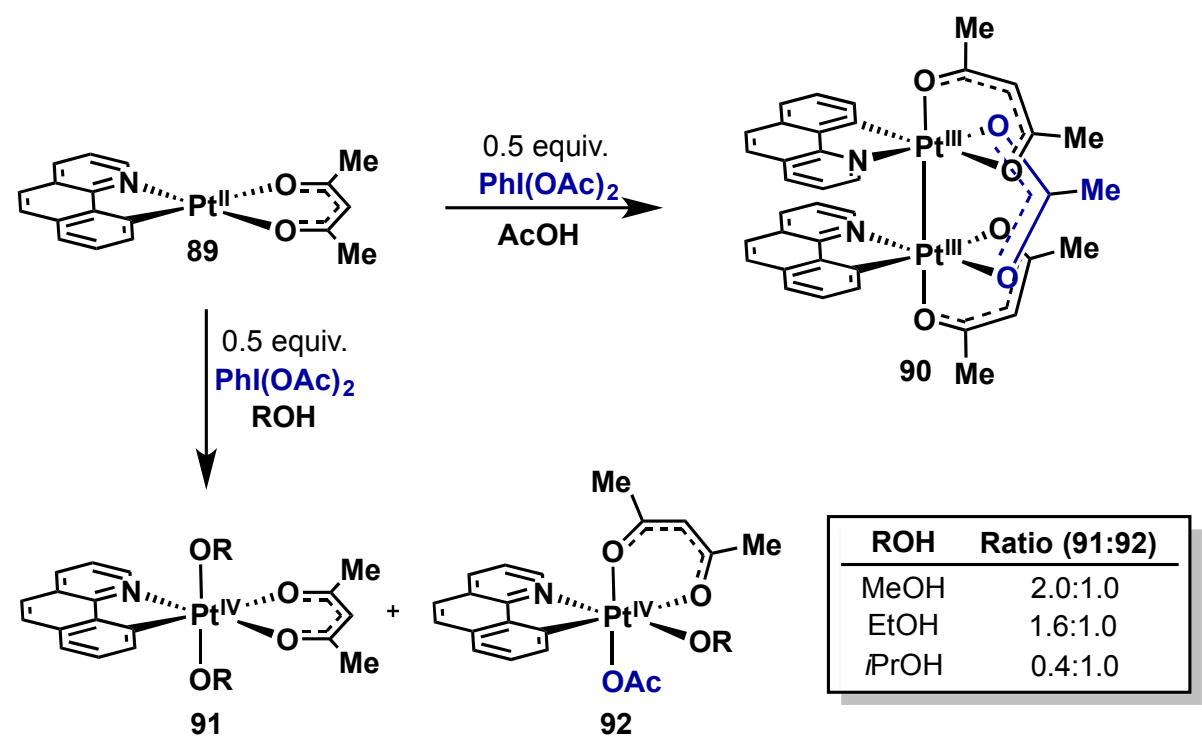

Scheme 44. Benzo[ $h]$ quinoline Pt(II) oxidation studies. Effect of solvent on oxidation product ratios.

A subsequent study by Sanford examined the oxidation of 2-phenylpyridine Pt(II) complex 93 with $\mathrm{PhICl}_{2}$, which led to a mixture of cis and trans Pt(IV) complexes (94-cis 94-trans, Scheme 45a) [91]. This was particularly interesting as the analogous $\mathrm{Pd}(\mathrm{II})$ complex has been found to give exclusive formation of the cis isomer (95) upon oxidation with $\mathrm{PhICl}_{2}$. $\mathrm{Pt}(\mathrm{II})$ complex 93 was also subject to a delicate interplay between $\mathrm{Pt}(\mathrm{IV})$ and $\mathrm{Pt}(\mathrm{III})-\mathrm{Pt}(\mathrm{III})$ dimer formation upon oxidation, similar to their previous report [90], however in this case product ratios were contingent on choice of external oxidant. Whereas $\mathrm{PhICl}_{2}$ gave exclusively $\mathrm{Pd}(\mathrm{IV})$ monomers, altering the oxidant to NCS provided a $\mathrm{Pt}(\mathrm{III})-\mathrm{Pt}(\mathrm{III})$ dimer as the major product (not shown). Rourke and co-workers showed that treatment of $\mathrm{Pt}(\mathrm{II})$ complex 96 with $\mathrm{PhICl}_{2}$ resulted in two-electron oxidation with concomitant $\mathrm{C}-\mathrm{H}$ activation to provide $\mathrm{Pt}(\mathrm{IV})$ dichloride 98 even at temperatures as low as $-40{ }^{\circ} \mathrm{C}$ (Scheme 46b) [92]. This result is notable as previous studies employing other oxidants (peroxides and molecular oxygen) produced complex mixtures. It is proposed that oxidation proceeds via a five-coordinate, cationic $\mathrm{Pt}(\mathrm{IV})$ intermediate (97) that is highly active towards arene functionalization.

Building on Ritter's use of poly(cationic) $\lambda^{3}$-iodanes in high oxidation state nickel and palladium-mediated fluorination (see Section 2.2.3.1 and Section 5.3), Dutton investigated the potential of poly(cationic) $\lambda^{3}$-iodanes to access a range of dicationic $\mathrm{Pd}(\mathrm{IV})$ and $\mathrm{Pt}(\mathrm{IV})$ complexes through the delivery of neutral heterocyclic ligands to the metal center (Scheme 46) [93]. They found that 2-phenylpyridine $\mathrm{Pt}(\mathrm{II})$ complex 93 could be cleanly oxidized to $\mathrm{Pt}(\mathrm{IV})$ complex 100 with a DMAP-derived poly(cationic) $\lambda^{3}$-iodane 99 (Scheme 46a). However, oxidation of dimethyl Pt(II) 101 led to a less defined product distribution (Scheme 46b), possibly arising from oxidative disproportionation. This reactivity has been documented in similar $\mathrm{Pt}(\mathrm{II}) / \mathrm{Pt}(\mathrm{IV})$ redox couples, however the intermediacy of $\mathrm{Pt}(\mathrm{III})$ intermediates cannot be ruled out in this case [94]. These oxidations were also performed on the analogous palladium complexes, which were found to be too unstable for isolation and underwent 
rapid disproportionation. While the Pt(IV) species 100 and 102 were isolable, it is notable that they are considerably less stable than complexes possessing anionic chloride or acetate ligands, and similar stability trends were observed for the palladium complexes. While this is detrimental in the context of complex isolation, it could be adventitious for enhancing the reactivity of both high-oxidation state palladium and platinum species in catalysis.

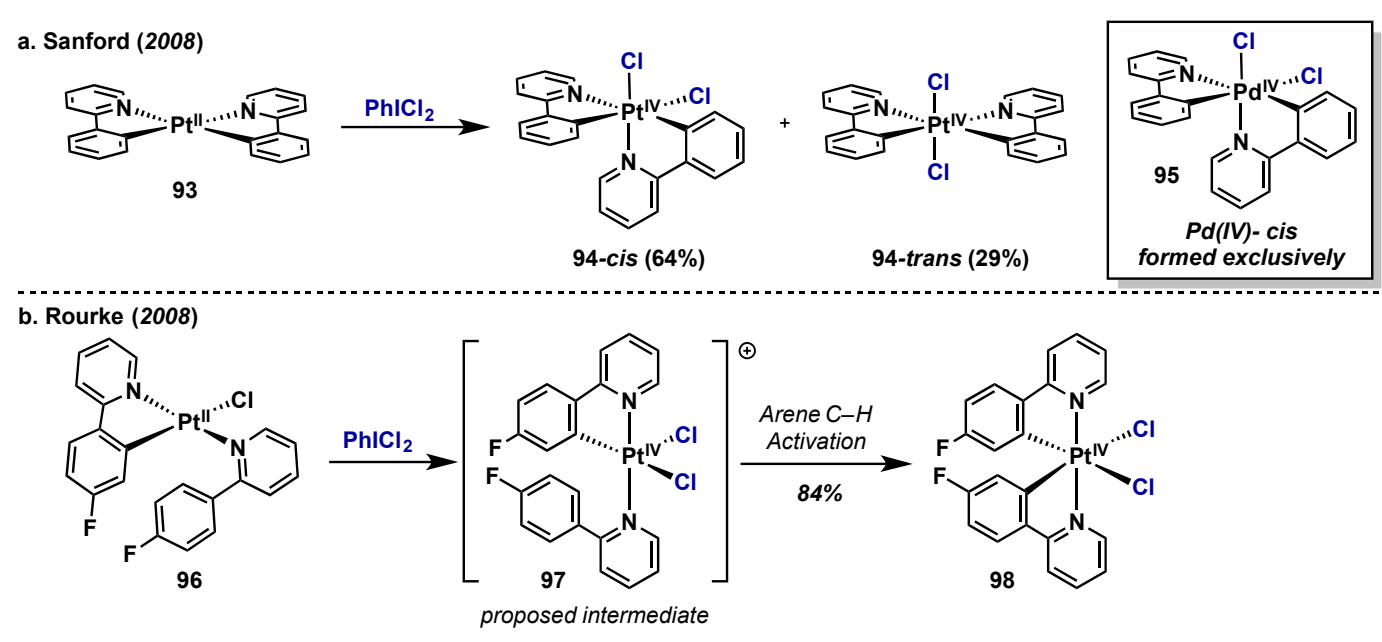

Scheme 45. (a) Oxidation of 2-phenylpryidine $\mathrm{Pt}(\mathrm{II})$ complex with $\mathrm{PhICl}_{2}$. Divergent complex geometry from $\mathrm{Pd}(\mathrm{II}) ;(\mathbf{b}) \mathrm{Pt}(\mathrm{II})$ oxidation with $\mathrm{PhICl}_{2}$ resulting in arene $\mathrm{C}-\mathrm{H}$ activation.

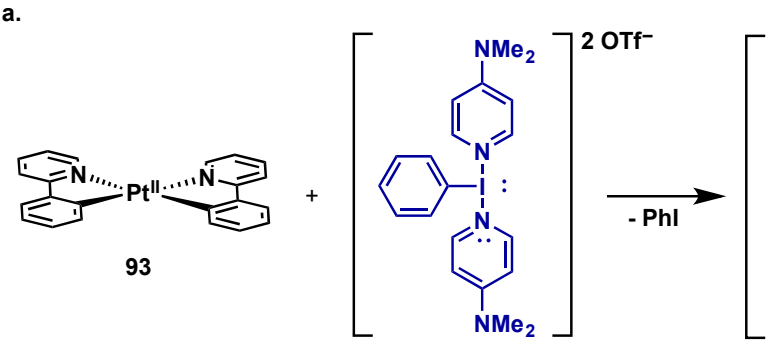

99

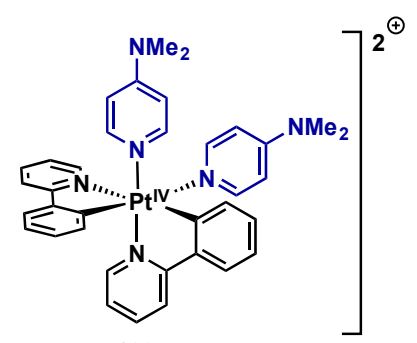

100

b.

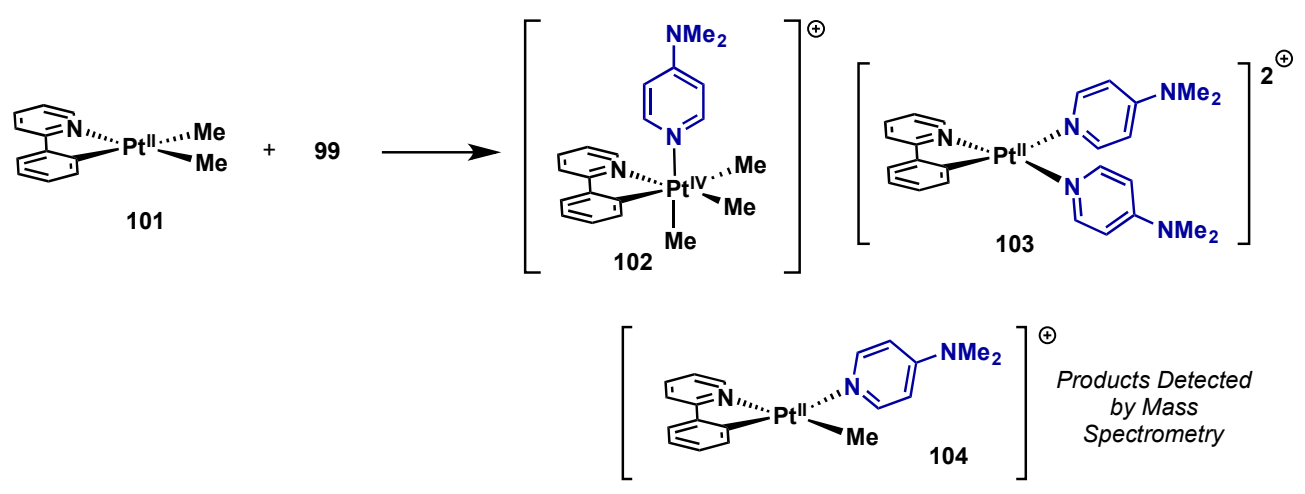

Scheme 46. Dicationic [PhI(4-DMAP) $\left.)_{2}\right][\mathrm{OTf}]$ mediated oxidation of (a) 2-Phenylpyridine $\mathrm{Pt}(\mathrm{II})$ complex 93; (b) Dimethyl Pt(II) complex 101.

\subsection{Catalytic Applications}

While platinum is most commonly employed as a model system, recent advancements have shown its viability in catalytic manifolds. Particularly interesting is the finding that platinum-catalyzed processes often display divergent reactivity and selectivity to those mediated by palladium. 
Suna reported that $\mathrm{PtCl}_{2}$ with $\mathrm{PhI}(\mathrm{OAc})_{2}$ cleanly acetoxylated the $\mathrm{C}-3$ position on various indoles (Scheme 47) [95]. $\mathrm{Pd}(\mathrm{OAc})_{2}$ was also a competent catalyst, however $\mathrm{PtCl}_{2}$ was found to be more efficient, giving cleaner reactions and higher isolated yields. Other oxidants including $\mathrm{K}_{2} \mathrm{~S}_{2} \mathrm{O}_{8}, m-\mathrm{CPBA}, t-\mathrm{BuOOH}$, and $\mathrm{Cu}(\mathrm{OAc})_{2}$ were all completely ineffective ( $0 \%$ conversion) and $\mathrm{Mg}$ peroxyphthalate gave a complex mixture of products. While not reported, oxidation to the active $\mathrm{Pt}(\mathrm{IV})$ species would likely proceed through intermediates similar to those shown in Scheme 43.

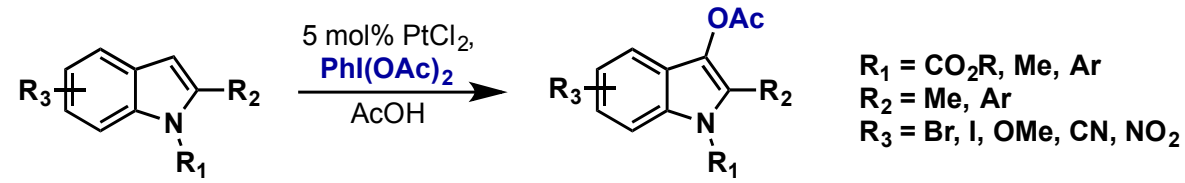

Scheme 47. $\mathrm{PtCl}_{2} / \mathrm{PhI}(\mathrm{OAc})_{2}$ mediated $\mathrm{C}-3$ acetoxylation of indoles.

In 2013, Sanford provided the first example of an intermolecular $\mathrm{C}\left(\mathrm{sp}^{2}\right)-\mathrm{H}$ arylation enabled by a $\mathrm{Pt}(\mathrm{II}) / \mathrm{Pt}(\mathrm{IV})$ manifold (Scheme 48a) [96]. The reaction was found to have a much broader scope than the analogous palladium-catalyzed transformations, being tolerant of a wide range of both electron rich and electron deficient arenes, and furthermore, a complete reversal in site-selectivity was observed when using $\mathrm{Na}_{2} \mathrm{PtCl}_{4}$ versus $\mathrm{Na}_{2} \mathrm{PdCl}_{4}$ (Scheme $48 \mathrm{~b}$ ). The proposed mechanism proceeds via a $\mathrm{Pt}(\mathrm{II}) / \mathrm{Pt}(\mathrm{IV})$ redox cycle with two-electron $\mathrm{C}-\mathrm{C}$ bond forming reductive elimination, analogous to previous work on Pd(IV) (see Section 2.2.5) [72].

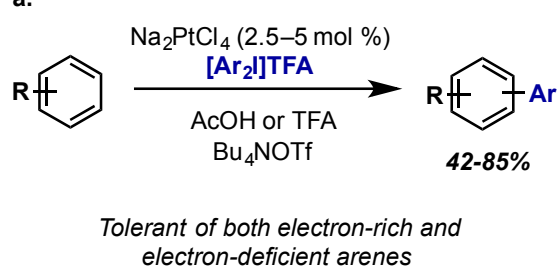

b.

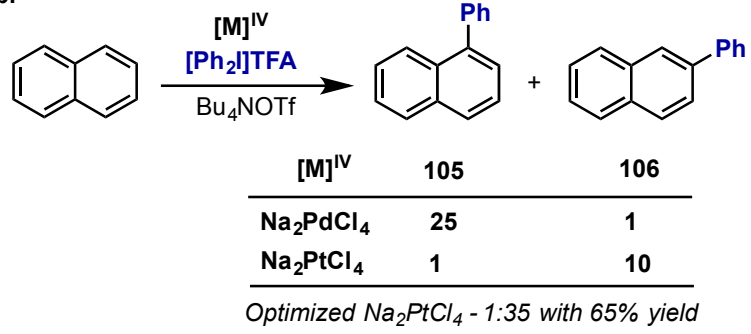

Scheme 48. (a) Intermolecular C-H arylation with Pt(II) and diaryliodonium salts; (b) Reversal of site selectivity for $\mathrm{Pt}(\mathrm{II})$ vs. $\mathrm{Pd}(\mathrm{II})$ in arene $\mathrm{C}-\mathrm{H}$ activation.

\subsection{Conclusions}

The true strength of the $\mathrm{Pt}(\mathrm{II}) / \mathrm{Pt}(\mathrm{IV})$ redox couple remains in its use as a model complex for more reactive $\mathrm{Pd}(\mathrm{II}) / \mathrm{Pd}(\mathrm{IV})$ species due to their increased stability. However, the potential synthetic utility of platinum catalyzed reactions is evident, having displayed enhanced reactivity, and divergent selectivity relative to palladium. Dutton's findings that oxidation employing poly(cationic) $\lambda^{3}$-iodanes produce less stable $\mathrm{Pt}(\mathrm{IV})$ centers relative to traditional oxidants may lead to more reactive $\mathrm{Pt}(\mathrm{IV})$ intermediates and expand their applications in oxidative couplings.

\section{Gold}

\subsection{Introduction}

Gold catalysis has historically proceeded through redox neutral pathways relying on its high efficiency as a carbophilic pi acid. This has seen wide application in the activation of alkynes and alkenes for nucleophilic attack and cycloisomerization cascades, and synthetic applications of these pathways have been recently reviewed [97-100]. Reactions containing $\mathrm{Au}(\mathrm{I}) / \mathrm{Au}(\mathrm{III})$ redox cycles are rare by comparison, a consequence of the high barrier for oxidation of $\mathrm{Au}(\mathrm{I})$ to $\mathrm{Au}(\mathrm{III})$ (redox potential $+1.41 \mathrm{~V})$. Typical oxidative addition/reductive elimination, which are ubiquitous in $\mathrm{Pd}(0) / \mathrm{Pd}(\mathrm{II})$ 
chemistry, are thereby challenging with $\mathrm{Au}(\mathrm{I}) / \mathrm{Au}(\mathrm{III})$ (Scheme 49a, 107 to 109) [101,102] and examples of such reactivity are scarce [103-105]. Instead, Au(III) complexes can be accessed via exposure of an $\mathrm{Au}(\mathrm{I})$ species, $\mathrm{L}_{\mathrm{n}}-\mathrm{Au}-\mathrm{X}$, to a powerful external oxidant, and in this context hypervalent iodine reagents have found widespread use, along with hydroperoxides, Selectfluor, and others. A catalytic cycle based on this approach is shown in Scheme 49a; oxidation of $\mathrm{L}_{n}-\mathrm{Au}-\mathrm{X}$ gives $\mathrm{Au}$ (III) species 107, followed by two subsequent ligand exchanges to access 109, which would then undergo rapid reductive elimination [102]. This strategy has led to developments in alkynylation, olefin functionalization, cross-couplings and dimerization/homo-coupling reactions using a wide range of oxidants beyond hypervalent iodine species and these reports have been recently reviewed by Gouverneur [102].

Unfortunately, advancements in reaction development centered on $\mathrm{Au}(\mathrm{I}) / \mathrm{Au}(\mathrm{III})$ have not coincided with equivalent mechanistic understanding of the oxidation/reduction pathways or speciation of the organometallic gold complexes involved. Oxidation potentials of active Au(I) species are varied, and can depend on both the counterion and the ligand sphere, making proper oxidant selection delicate and the generation of isolable $\mathrm{Au}(\mathrm{III})$ species challenging and unpredictable. However, pioneering studies by Hashmi [106,107], along with the synthesis and characterization of stoichiometric Au(III) complexes by Bennett [108], Lippert [109], Fuchita [110], and Constable [111], have laid the foundations for a more in depth understanding of the chemistry of these highly reactive intermediates (Scheme 49b).
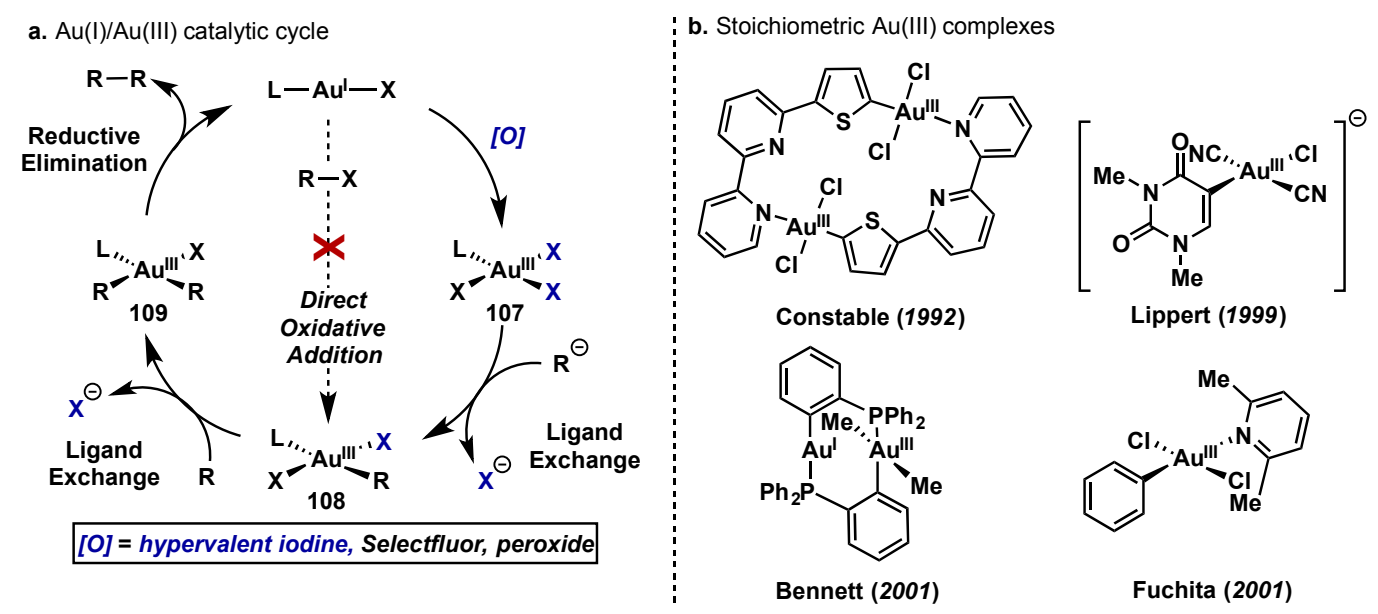

Scheme 49. (a) Plausible $\mathrm{Au}(\mathrm{I}) / \mathrm{Au}(\mathrm{III})$ catalytic cycle based on use of an external oxidant; (b) Pioneering examples of stoichiometric $\mathrm{Au}(\mathrm{III})$ complexes.

\subsection{Complex Synthesis and Characterization}

$\mathrm{Au}(\mathrm{I})$ cationic salts, along with phosphine and N-heterocyclic carbene (NHC) supported $\mathrm{Au}(\mathrm{I})$ complexes, are the most utilized in $\mathrm{Au}(\mathrm{I}) / \mathrm{Au}(\mathrm{III})$ catalysis. NHC-Au(I) chemistry in particular has gained immense popularity in the last decade, making them arguably the most well studied of Au(I) complexes. The strong $\sigma$-donation of the NHC ligand aides in stabilization of both the $\mathrm{Au}(\mathrm{I}) \mathrm{and} \mathrm{Au}(\mathrm{III})$ species, making these complexes ideal candidates for the synthesis of isolable Au(III) complexes [112].

Limbach and Nolan reported the synthesis of a range of NHC-Au(III) complexes via oxidation of an $\mathrm{NHC}-\mathrm{Au}(\mathrm{I})-\mathrm{Cl}$ with $\mathrm{PhICl}_{2}$ (Scheme 50, $110 \rightarrow$ 113) $[113,114]$. The oxidation could also be carried out with $\mathrm{Cl}_{2}(g)$ at cryogenic temperatures, however the oxidation with $\mathrm{PhICl}_{2}$ proceeded more cleanly, in higher yield, and at room temperature, making it far more advantageous. This advantage was attributed to the relatively milder oxidizing conditions when using $\mathrm{PhICl}_{2}$ versus $\mathrm{Cl}_{2}(g)$. Interestingly, attempted oxidations with other $\lambda^{3}$-iodanes such as $\mathrm{Ph}_{2} \mathrm{IBr}, \mathrm{PhI}(\mathrm{OAc})_{2}$, and $\mathrm{PhI}(\mathrm{OTFA})_{2}$ either failed to oxidize the $\mathrm{Au}(\mathrm{I})$ complexes or gave complex product mixtures. The authors assert that chlorine ligands are crucial to stabilize the $\mathrm{Au}(\mathrm{III})$ center and thus $\mathrm{PhICl}_{2}$ is optimal as it acts as both an oxidant and chlorinating agent. $\mathrm{NHC}-\mathrm{Au}(\mathrm{I})-\mathrm{Ph}$ complex 112 was also readily oxidized in high yield with $\mathrm{PhICl}_{2}$ to 
give 113, which the authors state is the first reported $\mathrm{Au}(\mathrm{III})$ complex of the type [ $\mathrm{AuArCl}_{2} \mathrm{~L}$ ] [113]. It is worth noting that trichloride $\mathrm{Au}(\mathrm{III})$ complex 111 could not be converted to 113 via transmetalation with $p$-methoxyphenylmagnesium bromide, instead giving rise to $4,4^{\prime}$-bismethoxybiphenyl via either a radical coupling or inner-sphere reductive elimination pathway.

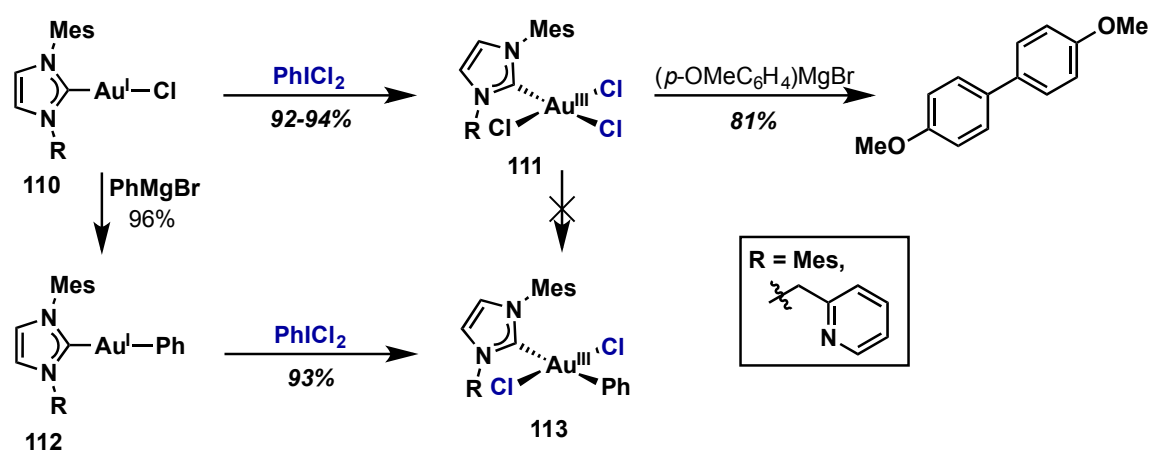

Scheme 50. Clean oxidation of NHC Au(I) complexes with $\mathrm{PhICl}_{2}$ by Nolan and Limbach.

It has also been shown by Nevado that $\mathrm{Au}(\mathrm{III})$ diacetate complexes are less stable than the analogous $\mathrm{Au}$ (III) dichloride complexes (Scheme 51). Upon oxidation with $\mathrm{PhICl}_{2}, \mathrm{Au}$ (III) dichloride complex 115 is isolated in high yields (Scheme 51a), however use of $\mathrm{PhI}(\mathrm{OAc})_{2}$ leads to isolation of $\mathrm{Au}(\mathrm{III})$ bispentafluorophenyl complex 119, via Au(I) mediated transmetalation (Scheme 51b) [115]. Ligand exchange is proposed to occur through two possible pathways, either via oxidation of $\mathrm{Au}(\mathrm{I})$ species 116 to give 117 or of a dissociated [ $\left.\mathrm{Au}\left(\mathrm{PPh}_{3}\right)_{2}\right]^{+}$species to give 118. Both of these complexes would then converge to give 119, where the chloride atom (observed in X-ray crystallography) is proposed to come from solvent activation.

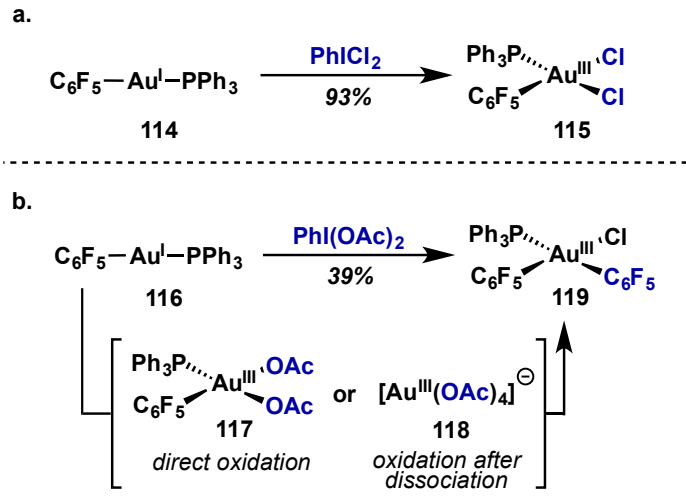

Scheme 51. (a) Oxidation of $\left[\mathrm{Au}(\mathrm{I})\left(\mathrm{C}_{6} \mathrm{~F}_{5}\right) \mathrm{PPh}_{3}\right]$ with $\mathrm{PhICl}_{2}$; (b) Oxidation of $\left[\mathrm{Au}(\mathrm{I})\left(\mathrm{C}_{6} \mathrm{~F}_{5}\right) \mathrm{PPh}_{3}\right]$ with $\mathrm{PhI}(\mathrm{OAc})_{2}$.

Based on these findings, $\mathrm{PhICl}_{2}$ has become the reagent of choice for the generation of isolable $\mathrm{Au}(\mathrm{III})$ complexes, particularly in the context of NHC complexes [112,116,117]. A noteworthy report from Huynh and co-workers utilized $\mathrm{PhICl}_{2}$ as the oxidant in a thorough investigation into the structural and electrochemical properties of a range of mono- and bis-NHC $\mathrm{Au}(\mathrm{I})$ and $\mathrm{Au}(\mathrm{IIII})$ complexes. This report is an excellent source for data on how oxidation state, NHC, and halide ligands effect the properties of NHC-Au species, and the reader is directed there for a detailed discussion of their findings [112].

Dutton and co-workers recently utilized (poly)cationic $\lambda^{3}$-iodanes as neutral ligand-donor oxidants to access tricationic $\mathrm{Au}(\mathrm{III})$ complexes [118]. The same group has used these oxidants for the study of $\mathrm{Pd}(\mathrm{IV})$ and $\mathrm{Pt}(\mathrm{IV})$ complexes (see Section 3.1) and Ritter also employed these reagents as oxidants in a high profile study on $\mathrm{Pd}(\mathrm{IV})$-catalyzed $\mathrm{C}-\mathrm{H}$ fluorination (see Section 2.2.3.1). 
Oxidation of $\mathrm{Au}(\mathrm{I})$ complex $\mathbf{1 2 0}$ with three different (poly)cationic $\lambda^{3}$-iodanes possessing varied pyridine ligands resulted in complexes 121-123 (Scheme 52). This discovery is significant as prior attempts to access similar complexes via salt metathesis on halogenated $\mathrm{Au}(\mathrm{III})$ intermediates led to complex decomposition, emphasizing the power of halide-free external oxidants in $\mathrm{Au}(\mathrm{I}) / \mathrm{Au}(\mathrm{III})$ redox chemistry [117]. Cyclic voltammetry reveals $\mathrm{Au}(\mathrm{III}) / \mathrm{Au}(\mathrm{I})$ reduction potentials ranging from -0.41 to $-0.04 \mathrm{~V}$ vs. [ $\left.\mathrm{Fc} \backslash \mathrm{Fc}^{+}\right]$for 121-123 (reference $0.069 \mathrm{~V}$ vs. [ $\left.\mathrm{Fc} \backslash \mathrm{Fc}^{+}\right]$for $[\mathrm{Au}(\mathrm{III}) / \mathrm{Au}(\mathrm{I})]\left[(\mathrm{dppe})_{2}\right]$ ), showing a trend that mirrors the electron donating ability of the different pyridine ligands $\left((\mathbf{1 2 1}) \mathrm{NMe}_{2}>(\mathbf{1 2 2}) \mathrm{H}>\right.$ $(\mathbf{1 2 3}) \mathrm{CN}$ ) and highlighting the potential to tune the reactivity of tricationic $\mathrm{Au}(\mathrm{III})$ complexes by varying the heterocyclic ligands. Facile ligand exchange from 123 was demonstrated with 2,2,2-tripyridine to give 124, which could undergo subsequent exchange with $\mathrm{H}_{2} \mathrm{O}$ to give $\mathrm{Au}(\mathrm{III})-\mathrm{OH}$ complex 125 . The synthesis of terminal $\mathrm{Au}(\mathrm{III})-\mathrm{OH}$ complexes is rare and previous complexes were accessed via salt metathesis with $\mathrm{AgClO}_{4}$ [119]. Intriguingly, homoleptic $\mathrm{Au}$ (III) complex (121) is stable to aqueous conditions, unlike $\mathrm{Au}(\mathrm{III})$ complexes (122 and 123). This distinction in reactivity also indicates that chemoselective ligand exchange could be possible in these $\mathrm{Au}(\mathrm{III})$ trications.

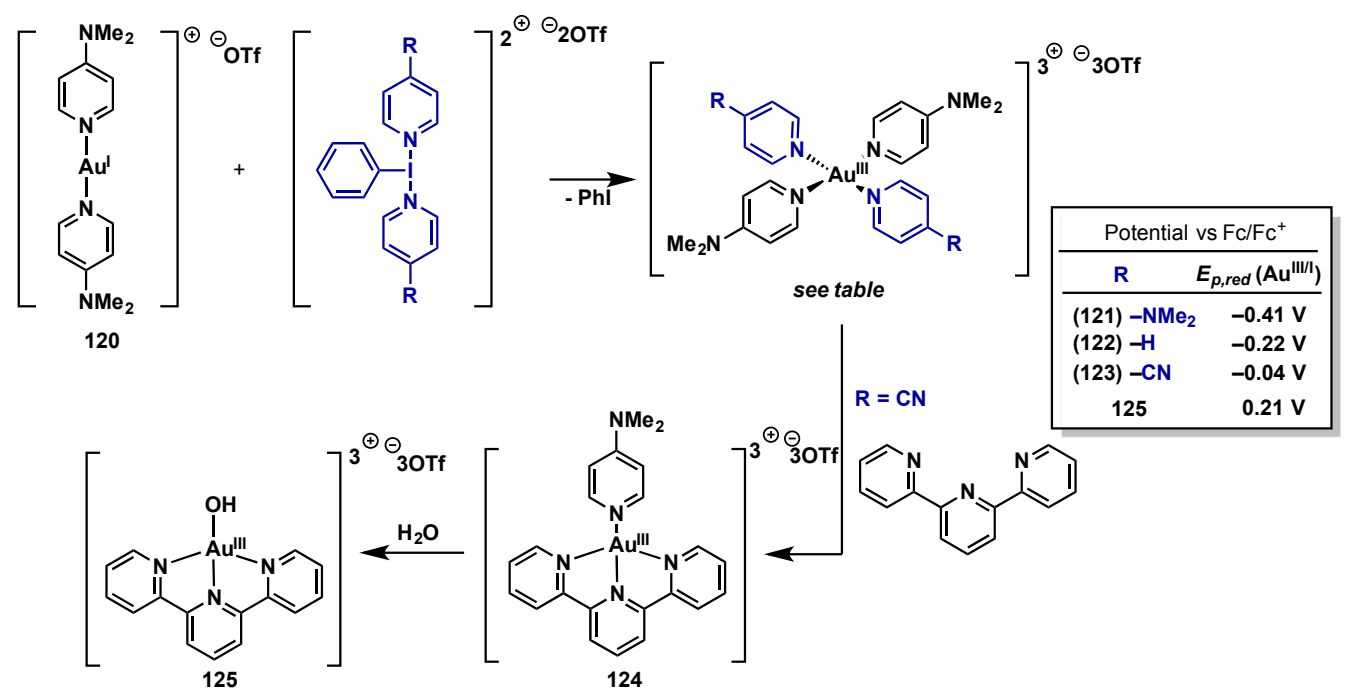

Scheme 52. Dutton's synthesis of tricationic $\mathrm{Au}(\mathrm{III})$ complexes and evaluation of their electrochemical properties.

\subsection{Synthetic Applications}

In 2008, Beller and Tse developed the first gold catalyzed homo-coupling of arenes using $\mathrm{HAuCl}_{4}$ with $\mathrm{PhI}(\mathrm{OAc})_{2}$ as the external oxidant (Scheme 53a) [120,121]. Mechanistic insights hint that $\mathrm{Au}(\mathrm{III})$ is the active $\mathrm{C}-\mathrm{H}$ functionalization catalyst and that a free radical cation is not likely. $\mathrm{PhI}(\mathrm{OAc})_{2}$ showed the highest conversion compared to other oxidants including $\mathrm{PhI}(\mathrm{OTFA})_{2}$, IBX and Oxone and subsequent studies found it was essential that the external oxidant be hypervalent iodine derived [121]. More recently, Larrosa and co-workers demonstrated that electron deficient arene- $\mathrm{Au}(\mathrm{I})$ species are capable of mediating hetero-coupling reactions with unactivated, electron-rich arenes utilizing Koser's reagent, $\mathrm{PhI}(\mathrm{OH}) \mathrm{OTs}$, as the external oxidant (Scheme 53b) [122]. PhI(OPiv) ${ }_{2}$ also gave very high yields in this transformation, however " $\mathrm{F}^{+}$" based oxidants Selectfluor and $\mathrm{XeF}_{2}$, as well as other acetate-ligated hypervalent iodine reagents $\left(\mathrm{PhI}(\mathrm{OAc})_{2}, \mathrm{PhI}(\mathrm{OTFA})_{2}\right)$, were ineffective, again emphasizing the delicate nature of oxidant selection in high-valent metal catalysis. It has also demonstrated that silylated arenes are capable of undergoing arylation with a range of electron-deficient and electron-rich arenes under $\mathrm{Au}(\mathrm{I}) / \mathrm{Au}(\mathrm{III})$ redox conditions, using an in situ formed oxidant from $\mathrm{PhI}(\mathrm{OAc})_{2}$ and camphor sulphonic acid (CSA) (Scheme 53c) [123]. Other carboxylate ligands of the $\mathrm{PhI}\left(\mathrm{O}_{2} \mathrm{CR}\right)_{2}$ type were also effective, however, $\lambda^{3}$-iodane iodosylbenzoic acid and the " $\mathrm{F}^{+"}$ oxidant Selectfluor were completely ineffective, producing none of the desired product. 

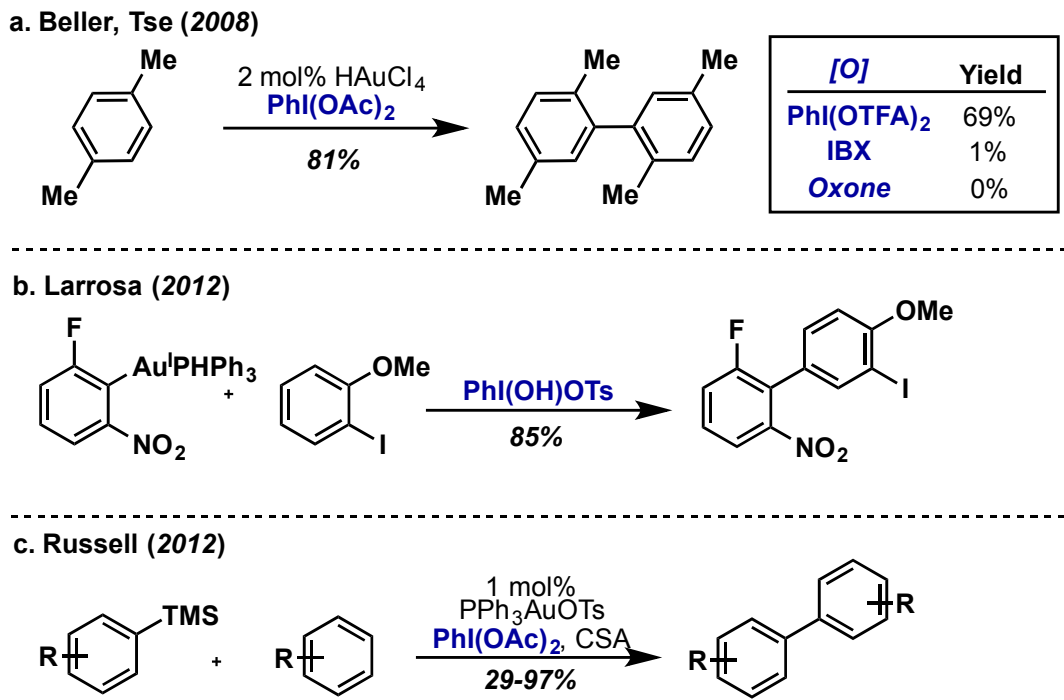

Scheme 53. (a) First example of a gold catalyzed homo-coupling by Tse and Beller; (b) Stoichiometric $\mathrm{Au}(\mathrm{I})$-arene hetero-coupling of unactivated arenes using Koser's reagent; (c) Gold catalyzed arylation of silylated arenes with electron-rich and electron-poor arenes by Lloyd-Jones and Russell.

Nevado recently provided mechanistic insights into the role of various oxidants in $\mathrm{Au}(\mathrm{I}) / \mathrm{Au}(\mathrm{III})$ oxidative couplings (Scheme 54) [124]. Oxidation of $\mathrm{Au}(\mathrm{I})$ complex with $\mathrm{PhI}(\mathrm{OAc})_{2}$ in the presence of $\mathrm{N}$-methylindole cleanly gave the hetero-coupling product (126) in $80 \%$ yield; this transformation was also successful using electron-rich arenes 1,3,5- and 1,2,5-trimethoxybenzene. Interestingly, the same transformation using $\mathrm{PhICl}_{2}$ as the external oxidant was only applicable to $\mathrm{N}$-methylindole as a substrate. Upon oxidation to $\mathrm{Au}(\mathrm{III})$ 127, arene-auration can occur through two modes: (1) electrophilic aromatic substitution to give $\mathbf{1 2 8}$ or (2) concerted C-H activation via 129, both of which converge to give intermediate 130, which undergoes $\mathrm{C}-\mathrm{C}$ bond-forming reductive elimination. The reactivity difference between $\mathrm{PhI}(\mathrm{OAc})_{2}$ and $\mathrm{PhICl}_{2}$ indicate that the basicity of the in-situ generated counterion may play a key role and, analogous to Sanford's work in $\mathrm{Pd}(\mathrm{II}) / \mathrm{PhI}(\mathrm{OAc})_{2} \mathrm{C}-\mathrm{H}$ activation [2], the acetate group may assist in the key activation step (129). This would account for the diminished reactivity seen with $\mathrm{PhICl}_{2}$ in the case of substrates possessing less acidic $\mathrm{C}-\mathrm{H}$ bonds such as 1,3,5- and 1,2,5-trimethoxybenzene, and suggest that $\mathrm{PhI}(\mathrm{OAc})_{2}$ may be superior to $\mathrm{PhICl}_{2}$ for $\mathrm{Au}(\mathrm{III})$-mediated $\mathrm{C}-\mathrm{H}$ activation.

$\mathrm{Au}(\mathrm{III})$-catalyzed arene alkynylations have been reported by both Nevado [125] and Waser [126], employing $\mathrm{PhI}(\mathrm{OAc})_{2}$ and an alkynyl benziodoxolone respectively (Scheme 55). The development of gold-mediated alkynylations of this type has been recently reviewed [127]. Nevado's work used $\mathrm{PhI}(\mathrm{OAc})_{2}$ as an oxidant to couple electron-withdrawn alkynes and unactivated, electron-rich arenes; oxidants including PhIO, Selectfluor, and TBHP gave significantly lower yields. Waser utilized a slightly different approach wherein 1-[(triisopropylsilyl)ethynyl]-1 $\lambda^{3}, 2$-benziodoxol-3(1H)-one (TIPS-EBX) served as both the oxidant and alkyne source, in the direct C3-alkynylation of indoles. Waser later extended this method to the alkynylation of other electron-rich heterocycles including thiophenes, anilines, and furans [128-130]. Although $\mathrm{Au}(\mathrm{I}) / \mathrm{Au}(\mathrm{III})$ redox couples are proposed in these cases via intermediates such as 132, $\mathrm{Au}(\mathrm{I})$ carbophilic pi activation cannot dismissed as subsequent $\alpha$ or $\beta$-elimination could provide the desired products via iodo- $\mathrm{Au}(\mathrm{I})$ intermediate $\mathbf{1 3 1}$. 

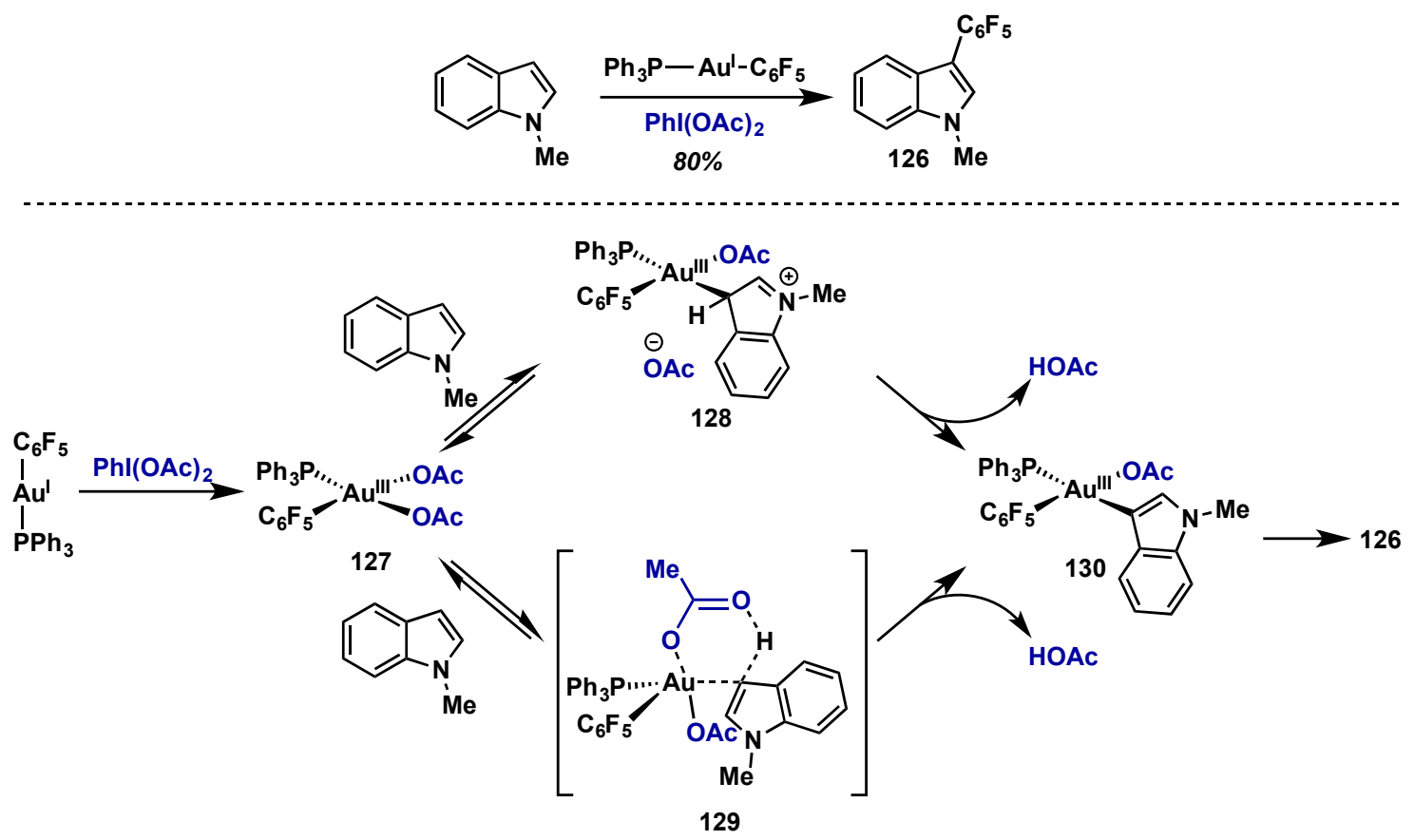

Scheme 54. Proposed mechanism of $\mathrm{Au}(\mathrm{I}) / \mathrm{Au}(\mathrm{III})$ catalyzed hetero-coupling of electron rich arenes.

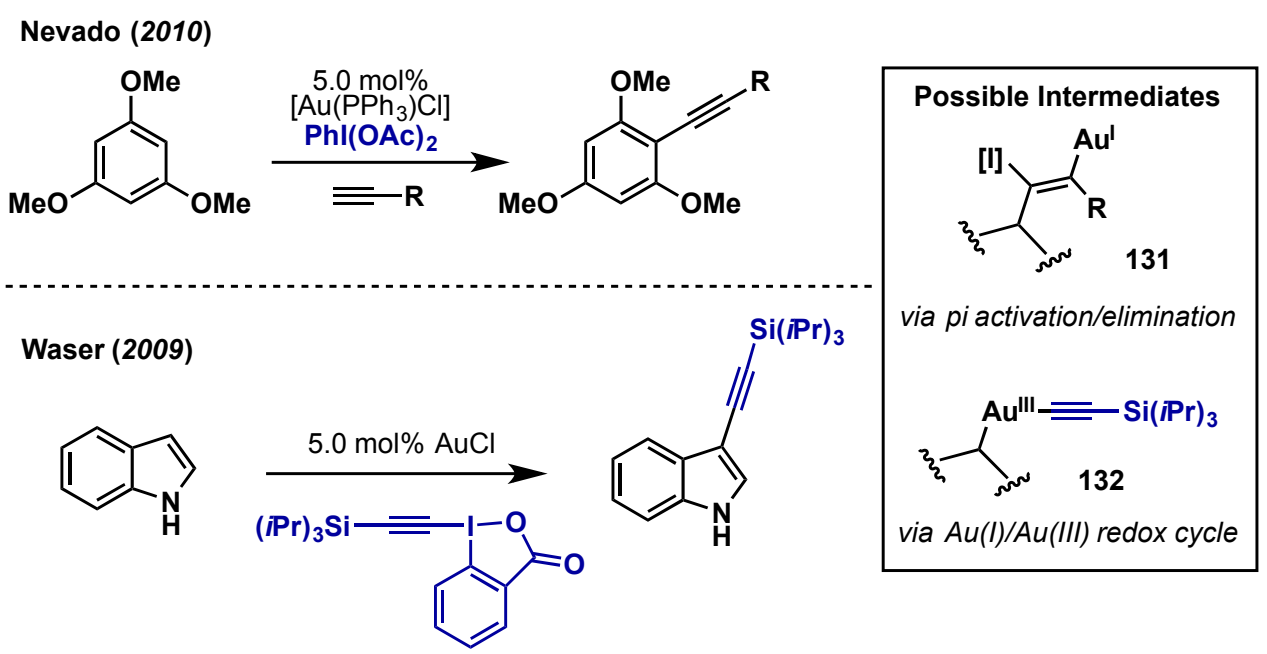

Scheme 55. Oxidative alkynylation reactions by Nevado and Waser. Two potential pathways for alkynylation based upon $\mathrm{Au}(\mathrm{I})$ oxidation or $\mathrm{Au}(\mathrm{I})$ pi activation.

In 2009, Muñiz and Iglesias took advantage of highly reactive Au(III) complexes to develop a gold-catalyzed alkene diamination reaction (Scheme 56), analogous to their previous report employing Pd(II)/Pd(IV) (see Section 2.2.4.1) [131]. Alkenes underwent intramolecular diamination with tosyl-protected ureas 133 under basic conditions using [ $\mathrm{Au}(\mathrm{OAc}) \mathrm{PPh}_{3}$ ] to give bicyclic ureas (136) in high yield. Redox neutral anti-aminoauration gives $\mathrm{Au}(\mathrm{I})$ intermediate 134, followed by irreversible oxidation by $\mathrm{PhI}(\mathrm{OAc})_{2}$ to $\mathrm{Au}(\mathrm{III})$ diacetate 135. Following deprotonation, $\mathrm{S}_{\mathrm{N}} 2$-type intramolecular cyclization provides the desired cyclic urea $\mathbf{1 3 6}$ and regenerates the $\mathrm{Au}(\mathrm{I})$ catalyst. Although the proposed $\mathrm{Au}(\mathrm{III})$ intermediates were too reactive to be isolated, mechanistic studies using a $\mathrm{PPh}_{3}-\mathrm{Au}(\mathrm{I})-\mathrm{Me}$ complex 137 gave an isomeric mixtures of $\mathrm{Au}(\mathrm{III})$ intermediates 138 and 139 upon oxidation with $\mathrm{PhI}(\mathrm{OAc})_{2}$, which were detectable by ${ }^{31} \mathrm{P}-\mathrm{NMR}$. 


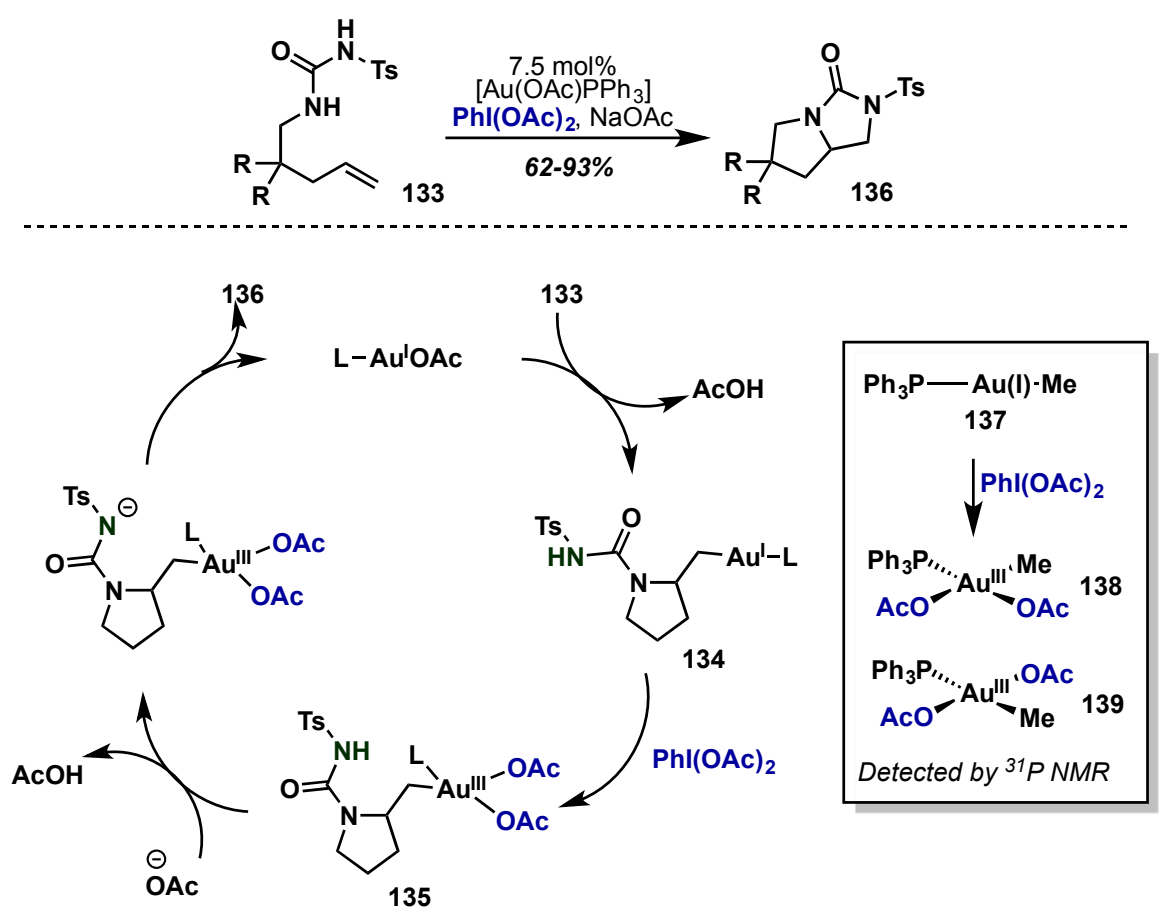

Scheme 56. $\mathrm{Au}(\mathrm{I}) / \mathrm{Au}(\mathrm{III})$ catalytic cycle for intramolecular diamination of olefins.

An interesting example of $\mathrm{C}-\mathrm{C}$ bond cleavage was demonstrated by Shi and co-workers with $\mathrm{Au}(\mathrm{I}) / \mathrm{Au}(\mathrm{III})$ catalysis and methylenecyclopropanes (Scheme 57) [132]. Precomplexation of alkene to $\mathrm{Au}(\mathrm{I})$ leads to a redox neutral allylic rearrangement to give 140 , which is oxidized with $\mathrm{PhI}(\mathrm{OAc})_{2}$ to give $\mathrm{Au}$ (III) diacetate 141. Reductive elimination from 141 would give the desired diacetate 142 with regeneration of a $\left[\mathrm{Au}(\mathrm{I})\left(\mathrm{PMe}_{3}\right) \mathrm{OAc}\right]$ catalyst.
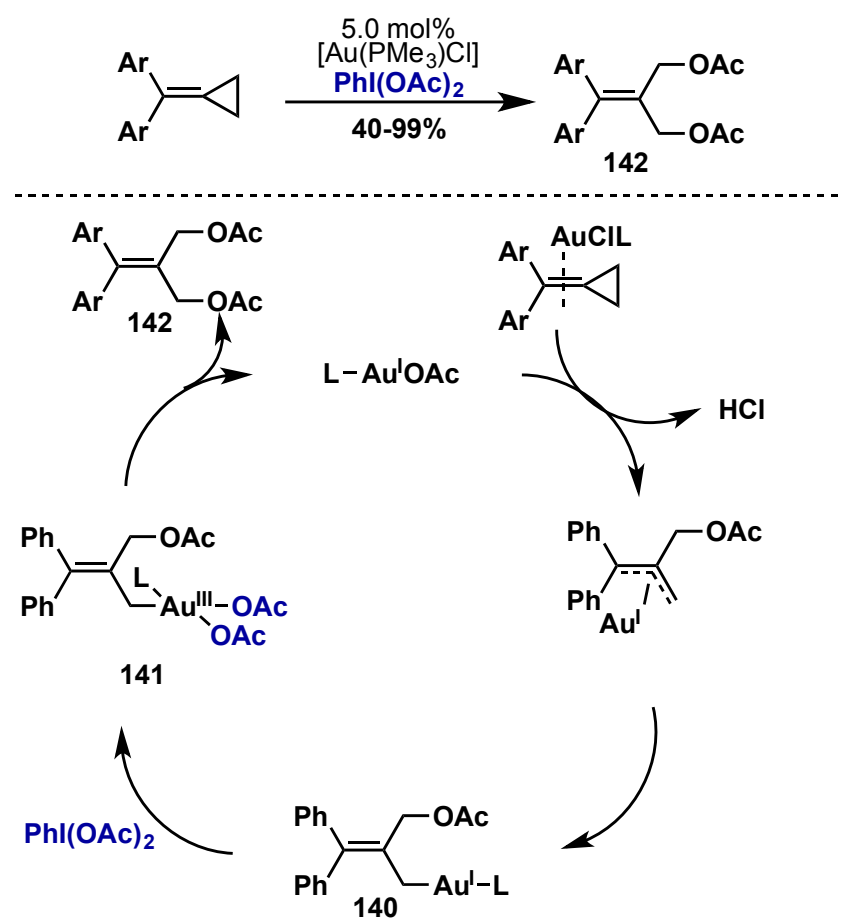

Scheme 57. $\mathrm{Au}(\mathrm{I}) / \mathrm{Au}(\mathrm{III})$ catalyzed diacetoxylation of methylenecyclopropanes via C-C bond cleavage. 


\subsection{Conclusions}

Although advancements have been made toward mechanistic understanding of $\mathrm{Au}(\mathrm{I}) / \mathrm{Au}(\mathrm{III})$-mediated oxidative couplings, it is clear that synthetic applications of gold redox chemistry are still in their infancy. As methods development and mechanistic elucidation in this field continues, the choice of external oxidant play a crucial role as it affects both the stability of the reactive $\mathrm{Au}(\mathrm{III})$ intermediates and their subsequent reactivity in organic transformations. Thus far, $\mathrm{PhICl}_{2}$ has emerged as a leader for the isolation of $\mathrm{Au}(\mathrm{III})$ complexes, due the mild reaction conditions and stabilization imparted by the transfer of chloride ligands. Conversely, $\mathrm{PhI}(\mathrm{OAc})_{2}$ is more efficient in catalytic manifolds as the resultant complexes are more reactive and acetate ligands can assist in key $\mathrm{C}-\mathrm{H}$ activation steps. The work of Dutton in the use of (poly)cationic $\lambda^{3}$-iodanes has laid the groundwork for the exploration of highly tunable $\mathrm{Au}(\mathrm{III})$ complexes and this discovery could lead to new developments in the chemistry of cationic $\mathrm{Au}(\mathrm{III})$ intermediates.

\section{Nickel}

\subsection{Introduction}

Nickel is a group 10 metal, the first-row counterpart of palladium. Low oxidation state nickel redox couples, such as $\mathrm{Ni}(0) / / \mathrm{Ni}(\mathrm{I}) / \mathrm{Ni}(\mathrm{II})$, have seen significant applications in catalysis, including Suzuki, Negishi, and Kumada couplings, as well as recent advancements in radical mediated cross-coupling reactions [133]. A recent resurgence in nickel-catalyzed processes has been fueled not only by its greater sustainability and economic advantages, but also by its unique electronic properties that facilitate reactivity inaccessible to its palladium counterpart. Unlike palladium, which relies almost exclusively on two-electron redox cycles, nickel can undergo facile one- and two-electron redox events, providing access to $\mathrm{Ni}(0), \mathrm{Ni}(\mathrm{I}), \mathrm{Ni}(\mathrm{II}), \mathrm{Ni}(\mathrm{III})$, and in rare examples, $\mathrm{Ni}(\mathrm{IV})$ oxidation states (Scheme 58 ). While these numerous pathways expand the scope of reactivity, they also make characterization and mechanistic investigations difficult due to the wide range of redox couples that could be invoked. Recent advancements in high oxidation state palladium chemistry has sparked a renewed investigation into the synthesis and characterization $\mathrm{Ni}(\mathrm{III})$ and $\mathrm{Ni}(\mathrm{IV})$ species, which could greatly expand the current scope of nickel-catalyzed reactions. In this section, we will highlight the key role that both ligand scaffold and oxidant can serve in the selection between either one- or two-electron pathways as well as the stability of the resultant high valent complexes. Hypervalent iodine oxidants have played a key role in the advancement of this field, analogous to their prominent role in the development of $\mathrm{Pd}(\mathrm{II}) / \mathrm{Pd}(\mathrm{IV})$ catalysis (see Section 2.1). In order to put modern approaches into context, we will begin with a brief history of isolated $\mathrm{Ni}(\mathrm{IV})$ complexes accessed via a variety of methods.

Traditional Modes of Ni catalysis: $\mathrm{Ni}(\mathrm{O}) / \mathrm{Ni}(\mathrm{I}) / \mathrm{Ni}(\mathrm{II})$

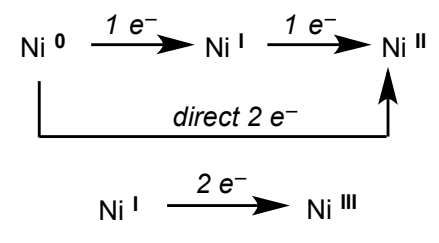

\section{Emerging area of research: $\mathrm{Ni}(\mathrm{II}) / \mathrm{Ni}(\mathrm{III}) / \mathrm{Ni}(\mathrm{IV})$}

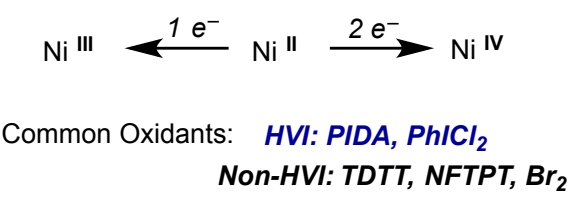

Scheme 58. Traditional and emerging nickel oxidation states invoked in catalysis, and common oxidants reported in the literature.

Reports on the isolation of $\mathrm{Ni}(\mathrm{IV})$ complexes date back to the mid 1970's, and these species were even proposed as intermediates in some of the first $\mathrm{Ni}(0)$ catalyzed cross coupling reactions. The first diorganonickel (IV) complex was synthesized and isolated by Cordier in 1994 through oxidative addition of methyl iodide to a $\mathrm{Ni}(\mathrm{II})$ precursor with acylphenolato and trimethylphosphine ligands (Scheme 59) [134]. In this case, the rigid chelate ring contains a hard base and powerful 
$\sigma$-donating phosphine ligands that provide substantial stability to the high-oxidation nickel complex. In 1999, Tanaka et al reported the first silylnickel(IV) complex (Scheme 59) through a proposed oxidative addition of 1,2-disilylbenzene to a $\mathrm{Ni}(\mathrm{dmpe})_{2}$ and subsequent elimination of $\mathrm{H}_{2}$ [135]. Again, this complex was stabilized by strong $\sigma$-donor ligands and a rigid chelate similar to that of Cordier, and in both reports, X-ray crystallographic analysis confirmed an octahedral geometry. In 2003, Linden reported an isolable Ni(IV) complex containing three sigma bonded norbonyl ligands in a pseudo-tetrahedral geometry (Scheme 59) [136]. This species was accessed via oxidation of a tris(1-norbornyl)nickel(II) complex anion with $\mathrm{O}_{2}$ at $-60{ }^{\circ} \mathrm{C}$. Along with being strong $\sigma$-donor ligands, the steric bulk of the 1-norbonyl ligands provides shielding necessary for stabilization of the trialkylnickel(IV) species. Most recently, the Steigerwald group isolated a tetraalkyl aspirocyclononane $\mathrm{Ni}(\mathrm{IV})$ complex that is remarkably stable to oxygen and high temperatures (Scheme 59) [137]. The complex was isolated as an intermediate in a Ni(0) catalyzed strain release ring-opening polymerization, formed via the combination of two molecules of substrate into a dimeric bismetallocyclopentane nickel species. The remarkable stability of this complex is attributed to the high degree of steric shielding afforded by the large alkyl ligands. From these reports, common features emerge which stabilize high oxidation state nickel complexes: strong $\sigma$-donor ligands, rigid chelation, and steric shielding of the metal center. Additionally, these examples highlight the unusual stability of the nickel-alkyl bond, a feature not common in late transition metal organometallic complexes. Finally, a wide range of oxidants, varied in mechanism and strength, were utilized to access these systems, ranging from $\mathrm{C}-\mathrm{X}$ oxidative addition to $\mathrm{O}_{2}$ oxidation at low temperature. While these studies provide valuable evidence for the viability of $\mathrm{Ni}(\mathrm{IV})$ species and the oxidants capable of accessing them, they are not readily translatable to catalytic manifolds.

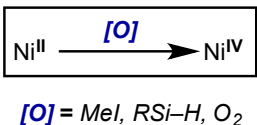

$[\mathrm{O}]=\mathrm{Mel}, \mathrm{RSi}-\mathrm{H}, \mathrm{O}_{2}$

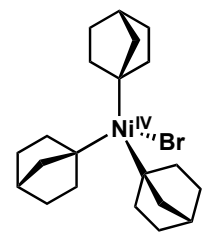

Linden (2003)
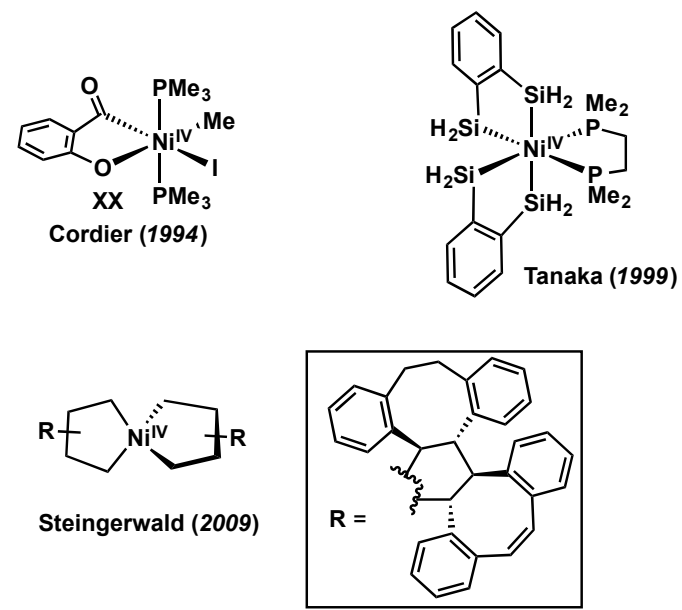

Scheme 59. Examples of isolated organonickel (IV) complexes. Highly rigid ligand scaffolds and strong $\sigma$-donor ligands are common features that aid in stabilization of these species.

Over the last 10 years, a renewed interest in this has focused on the subsequent reactivity and possible synthetic utility of $\mathrm{Ni}(\mathrm{IV})$ species, along with ligand scaffolds and oxidants that could be developed into viable catalytic systems. In this effort, hypervalent iodine reagents have emerged as promising candidates for both species isolation and catalysis.

\subsection{Stoichiometric Studies}

Continued efforts in the stoichiometric synthesis and characterization of $\mathrm{Ni}(\mathrm{IV})$ complexes have expanded to include their subsequent reactivity, particularly in $\mathrm{C}-\mathrm{C}$ and $\mathrm{C}-\mathrm{X}$ bond forming reductive eliminations. The most challenging element of this work has been species isolation and proof of either $\mathrm{Ni}(\mathrm{II}) / \mathrm{Ni}(\mathrm{III})$ or $\mathrm{Ni}(\mathrm{II}) / \mathrm{Ni}(\mathrm{IV})$ redox couples, as these intermediates are highly reactive and short lived. 
The Sanford group has spearheaded these efforts, building on their extensive work in high oxidation state palladium chemistry. They have explored the viability of both $\mathrm{Ni}(\mathrm{III})$ and $\mathrm{Ni}(\mathrm{IV})$ manifolds as inexpensive analogues to $\mathrm{Pd}(\mathrm{IV})$ in C-X reductive eliminations. A 2010 report studied the oxidation of complex 143 with an excess of $\mathrm{PhICl}_{2}$, which yielded an approximately 2:1 mixture of $\mathrm{C}-\mathrm{Cl}$ and $\mathrm{C}-\mathrm{Br}$ reductive elimination products (Scheme 60a) [138]. This represented the first example of $\mathrm{C}-\mathrm{X}$ bond forming reductive elimination from nickel. They propose the likely intermediacy of a $\mathrm{Ni}(\mathrm{III})$ species (144), however note that two-electron oxidation to $\mathrm{Ni}(\mathrm{IV})(\mathbf{1 4 5})$ cannot be ruled out due to an inability to isolate the reactive intermediates. It is also noteworthy that both the chlorine ligands introduced upon oxidation, and the bromine ligand present in complexes 144 and 145, were available for $\mathrm{C}-\mathrm{X}$ reductive elimination.

A subsequent study by Sanford examined the oxidation of a $\mathrm{Ni}(\mathrm{PhPy})_{2}$ complex (146), which can then undergo competitive $\mathrm{C}-\mathrm{X}$ or $\mathrm{C}-\mathrm{C}$ reductive elimination (Scheme 60b) [139]. The analogous palladium complex had previously been shown to undergo preferential $\mathrm{C}-\mathrm{X}$ reductive elimination when exposed to a variety of oxidants, including hypervalent iodine reagents (see Section 2.2.3.1), and thus this study provided an excellent comparison of the reactivity of these two metals. It was shown that upon oxidation with $\mathrm{PhICl}_{2}$, complex 146 gave only trace $\mathrm{C}-\mathrm{Cl}$ bond formation $(3 \%, 147)$ and the major product 148 was that of $\mathrm{C}-\mathrm{C}$ reductive elimination. Interestingly, oxidation of 146 with other $\mathrm{Cl}^{+}$sources, $\mathrm{NCS}$ or $\mathrm{CuCl}_{2}$, provided no observable $\mathrm{C}-\mathrm{Cl}$ products, showing a slight but significant divergence in reactivity of the hypervalent iodine oxidant. Again, in this study, no high oxidation state intermediates could be isolated or observed in situ, although the divergent reactivity from that of palladium may suggest a difference in mechanism.
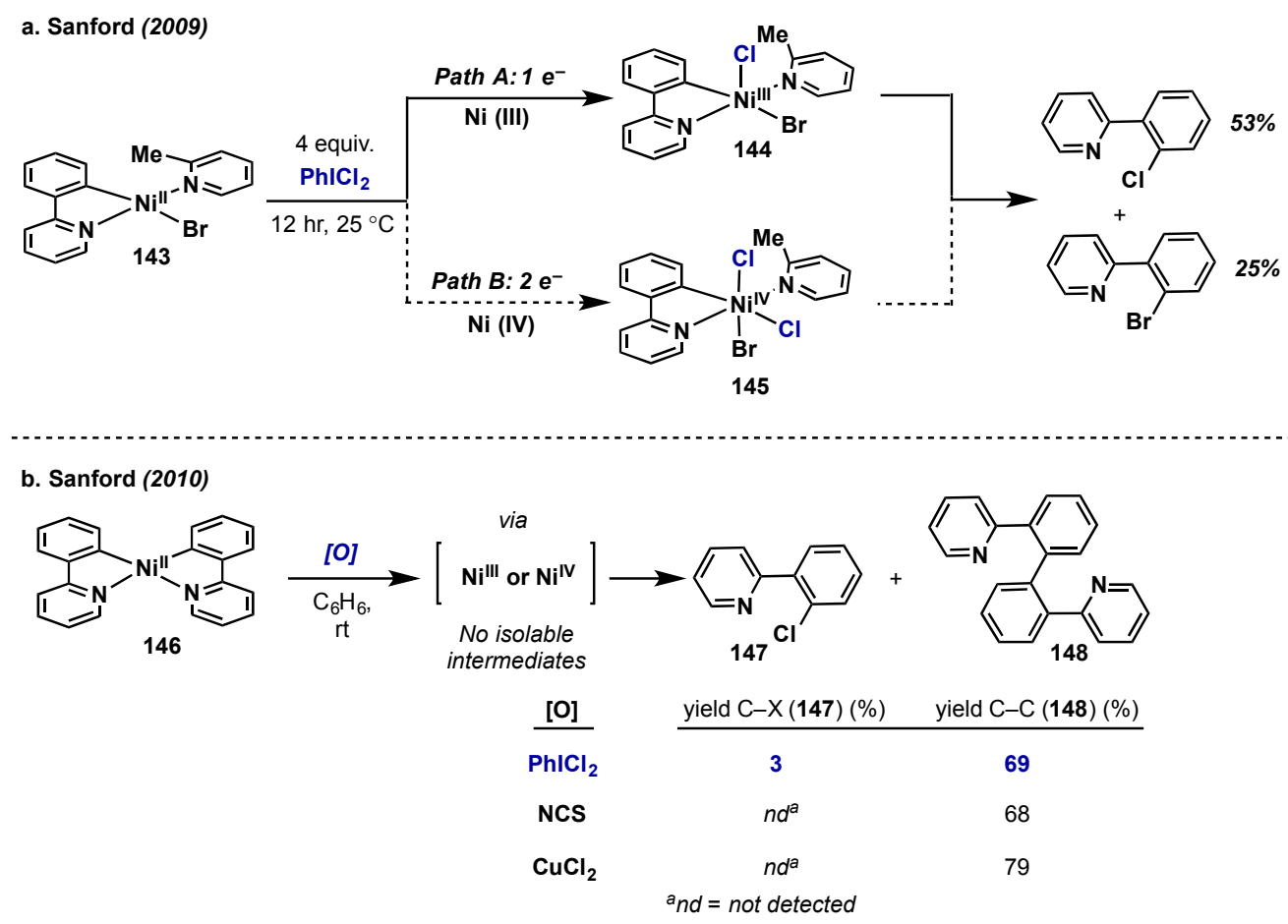

Scheme 60. $\mathrm{C}-\mathrm{X}$ versus $\mathrm{C}-\mathrm{C}$ bond forming reductive elimination from high oxidation state nickel.

(a) Competitive $\mathrm{C}-\mathrm{Br}$ vs. $\mathrm{C}-\mathrm{Cl}$ bond formation; (b) Competitive $\mathrm{C}-\mathrm{Cl}$ vs. $\mathrm{C}-\mathrm{C}$ bond formation.

Recently, in a high-profile report, the same group succeeded in the isolation and characterization of a $\mathrm{Ni}(\mathrm{IV}$ ) intermediate upon oxidation of a diorganonickel(II) complex 149 (Scheme 61) [140]. At the outset of their study, key insights into the stability of $\mathbf{1 4 9}$ to oxidation were obtained via cyclic voltammetry. Observation of two quasi-reversible oxidation peaks at $-0.61 \mathrm{~V}$ and $+0.27 \mathrm{vs}$. $\mathrm{Fc} / \mathrm{Fc}^{+}$, representative of $\mathrm{Ni}(\mathrm{II}) / \mathrm{Ni}(\mathrm{III})$ and $\mathrm{Ni}(\mathrm{III}) / \mathrm{Ni}(\mathrm{IV})$ redox couples, is noteworthy as these potentials 
are relatively low and hints that catalytic cycles with interchange between these redox states could be plausible. Initially, oxidation of 149 with hypervalent iodine reagents $\mathrm{PhI}(\mathrm{OAc})_{2}, \mathrm{PhICl}_{2}$, or $\mathrm{F}^{+}$source NFTPT resulted in rapid $\mathrm{C}\left(\mathrm{sp}^{3}\right)-\mathrm{C}\left(\mathrm{sp}^{2}\right)$ reductive elimination to give cyclobutane 151 , not allowing for study of any intermediates. However, use of TDTT resulted in formation of a stable $\mathrm{Ni}(\mathrm{IV})-\mathrm{CF}_{3}$ intermediate 152 that was detectable by ${ }^{1} \mathrm{H}$ - and ${ }^{19} \mathrm{~F}-\mathrm{NMR}$, before giving rise to the same cyclobutane product 151. Further evidence for the intermediacy of a Ni(IV) species was provided through X-ray crystallographic characterization of a complex possessing a tridentate tris(2-pyridyl) methane ligand, again upon oxidation with TDTT (not shown). Although products of oxidation with hypervalent iodine reagents were not directly observed in this case, the analogous reactivity of complex 150 to that of hypervalent iodine-mediated oxidation provides strong evidence that those reactions are also proceeding via a $\mathrm{Ni}(\mathrm{II}) / \mathrm{Ni}(\mathrm{IV})$ redox couple. This study provides clear evidence for the accessibility of $\mathrm{Ni}(\mathrm{II}) / \mathrm{Ni}(\mathrm{IV})$ catalysis manifolds and supports further efforts for developing reactions that invoke this pathway. It also shows that the development of novel $\mathrm{C}-\mathrm{X}$ bond-forming reactions, analogous to those with $\mathrm{Pd}(\mathrm{II}) / \mathrm{Pd}(\mathrm{IV})$, will likely require ligand scaffolds that are not capable of undergoing competitive $\mathrm{C}-\mathrm{C}$ reductive elimination.

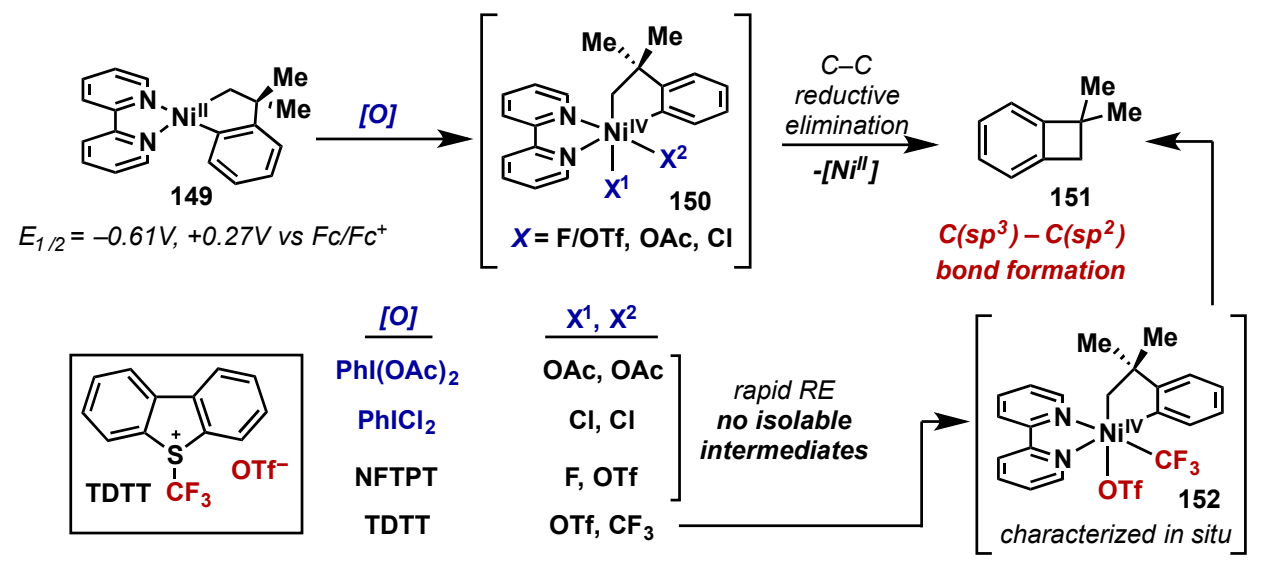

Scheme 61. Oxidation and reductive elimination from a $\mathrm{Ni}(\mathrm{IV})$ intermediate using hypervalent iodine, $\mathrm{F}^{+}$, and $\mathrm{CF}_{3}{ }^{+}$sources. Rapid and selective $\mathrm{C}-\mathrm{C}$ bond formation was observed in the case of all hypervalent iodine oxidants.

Sanford's group has recently utilized tripyrazoylborate (Tp) as a supporting ligand to isolate Ni(IV) complex 153 and examine its competency in $\mathrm{C}\left(\mathrm{sp}^{2}\right)-\mathrm{CF}_{3}$ reductive eliminations (Scheme 62a) [141]. Oxidation was examined with a variety of Ar-X species and it was found that only aryldiazonium salts and diaryliodonium salts were competent oxidants, with diaryliodonium salts giving superior yields of complex 154. This represents the first evidence of the accessibility of the $\mathrm{Ni}(\mathrm{II}) / \mathrm{Ni}(\mathrm{IV})$ manifold under mild conditions with diaryliodonium salts. 154 was further shown to undergo clean $\mathrm{C}_{-} \mathrm{CF}_{3}$ bond formation upon heating and results suggest a two-electron reductive elimination pathway. Sanford also recently reported the oxidation of a TpNi(II)biphenyl complex 155 and its subsequent reactivity in $\mathrm{C}-\mathrm{O}$ bond reductive elimination (Scheme 62b) [142]. Oxidation with PhI(OTFA) $)_{2}$ for just 10 min at $25{ }^{\circ} \mathrm{C}$ cleanly produced 156 in 50\% isolated yield. In line with their previous studies, intramolecular $\mathrm{C}\left(\mathrm{sp}^{2}\right)-\mathrm{O}$ coupling from 156 was slow, however 157 could be detected upon heating, the result of $\mathrm{C}-\mathrm{O}$ bond-forming reductive elimination followed by cyclization and hemiketalization. It was also found that the -OTFA ligand could under rapid displacement with a nucleophilic source of $-\mathrm{CF}_{3}$, which would then undergo slow $\mathrm{C}-\mathrm{CF}_{3}$ reductive elimination (not shown). Taken together, these two reports show the relatively facile access of the $\mathrm{Ni}(\mathrm{II}) / \mathrm{Ni}(\mathrm{IV})$ manifold with hypervalent iodine reagents and lend strong support for the development of diverse catalytic reactions via this pathway. Furthermore, the tripyrazoylborate ligand is emerging as an excellent choice for stabilization and isolation of high oxidation state nickel complexes. 
a. Sanford (2015)
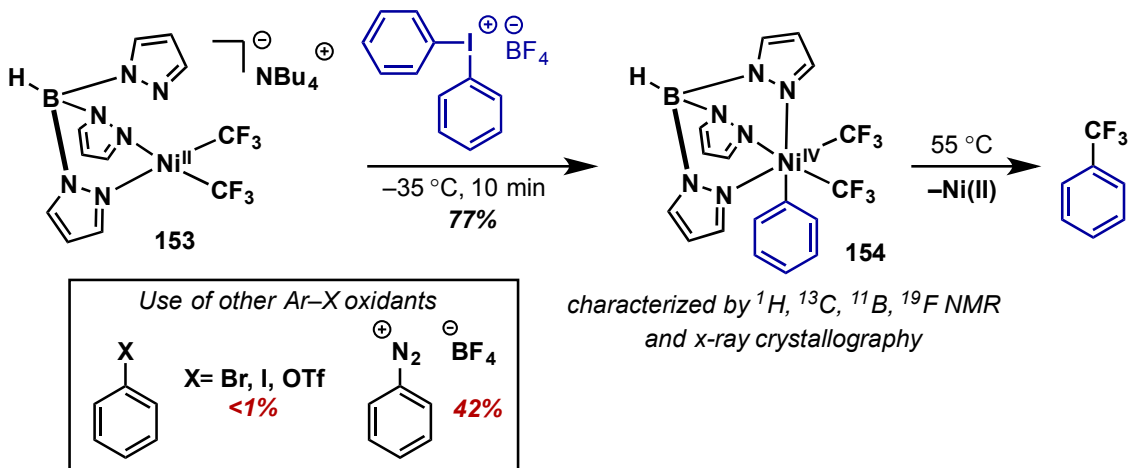

characterized by ${ }^{1} \mathrm{H},{ }^{13} \mathrm{C},{ }^{11} \mathrm{~B},{ }^{19} \mathrm{~F} N \mathrm{NMR}$

and $x$-ray crystallography

b. Sanford (2017)

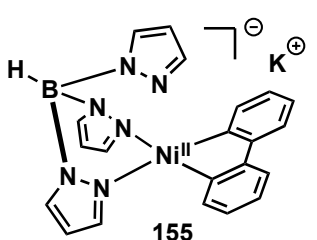

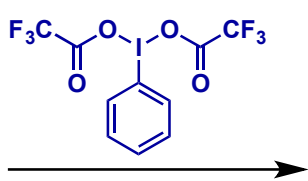

$10 \min , 25^{\circ} \mathrm{C}$

$50 \%$

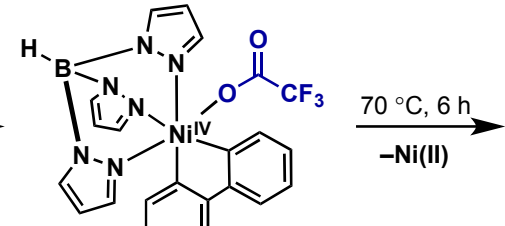

156

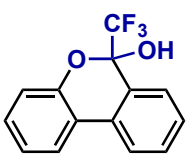

157

Scheme 62. Use of tripyrazoylborate (Tp) ligand in the synthesis and characterization of $\mathrm{Ni}(\mathrm{IV})$ species via oxidation with hypervalent iodine reagents. (a) Use of diaryliodonium salts; (b) Use of PhI $(\mathrm{OTFA})_{2}$.

Taking advantage of the excellent $\sigma$-donor ability of $\mathrm{N}$-heterocyclic carbenes (NHCs), Alison Fout's group reported the isolation of $\mathrm{Ni}(\mathrm{IV})$ complex 159 and its reactivity has an electrophilic halogen surrogate (Scheme 63) [143]. Initial characterization of $\mathrm{Ni}(\mathrm{II})$ species 158 via cyclic voltammetry revealed only a single reversible oxidation wave at $+0.57 \mathrm{~V}$ vs. $\mathrm{Fc}_{\mathrm{c}} / \mathrm{Fc}^{+}$, which was attributed to the $\mathrm{Ni}(\mathrm{II}) / \mathrm{Ni}(\mathrm{III})$ couple. Thus, it was somewhat surprising that treatment of $\mathbf{1 5 8}$ with common outer-sphere one-electron oxidants such as $\mathrm{Ag}^{+}, \mathrm{Ph}_{3} \mathrm{C}^{+}, \mathrm{or} \mathrm{Fc}^{+}$, was unsuccessful. However, treatment of 158 with $\mathrm{PhICl}_{2}$ resulted in clean two-electron oxidation to give 159, which was characterized by $\mathrm{X}$-ray crystallography. This result was the first definitive evidence that hypervalent iodine reagents were competent oxidants in the $\mathrm{Ni}(\mathrm{II}) / \mathrm{Ni}(\mathrm{IV})$ redox couple. Also notable is the significantly higher oxidation potential of $\mathbf{1 5 8}$ relative to that of $\mathbf{1 4 9}$ (see Scheme 61) and yet $\mathrm{PhICl}_{2}$ was still a competent oxidant. In the continued development of this field, it will likely be important to continue to obtain electrochemical measurements of both hypervalent iodine reagents and metal complexes, which could then be used as a predictive tool for the success of the subsequent oxidation.
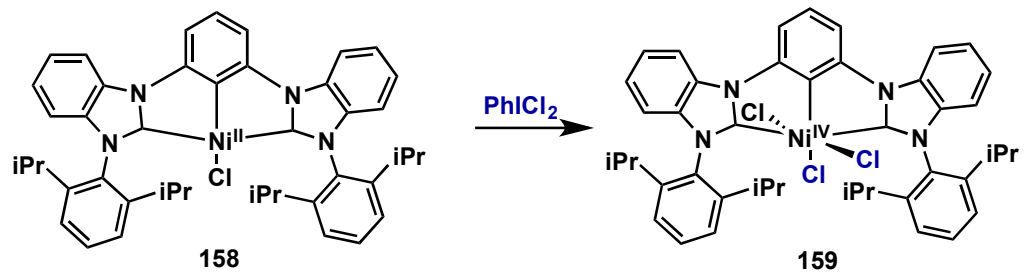

$\mathrm{Ni}(\mathrm{II}) / \mathrm{Ni}(\mathrm{III})-\rightarrow \mathrm{E}_{1} / 2=+0.57 \mathrm{~V}$ vs $\mathrm{Fc}_{2} / \mathrm{Fc}^{+}$

Scheme 63. Two electron oxidation of $\mathrm{Ni}(\mathrm{II})$ monoanionic bis(carbene) pincer complex with $\mathrm{PhICl}_{2}$ and characterization of stable $\mathrm{Ni}(\mathrm{IV})$ intermediate 159.

\subsection{Synthetic Applications}

Catalytic cycles, and thus also synthetic applications, invoking high oxidation state nickel intermediates remain quite rare. However, building on the body of work in stoichiometric complex 
synthesis, such reports are beginning to emerge, but the oxidation states in play are difficult to discern. Below we outline recent catalytic reports invoking both $\mathrm{Ni}(\mathrm{III})$ and $\mathrm{Ni}(\mathrm{IV})$ intermediates via oxidation with hypervalent iodine reagents as well as synthetically relevant applications involving stoichiometric complexes.

The Nocera group reported the catalytic photoelimination of $\mathrm{Cl}_{2}$ from a $\mathrm{Ni}(\mathrm{III})$ intermediate, accessed via one-electron oxidation of a $\mathrm{Ni}(\mathrm{II})$ species with $\mathrm{PhICl}_{2}$ (Scheme 64) [144]. In this case, careful control of the equivalents of $\mathrm{PhICl}_{2}$ allows for selective transfer of a single chlorine atom. It is also possible that the ligand scaffold does not lower the oxidation potential far enough to make a subsequent $\mathrm{Ni}(\mathrm{III}) / \mathrm{Ni}(\mathrm{IV})$ oxidation accessible in this case, however electrochemical measurements on this complex were not provided.

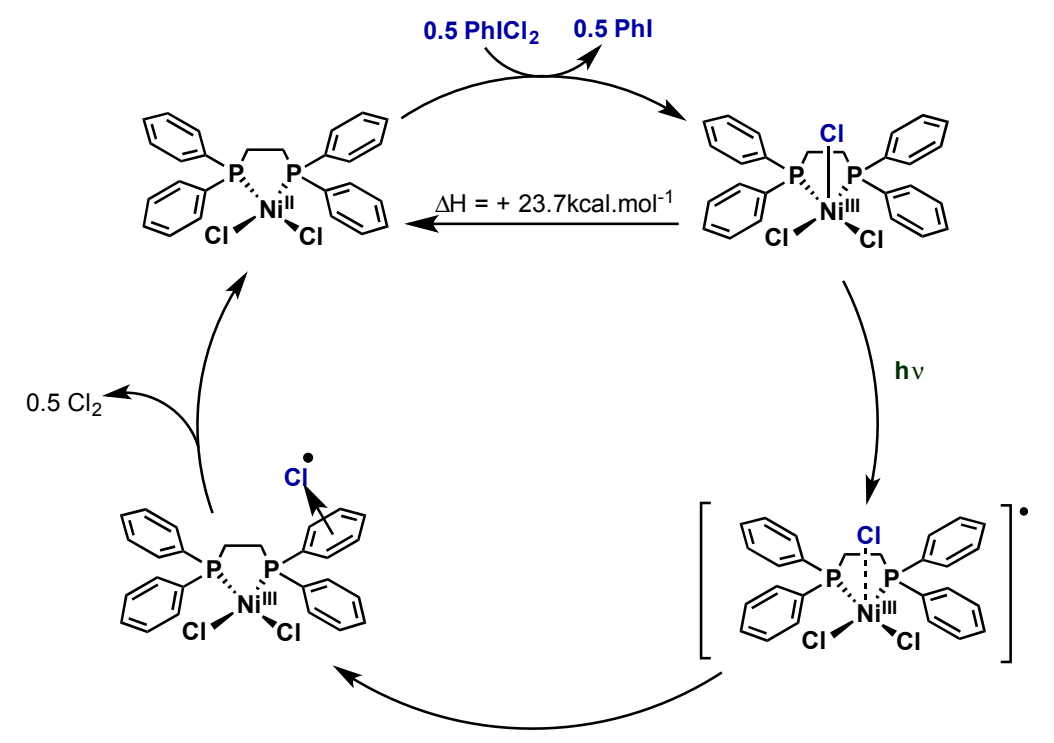

Scheme 64. Photoelimination of $\mathrm{Cl}_{2}$ via single electron $\mathrm{Ni}(\mathrm{II}) / \mathrm{Ni}(\mathrm{III})$ cycle mediated by $\mathrm{PhICl}_{2}$.

Chatani's group invoked a $\mathrm{Ni}(\mathrm{II}) / \mathrm{Ni}(\mathrm{IV})$ catalytic cycle in their development of a directed $\mathrm{C}\left(\mathrm{sp}^{3}\right)-\mathrm{H}$ arylation with diaryliodonium salts (Scheme 65) [145]. A variety of diaryliodonium salts bearing different counter ions such were examined, however high yields were only obtained in the case of triflate, presumably due to the necessary regeneration of the $\mathrm{Ni}(\mathrm{OTf})_{2}$ catalyst. Although no intermediates were isolated, radical trap experiments with TEMPO gave no TEMPO-adducts, providing at least preliminary evidence against one-electron pathways.
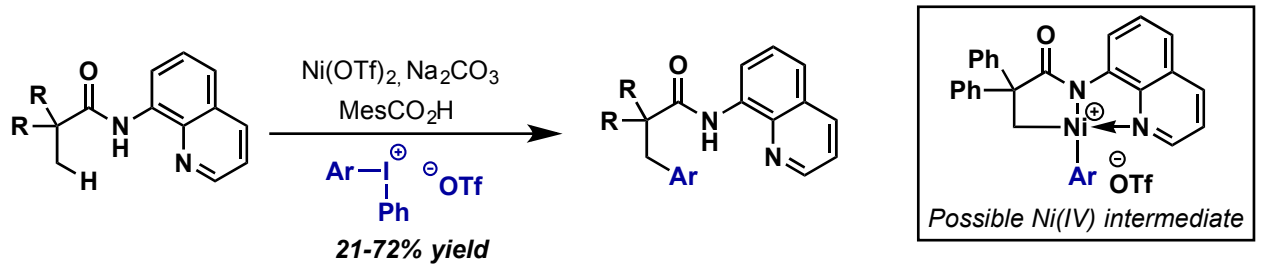

Scheme 65. $\mathrm{C}\left(\mathrm{sp}^{3}\right)-\mathrm{H}$ arylation with diaryliodonium salts through a proposed $\mathrm{Ni}(\mathrm{II}) / \mathrm{Ni}(\mathrm{IV})$ catalytic cycle.

Continuing their work in oxidative fluorination chemistry (for palladium analogue see Section 2.2.3.1), the Ritter group reported the development of a one-step oxidative radiofluorination of arenes employing $\mathrm{Ni}$ (II) complex $\mathbf{1 6 0}$ with aqueous ${ }^{18} \mathrm{~F}$, and poly(cationic) $N$-ligated $\lambda^{3}$-iodane 161 as the oxidant (Scheme 66) [146]. This one-step oxidation/C-F bond formation proceeds via the two-electron oxidation of 160 by cationic hypervalent iodine 161, which undergoes ligand exchange 
with nucleophilic fluoride and subsequent reductive elimination. The use of (poly)cationic $\lambda^{3}$-iodane 161 is critical in this case as the desired ${ }^{18} \mathrm{~F}$ reductive elimination could easily be outcompeted by the $-\mathrm{X}$ ligands transferred to the metal center with traditional hypervalent iodine complexes (i.e., $-\mathrm{Cl}$, -OAc, -OTFA) [40]. Instead complex 161 transfers two "innocent" heterocyclic ligands, allowing for the challenging C-F reductive elimination to proceed in high yield. Even though the detailed mechanistic studies were not reported, the formation of $\mathrm{Ni}(\mathrm{IV})$ intermediate $\mathbf{1 6 2}$ is reasonable by analogy to their prior reports, as well as work by Dutton employing (poly)cationic $\lambda^{3}$-iodanes as two-electron oxidants in the generation of $\mathrm{Pd}(\mathrm{IV})$ and $\mathrm{Pt}(\mathrm{IV})$ species (see Section 3.1). This work shows the promise of the relatively unexplored class of (poly)cationic $\lambda^{3}$-iodanes as powerful oxidants that allow for challenging reductive eliminations that would be precluded with the use of more common oxidants.

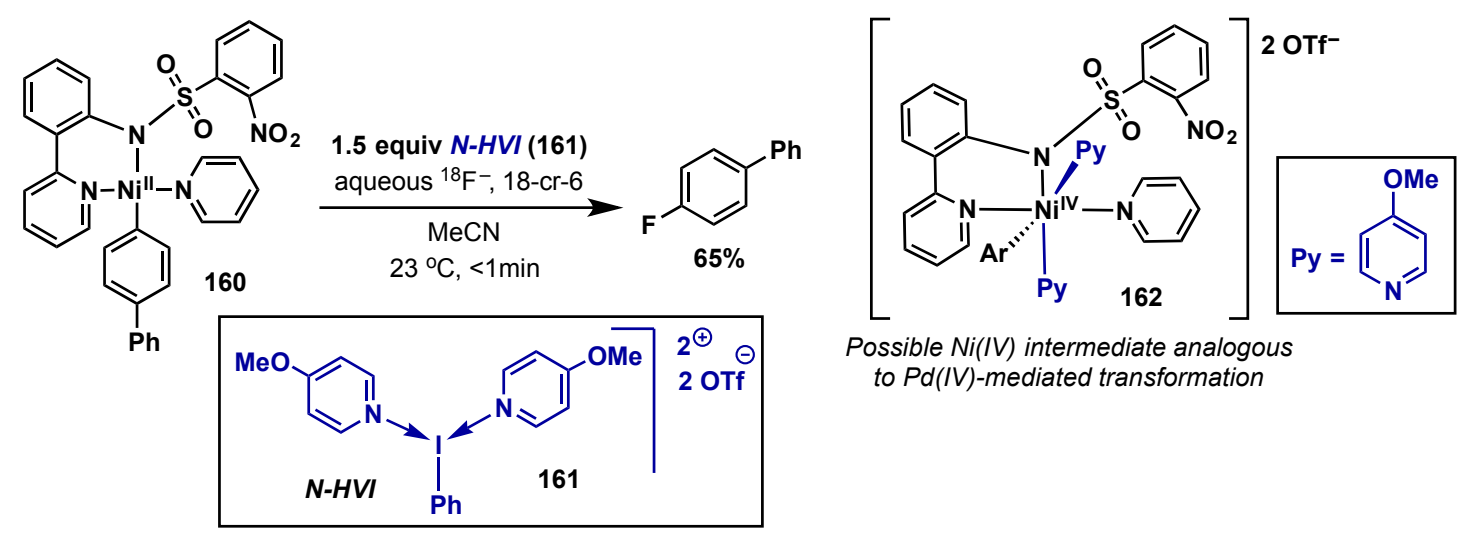

Scheme 66. Ritter's nickel-mediated radiofluorination via oxidation of Ni(II) with (poly)cationic $\lambda^{3}$-iodane 161, possessing neutral heterocycle ligands.

\subsection{Conclusions}

High valent nickel catalysis, specifically via the $\mathrm{Ni}(\mathrm{II}) / \mathrm{Ni}(\mathrm{IV})$ redox couple is an emerging area of research that has the potential to offer novel and powerful reactivity. The continued growth and maturation of this area will rely on continued efforts to understand the role that ligand scaffold and oxidant can play in the oxidation states accessible, as well as studies aimed at the isolation and characterization of these high oxidation state complexes. Furthermore, a more detailed mechanistic understanding of reported synthetic methods will educate further reaction development.

\section{Copper}

\subsection{Introduction}

As recently as the year 2000, reports of isolable high-valent organometallic $\mathrm{Cu}$ (III) species were extremely rare (Scheme 67a) [147-149] and little was known about the potential role of $\mathrm{Cu}$ (I)/Cu(III) cycles in catalysis. However, significant progress has been made in this area over the last 15 years and modern analytical techniques such as rapid-injection NMR (RI-NMR) have provided clear evidence of $\mathrm{Cu}$ (III) intermediates in carbon-carbon, carbon-halogen, and carbon-nitrogen bond forming reactions (Scheme 67b) [1]. Applications of hypervalent iodine reagents in this area are scarce however one could imagine that this will be a fruitful area of research in the coming years. In this section recent examples of proposed $\mathrm{Cu}(\mathrm{I}) / \mathrm{Cu}(\mathrm{III})$ redox cycles involving hypervalent iodine reagents will be presented, though the underlying mechanisms of these transformations are still the subject of debate in the literature. 
a.

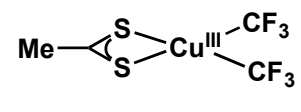

Burton (1989)
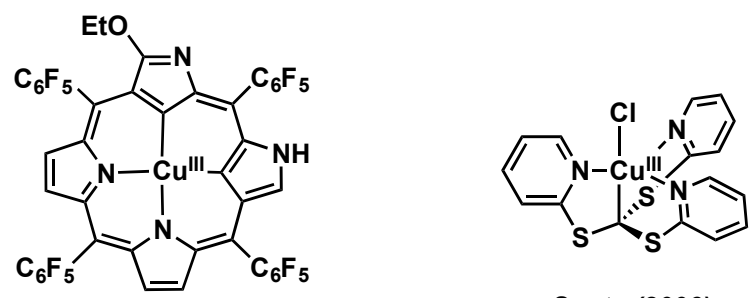

Santo (2006)

Osuka (2000)

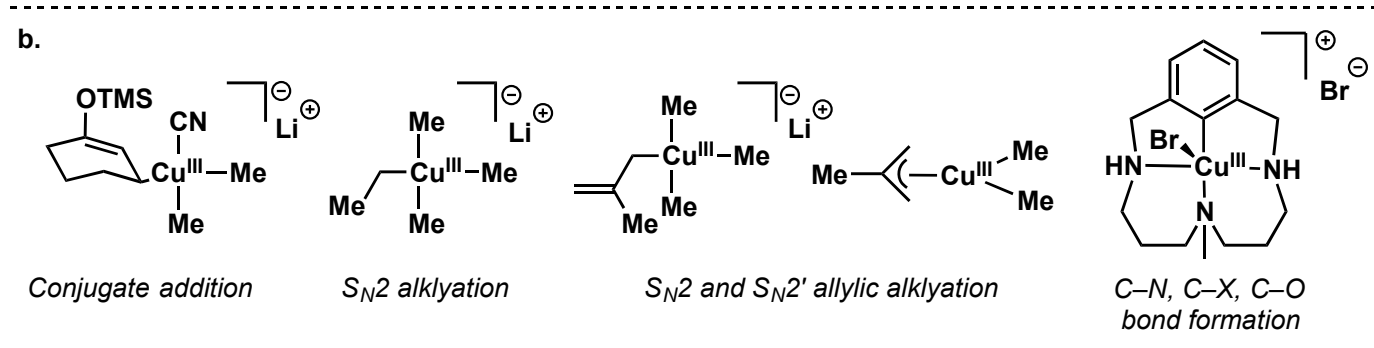

Scheme 67. (a) Examples of isolable $\mathrm{Cu}$ (III) complexes; (b) Observed $\mathrm{Cu}(\mathrm{III})$ species by rapid-injection (RI) NMR spectroscopy.

\subsection{Synthetic Applications}

Gaunt and co-workers have reported landmark examples of $\mathrm{Cu}(\mathrm{I}) / \mathrm{Cu}(\mathrm{III})$ catalysis through $\mathrm{C}-\mathrm{H}$ arylation of indoles and benzene derivatives with diaryliodonium salts (Scheme 68) [150,151]. Remarkably, these arylations proceeded with extremely high C3- and meta-selectivity respectively, complimentary to the analogous $\mathrm{Pd}(\mathrm{II})$-catalyzed transformations which give exclusively products arising from directed $\mathrm{C}-\mathrm{H}$ activation. Shown in the context of arene functionalization (Scheme 69), the authors propose a catalytic cycle involving $\mathrm{Ph}_{2} \mathrm{IBF}_{4}$-mediated oxidation of $\mathrm{Cu}(\mathrm{I})$ to a highly electrophilic $\mathrm{Cu}(\mathrm{III})$ complex 163, accompanied by aryl transfer. This species then undergoes meta-selective Friedel-Crafts-type metalation, facilitated by the pendant amide, followed by rearomatization to give $\mathrm{Cu}(\mathrm{III})$ complex 164 . $\mathrm{C}-\mathrm{C}$ bond forming reductive elimination would provide the desired arylated product and regenerate $\mathrm{Cu}(\mathrm{I}) \mathrm{OTf}$. While this mechanism explains the observed selectivity, the intermediacy of $\mathrm{Cu}(\mathrm{III})$ in these processes has not been confirmed experimentally. The authors note that the addition of a radical inhibitor, 1,1-diphenylethylene, does not inhibit product formation, suggesting a radical mechanism is unlikely. In contrast, Buchwald has shown that $\mathrm{Cu}(\mathrm{I})$-catalyzed processes involving Togni's reagent proceed via one-electron radical cascades [152].

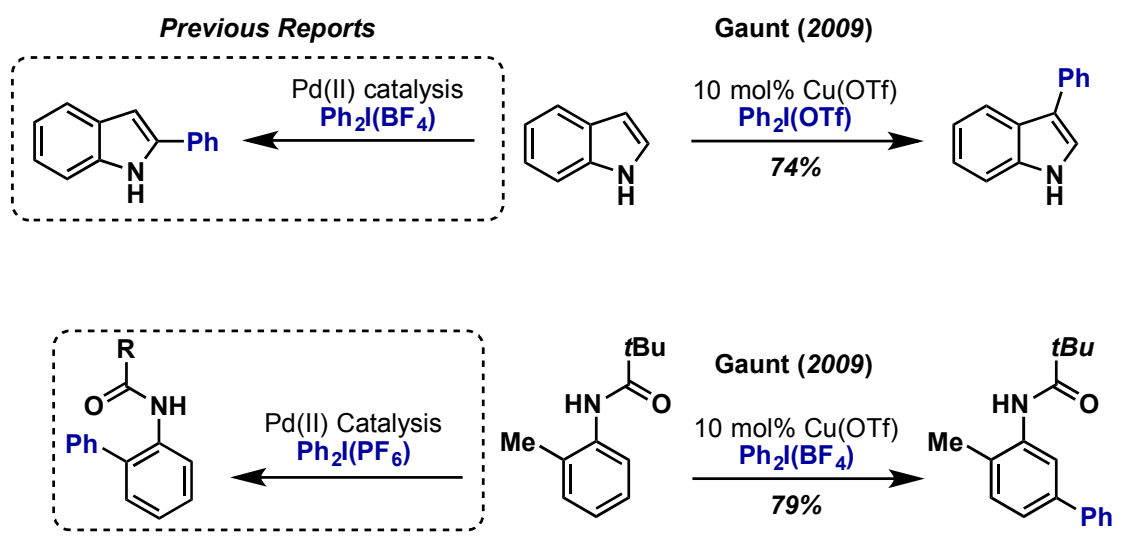

Scheme 68. Copper-catalyzed oxidative arylation reactions with diaryliodonium salts show complimentary regioselectivity to analogous palladium-catalyzed systems. 


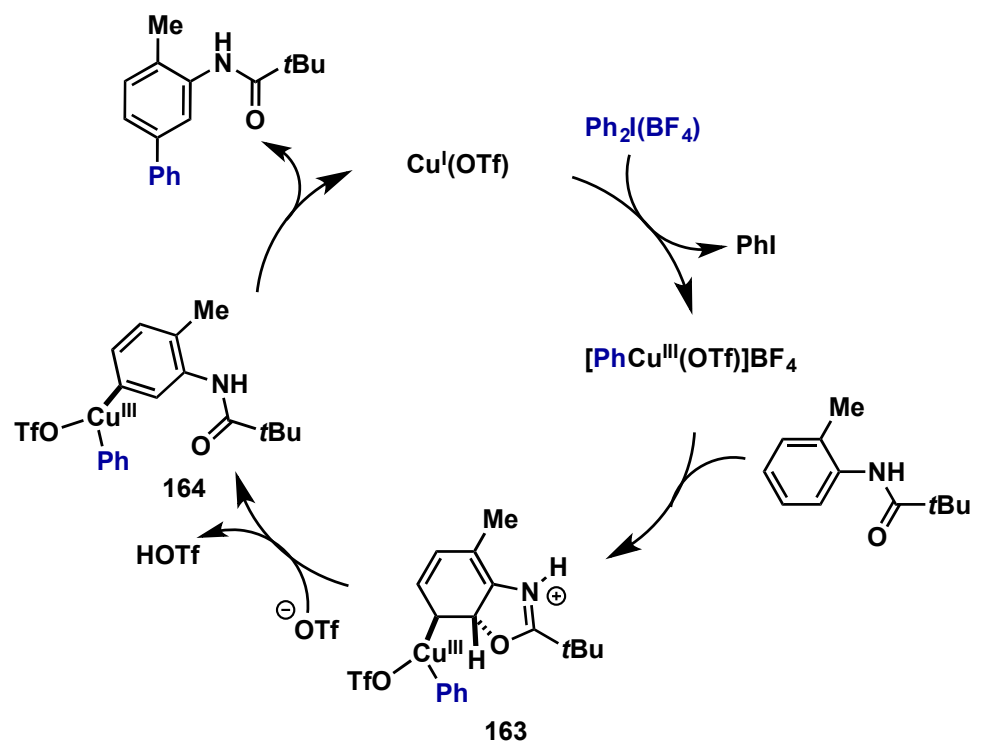

Scheme 69. Proposed $\mathrm{Cu}(\mathrm{I}) / \mathrm{Cu}(\mathrm{III})$ catalytic cycle for $\mathrm{C}-\mathrm{H}$ functionalization of benzene derivatives.

\subsection{Conclusions}

The past 15 years have provided critical experimental evidence for the intermediacy of $\mathrm{Cu}(\mathrm{III})$ in a variety of catalytic transformations. Hypervalent iodine reagents have been applied in seminal reports by Gaunt using diaryliodonium salts in $\mathrm{C}-\mathrm{H}$ arylation, however experimental evidence supporting a $\mathrm{Cu}(\mathrm{I}) / \mathrm{Cu}(\mathrm{III})$ pathway is still lacking. Therefore, while the potential of hypervalent iodine reagents in high-valent copper catalysis is immense, the continued development of this area will require a more detailed mechanistic understanding of the pathways involved.

\section{Miscellaneous High Valent Metal Complexes}

In addition to the applications discussed thus far, hypervalent iodine reagents have been utilized as oxidants for a wide range of metals less prevalent in traditional catalysis. These include oxidations of Mo, W, V, Ce, Ir, Fe and Rh, with a large focus on high valent complex isolation but a few recent examples also include catalytic reaction development. In this area, $\mathrm{PhICl}_{2}$ and $\mathrm{PhI}(\mathrm{OAc})_{2}$ have been the most widely applied due to their well-studied reactivity and their inherent transfer of chloride and acetate ligands capable of stabilizing high oxidation state species.

\subsection{Complex Synthesis and Isolation}

Scheme 70 summarizes the diverse metal complexes that have been accessed via hypervalent iodine oxidants. These complexes vary in their oxidation states, geometries, ligand scaffolds, and were accessed through both one- and two-electron oxidation pathways. Filippou utilized $\mathrm{PhICl}_{2}$ in an oxidative decarbonylation approach to accessing $\mathrm{Mo}(\mathrm{IV})$ and $\mathrm{W}(\mathrm{IV})$ complexes en route to studying trichlorogermyl compounds [153]. Legzdins synthesized a V(II) nitrosyl complex using $\mathrm{PhICl}_{2}$ in order to study the nitrosyl ligand effects on early transition metals [154]. In an effort to improve the syntheses of Ce(IV) amides, Andwander and Edelmann synthesized a Ce(IV) complex with use of $\mathrm{PhICl}_{2}$ as a one-electron oxidant [155]. Neve used $\mathrm{PhICl}_{2}$ to study the structure and properties of an Ir(III) dimer [156]. A report from Nocera synthesized $\mathrm{Rh}$ (III) complexes with $\mathrm{PhICl}_{2}$ as part of a study to understand the role of $\mathrm{Rh}(\mathrm{III})$ hydride complexes in the reduction of oxygen to $\mathrm{H}_{2} \mathrm{O}$ in reactions with $\mathrm{HCl}$ [157]. Periana demonstrated functionalization of an $\operatorname{Ir}(\mathrm{V})$ complex with both $\mathrm{PhI}(\mathrm{OAc})_{2}$ and $\mathrm{PhI}(\mathrm{OTFA})_{2}$ in order study oxy-functionalization reactions from high oxidation state iridium [158]. Although not shown in Scheme 70, $\mathrm{PhI}(\mathrm{OAc})_{2}$ and $\mathrm{PhICl}_{2}$ also have rich histories as co-oxidants in the study of metalloporphyrins [159-161]. 


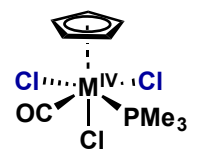

[M = Mo or $\mathbf{W}]$

Filippou (1999)

$\mathrm{PhICl}_{2}$

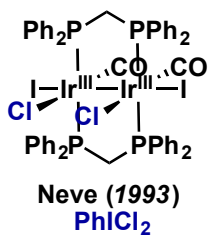

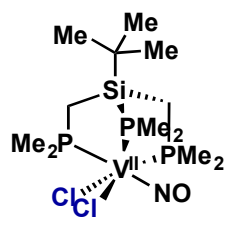

Legzdins (2002)

$\mathrm{PhICl}_{2}$

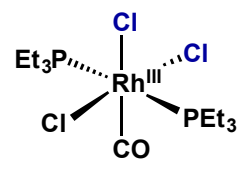

Nocera (2012)

$\mathrm{PhICl}_{2}$

íot shown:

of $\mathrm{Mn}, \mathrm{Cr}$, Fe, Ru porphyrins

by $\mathrm{PhI}(\mathrm{OAc})_{2}$ and $\mathrm{PhICl}_{2}$<smiles>CN(C)C(Cl)(N=O)N(C)N</smiles>

Andwander/Edelmann (2010) $\mathrm{PhICl}_{2}$

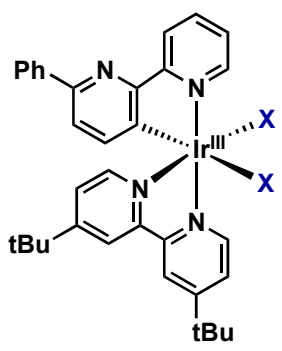

Periana (2007) $\mathrm{Phl}(\mathrm{OAc})_{2}$ or Phl(OTFA)

Scheme 70. Examples of high oxidation state transition metal complexes accessed by oxidation with $\mathrm{PhI}(\mathrm{OAc})_{2}$ and $\mathrm{PhICl}_{2}$.

\subsection{Catalytic Applications}

Although one-electron manifolds are not prototypical of hypervalent iodine reagents, diaryliodonium salts have been reported to serve as one-electron oxidants in both iron and iridium catalyzed transformations. Photoredox catalysis using $\operatorname{Ir}(\mathrm{III})(\mathrm{phpy})_{3}$, with $\mathrm{Ph}_{2} \mathrm{I}\left(\mathrm{BF}_{4}\right)$ as both the external oxidant and phenyl source, was successfully applied to the methoxyphenylation of styrene derivatives (Scheme 71) [162]. It is proposed that $\mathrm{Ph}_{2} \mathrm{I}\left(\mathrm{BF}_{4}\right)$ transfers a phenyl radical to styrene with in situ oxidation of $\operatorname{Ir}(\mathrm{III})(\mathrm{phpy})_{3}{ }^{+}$to $\operatorname{Ir}(\mathrm{IV})(\mathrm{phpy})_{3}{ }^{+}$. Further oxidation to a benzylic cation followed by trapping with methanol gives the difunctionalized product.
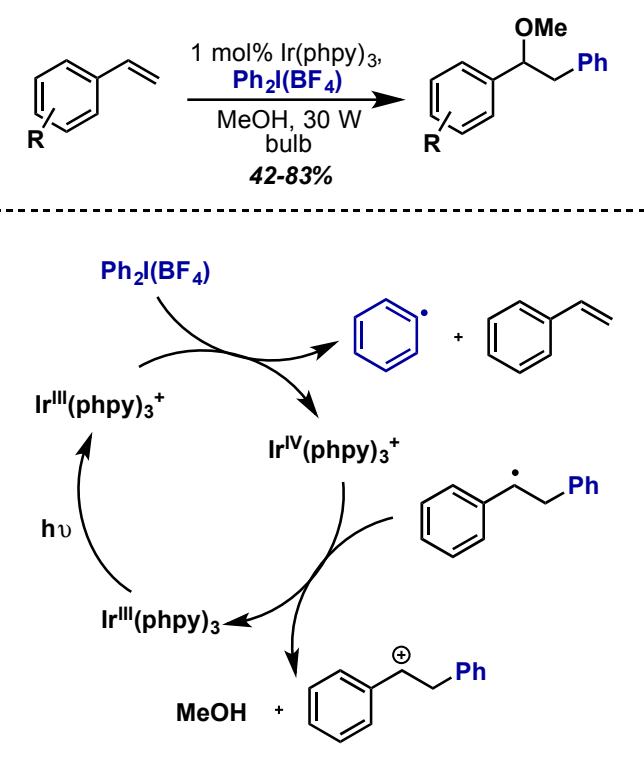

Scheme 71. $\operatorname{Ir}(\mathrm{III})(\mathrm{phpy})_{3}$ catalyzed photoredox oxyarylation of styrene derivatives.

Loh has shown that $\mathrm{Ph}_{2} \mathrm{I}(\mathrm{OTf})$ can act as a one-oxidant in an $\mathrm{Fe}(\mathrm{II}) / \mathrm{Fe}(\mathrm{III})$ catalyzed intramolecular radical cyclization cascade (Scheme 72) [163]. It is proposed that $\mathrm{Ph}_{2} \mathrm{I}(\mathrm{OTf})$ produces a phenyl radical upon oxidation of $\mathrm{Fe}(\mathrm{II})$ to $\mathrm{Fe}(\mathrm{III})$ with subsequent hydrogen abstraction from dichloromethane. 
Although these one-electron pathways remain rare, these reports show promise for the further development of hypervalent iodine reagents in these manifolds.

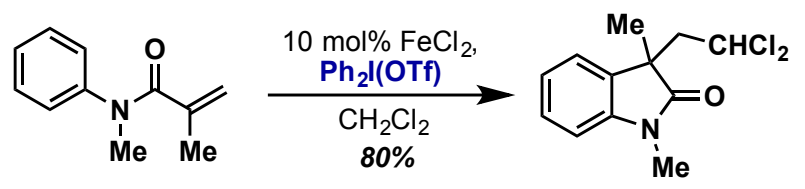

Scheme 72. $\mathrm{FeCl}_{2}$ catalyzed carbochloromethylation of activated alkenes.

\subsection{Conclusions}

The versatility of hypervalent iodine reagents is evident in the wide range of metal centers that they are capable of oxidizing. Their application in the isolation and characterization of late transition metal complexes provides critical insights into the further development and application of these species. Furthermore, their ability to facilitate one-electron pathways has enabled their extension into metal catalyzed photoredox and radical cascade reactions.

\section{Conclusions}

High valent metal catalysis is still an emerging field that continues to be rich with opportunities for novel and creative reaction development. Hypervalent iodine reagents have emerged as versatile oxidants in this area, providing versatile reactivity, heteroatom ligands, and mild reaction conditions. These reagents are also environmentally benign, non-toxic, and relatively inexpensive compared to other inorganic oxidants. Despite their broad utility, there remain limitations in their application; they produce stoichiometric organic byproducts, there is a limited scope of heteroatoms ligands available, and their use in facilitating challenging reductive eliminations (i.e., $-\mathrm{CF}_{3},-\mathrm{F}$ ) is limited. Future developments in more diverse hypervalent iodine scaffolds, particularly in those that could act as "innocent" oxidants, or those that could be readily recycled/regenerated, has the potential to greatly expand the utility of this already powerful reaction manifold.

Acknowledgments: The authors would like to thank Temple University for their support. Additionally, acknowledgement is made to the donors of the American Chemical Society Petroleum Research Fund for support of this research.

Conflicts of Interest: The authors declare no conflict of interest.

\section{References}

1. Hickman, A.J.; Sanford, M.S. High-valent organometallic copper and palladium in catalysis. Nature 2012, 484, 177-185. [CrossRef] [PubMed]

2. Lyons, T.W.; Sanford, M.S. Palladium-Catalyzed Ligand-Directed C-H Functionalization Reactions. Chem. Rev. 2010, 110, 1147-1169. [CrossRef] [PubMed]

3. Canty, A.J. Development of organopalladium(IV) chemistry: Fundamental aspects and systems for studies of mechanism in organometallic chemistry and catalysis. Acc. Chem. Res. 1992, 25, 83-90. [CrossRef]

4. Xu, L.-M.; Li, B.-J.; Yang, Z.; Shi, Z.-J. Organopalladium(IV) chemistry. Chem. Soc. Rev. 2010, 39, 712-733. [CrossRef] [PubMed]

5. Sehnal, P.; Taylor, R.J.K.; Fairlamb, I.J.S. Emergence of Palladium(IV) Chemistry in Synthesis and Catalysis. Chem. Rev. 2010, 110, 824-889. [CrossRef] [PubMed]

6. Dick, A.R.; Sanford, M.S. Transition metal catalyzed oxidative functionalization of carbon-hydrogen bonds. Tetrahedron 2006, 62, 2439-2463. [CrossRef]

7. Topczewski, J.J.; Sanford, M.S. Carbon-hydrogen $(\mathrm{C}-\mathrm{H})$ bond activation at $\mathrm{Pd}^{\mathrm{IV}}$ : A frontier in $\mathrm{C}-\mathrm{H}$ functionalization catalysis. Chem. Sci. 2014, 6, 70-76. [CrossRef] 
8. Racowski, J.M.; Sanford, M.S. Carbon-Heteroatom Bond-Forming Reductive Elimination from Palladium(IV) Complexes. In Higher Oxidation State Organopalladium and Platinum Chemistry; Springer: Berlin/Heidelberg, Germany, 2011; Volume 35, pp. 61-84.

9. Byers, P.K.; Canty, A.J.; Skelton, B.W.; White, A.H. The oxidative addition of lodomethane to [PdMe $\left.\mathrm{Pd}_{2}(\mathrm{bpy})\right]$ and the X-ray structure of the organopalladium(IV) product fac-[PdMe $\left.3(\mathrm{bpy})_{1}\right]$ (bpy $=2,2^{\prime}$-bipyridyl). J. Chem. Soc. Chem. Commun. 1986, 1722-1724. [CrossRef]

10. Yoneyama, T.; Crabtree, R.H. Pd(II) catalyzed acetoxylation of arenes with iodosyl acetate. J. Mol. Catal. A Chem. 1996, 108, 35-40. [CrossRef]

11. Stock, L.M.; Tse, K.T.; Vorvick, L.J.; Walstrum, S.A. Palladium(II) acetate catalyzed aromatic substitution reaction. J. Org. Chem. 1981, 46, 1757-1759. [CrossRef]

12. Dick, A.R.; Hull, K.L.; Sanford, M.S. A Highly Selective Catalytic Method for the Oxidative Functionalization of C-H Bonds. J. Am. Chem. Soc. 2004, 126, 2300-2301. [CrossRef] [PubMed]

13. Kalyani, D.; Sanford, M.S. Regioselectivity in Palladium-Catalyzed C-H Activation/Oxygenation Reactions. Org. Lett. 2005, 7, 4149-4152. [CrossRef] [PubMed]

14. Kalberer, E.W.; Whitfield, S.R.; Sanford, M.S. Application of recyclable, polymer-immobilized iodine(III) oxidants in catalytic C-H bond functionalization. J. Mol. Catal. A Chem. 2006, 251, 108-113. [CrossRef]

15. Desai, L.V.; Hull, K.L.; Sanford, M.S. Palladium-Catalyzed Oxygenation of Unactivated sp ${ }^{3}$ C-H Bonds. J. Am. Chem. Soc. 2004, 126, 9542-9543. [CrossRef] [PubMed]

16. Neufeldt, S.R.; Sanford, M.S. O-acetyl oximes as transformable directing groups for Pd-catalyzed C-H bond functionalization. Org. Lett. 2010, 12, 532-535. [CrossRef] [PubMed]

17. Wang, D.-H.; Hao, X.-S.; Wu, D.-F.; Yu, J.-Q. Palladium-catalyzed oxidation of Boc-protected N-methylamines with IOAc as the oxidant: A Boc-directed $\mathrm{sp}^{3}$ C-H bond activation. Org. Lett. 2006, 8, 3387-3390. [CrossRef] [PubMed]

18. Cook, A.K.; Sanford, M.S. Mechanism of the palladium-catalyzed arene C-H acetoxylation: A comparison of catalysts and ligand effects. J. Am. Chem. Soc. 2015, 137, 3109-3118. [CrossRef] [PubMed]

19. Dick, A.R.; Kampf, J.W.; Sanford, M.S. Unusually Stable Palladium(IV) Complexes: Detailed Mechanistic Investigation of C-O Bond-Forming Reductive Elimination. J. Am. Chem. Soc. 2005, 127, 12790-12791. [CrossRef] [PubMed]

20. Racowski, J.M.; Dick, A.R.; Sanford, M.S. Detailed study of C-O and C-C bond-forming reductive elimination from stable C2N2O2-ligated palladium(IV) complexes. J. Am. Chem. Soc. 2009, 131, 10974-10983. [CrossRef] [PubMed]

21. Cheng, X.-F.; Li, Y.; Su, Y.-M.; Yin, F.; Wang, J.-Y.; Sheng, J.; Vora, H.U.; Wang, X.-S.; Yu, J.-Q. Pd(II)-catalyzed enantioselective C-H activation/C-O bond formation: Synthesis of chiral benzofuranones. J. Am. Chem. Soc. 2013, 135, 1236-1239. [CrossRef] [PubMed]

22. Emmert, M.H.; Cook, A.K.; Xie, Y.J.; Sanford, M.S. Remarkably high reactivity of $\mathrm{Pd}(\mathrm{OAc})_{2} /$ pyridine catalysts: Nondirected C-H oxygenation of arenes. Angew. Chem. Int. Ed. 2011, 50, 9409-9412. [CrossRef] [PubMed]

23. Zhang, S.-Y.; He, G.; Zhao, Y.; Wright, K.; Nack, W.A.; Chen, G. Efficient alkyl ether synthesis via palladium-catalyzed, picolinamide-directed alkoxylation of unactivated $\mathrm{C}\left(\mathrm{sp}^{3}\right)-\mathrm{H}$ and $\mathrm{C}\left(\mathrm{sp}^{2}\right)-\mathrm{H}$ bonds at remote positions. J. Am. Chem. Soc. 2012, 134, 7313-7316. [CrossRef] [PubMed]

24. Shan, G.; Yang, X.; Zong, Y.; Rao, Y. An efficient palladium-catalyzed C-H alkoxylation of unactivated methylene and methyl groups with cyclic hypervalent iodine (i(3+)) oxidants. Angew. Chem. Int. Ed. 2013, 52, 13606-13610. [CrossRef] [PubMed]

25. Liu, G.; Stahl, S.S. Highly regioselective Pd-catalyzed intermolecular aminoacetoxylation of alkenes and evidence for cis-aminopalladation and $\mathrm{S}_{\mathrm{N}} 2 \mathrm{C}-\mathrm{O}$ bond formation. J. Am. Chem. Soc. 2006, 128, 7179-7181. [CrossRef] [PubMed]

26. Desai, L.V.; Sanford, M.S. Construction of tetrahydrofurans by PdII/PdIV-catalyzed aminooxygenation of alkenes. Angew. Chem. Int. Ed. Engl. 2007, 46, 5737-5740. [CrossRef] [PubMed]

27. Li, Y.; Song, D.; Dong, V.M. Palladium-Catalyzed Olefin Dioxygenation. J. Am. Chem. Soc. 2008, 130, 2962-2964. [CrossRef] [PubMed]

28. Neufeldt, S.R.; Sanford, M.S. Asymmetric chiral ligand-directed alkene dioxygenation. Org. Lett. 2013, 15, 46-49. [CrossRef] [PubMed]

29. Pilarski, L.T.; Selander, N.; Böse, D.; Szabó, K.J. Catalytic allylic C-H acetoxylation and benzoyloxylation via suggested (eta(3)-allyl)palladium(IV) intermediates. Org. Lett. 2009, 11, 5518-5521. [CrossRef] [PubMed] 
30. Alam, R.; Pilarski, L.T.; Pershagen, E.; Szabó, K.J. Stereoselective intermolecular allylic C-H trifluoroacetoxylation of functionalized alkenes. J. Am. Chem. Soc. 2012, 134, 8778-8781. [CrossRef] [PubMed]

31. Bigi, M.A.; White, M.C. Terminal Olefins to Linear $\alpha, \beta$-Unsaturated Ketones: Pd(II)/Hypervalent Iodine Co-catalyzed Wacker Oxidation-Dehydrogenation. J. Am. Chem. Soc. 2013, 135, 7831-7834. [CrossRef] [PubMed]

32. Giri, R.; Chen, X.; Hao, X.-S.; Li, J.-J.; Liang, J.; Fan, Z.-P.; Yu, J.-Q. Catalytic and stereoselective iodination of prochiral C-H bonds. Tetrahedron Asymmetry 2005, 16, 3502-3505. [CrossRef]

33. Giri, R.; Chen, X.; Yu, J.-Q. Palladium-catalyzed asymmetric iodination of unactivated C-H bonds under mild conditions. Angew. Chem. Int. Ed. Engl. 2005, 44, 2112-2115. [CrossRef]

34. Mei, T.-S.; Giri, R.; Maugel, N.; Yu, J.-Q. Pd(II)-catalyzed monoselective ortho halogenation of C-H bonds assisted by counter cations: A complementary method to directed ortho lithiation. Angew. Chem. Int. Ed. 2008, 47, 5215-5219. [CrossRef] [PubMed]

35. McCall, A.S.; Wang, H.; Desper, J.M.; Kraft, S. Bis-N-heterocyclic carbene Palladium(IV) tetrachloride complexes: Synthesis, reactivity, and mechanisms of direct chlorinations and oxidations of organic substrates. J. Am. Chem. Soc. 2011, 133, 1832-1848. [CrossRef] [PubMed]

36. Lee, E.; Kamlet, A.S.; Powers, D.C.; Neumann, C.N.; Boursalian, G.B.; Furuya, T.; Choi, D.C.; Hooker, J.M.; Ritter, T. A fluoride-derived electrophilic late-stage fluorination reagent for PET imaging. Science 2011, 334, 639-642. [CrossRef] [PubMed]

37. Furuya, T.; Kaiser, H.M.; Ritter, T. Palladium-mediated fluorination of arylboronic acids. Angew. Chem. Int. Ed. 2008, 47, 5993-5996. [CrossRef] [PubMed]

38. Hull, K.L.; Anani, W.Q.; Sanford, M.S. Palladium-catalyzed fluorination of carbon-hydrogen bonds. J. Am. Chem. Soc. 2006, 128, 7134-7135. [CrossRef] [PubMed]

39. Wang, X.; Mei, T.-S.; Yu, J.-Q. Versatile $\mathrm{Pd}(\mathrm{OTf})_{2} \cdot 2 \mathrm{H}_{2} \mathrm{O}$-catalyzed ortho-fluorination using NMP as a promoter. J. Am. Chem. Soc. 2009, 131, 7520-7521. [CrossRef]

40. McMurtrey, K.B.; Racowski, J.M.; Sanford, M.S. Pd-Catalyzed C-H Fluorination with Nucleophilic Fluoride. Org. Lett. 2012, 14, 4094-4097. [CrossRef] [PubMed]

41. Selander, N.; Willy, B.; Szabó, K.J. Selective C-H borylation of alkenes by palladium pincer complex catalyzed oxidative functionalization. Angew. Chem. Int. Ed. 2010, 49, 4051-4053. [CrossRef] [PubMed]

42. Muñiz, K.; Martínez, C.; Iglesias, A. The Quest for Palladium-Catalysed Alkyl-Nitrogen Bond Formation. Chem. Rec. 2016, 16, 2561-2572. [CrossRef] [PubMed]

43. Streuff, J.; Hövelmann, C.H.; Nieger, M.; Muñiz, K. Palladium(II)-catalyzed intramolecular diamination of unfunctionalized alkenes. J. Am. Chem. Soc. 2005, 127, 14586-14587. [CrossRef] [PubMed]

44. Muñiz, K.; Hövelmann, C.H.; Streuff, J. Oxidative diamination of alkenes with ureas as nitrogen sources: Mechanistic pathways in the presence of a high oxidation state palladium catalyst. J. Am. Chem. Soc. 2008, 130, 763-773. [CrossRef] [PubMed]

45. Iglesias, A.; Muñiz, K. Studies on Alkyl-Nitrogen Bond Formation via Reductive Elimination from Monomeric Palladium Complexes in High Oxidation State. Helv. Chim. Acta 2012, 95, 2007-2025. [CrossRef]

46. Hövelmann, C.H.; Streuff, J.; Brelot, L.; Muñiz, K. Direct synthesis of bicyclic guanidines through unprecedented Palladium(II) catalysed diamination with copper chloride as oxidant. Chem. Commun. (Camb.) 2008, 2334-2336. [CrossRef] [PubMed]

47. Welbes, L.L.; Lyons, T.W.; Cychosz, K.A.; Sanford, M.S. Synthesis of cyclopropanes via Pd(II/IV)-catalyzed reactions of enynes. J. Am. Chem. Soc. 2007, 129, 5836-5837. [CrossRef] [PubMed]

48. Muñiz, K. Advancing palladium-catalyzed C-N bond formation: Bisindoline construction from successive amide transfer to internal alkenes. J. Am. Chem. Soc. 2007, 129, 14542-14543. [CrossRef] [PubMed]

49. Iglesias, A.; Pérez, E.G.; Muñiz, K. An Intermolecular Palladium-Catalyzed Diamination of Unactivated Alkenes. Angew. Chem. Int. Ed. 2010, 49, 8109-8111. [CrossRef] [PubMed]

50. Muñiz, K.; Kirsch, J.; Chávez, P. Intermolecular Regioselective 1,2-Diamination of Allylic Ethers. Adv. Synth. Catal. 2011, 353, 689-694. [CrossRef]

51. Martínez, C.; Muñiz, K. Palladium-catalyzed vicinal difunctionalization of internal alkenes: Diastereoselective synthesis of diamines. Angew. Chem. Int. Ed. 2012, 51, 7031-7034. [CrossRef] [PubMed]

52. Ingalls, E.L.; Sibbald, P.A.; Kaminsky, W.; Michael, F.E. Enantioselective palladium-catalyzed diamination of alkenes using $N$-fluorobenzenesulfonimide. J. Am. Chem. Soc. 2013, 135, 8854-8856. [CrossRef] [PubMed] 
53. Sibbald, P.A.; Michael, F.E. Palladium-catalyzed diamination of unactivated alkenes using $N$-fluorobenzenesulfonimide as source of electrophilic nitrogen. Org. Lett. 2009, 11, 1147-1149. [CrossRef] [PubMed]

54. Dick, A.R.; Remy, M.S.; Kampf, J.W.; Sanford, M.S. Carbon-Nitrogen Bond-Forming Reactions of Palladacycles with Hypervalent Iodine Reagents. Organometallics 2007, 26, 1365-1370. [CrossRef]

55. Thu, H.-Y.; Yu, W.-Y.; Che, C.-M. Intermolecular amidation of unactivated $\mathrm{sp}^{2}$ and $\mathrm{sp}^{3} \mathrm{C}-\mathrm{H}$ bonds via palladium-catalyzed cascade C-H activation/nitrene insertion. J. Am. Chem. Soc. 2006, 128, 9048-9049. [CrossRef] [PubMed]

56. Nadres, E.T.; Daugulis, O. Heterocycle synthesis via direct $\mathrm{C}-\mathrm{H} / \mathrm{N}-\mathrm{H}$ coupling. J. Am. Chem. Soc. 2012, 134, 7-10. [CrossRef] [PubMed]

57. He, G.; Zhao, Y.; Zhang, S.; Lu, C.; Chen, G. Highly efficient syntheses of azetidines, pyrrolidines, and indolines via palladium catalyzed intramolecular amination of $\mathrm{C}\left(\mathrm{sp}^{3}\right)-\mathrm{H}$ and $\mathrm{C}\left(\mathrm{sp}^{2}\right)-\mathrm{H}$ bonds at $\gamma$ and $\delta$ positions. J. Am. Chem. Soc. 2012, 134, 3-6. [CrossRef] [PubMed]

58. Iglesias, A.; Alvarez, R.; de Lera, A.R.; Muñiz, K. Palladium-catalyzed intermolecular C(sp $\left.{ }^{3}\right)-H$ amidation. Angew. Chem. Int. Ed. 2012, 51, 2225-2228. [CrossRef] [PubMed]

59. Tang, S.; Peng, P.; Pi, S.-F.; Liang, Y.; Wang, N.-X.; Li, J.H. Sequential intermolecular aminopalladation/ ortho-arene C-H activation reactions of $\mathrm{N}$-phenylpropiolamides with phthalimide. Org. Lett. 2008, 10, 1179-1182. [CrossRef] [PubMed]

60. Jordan-Hore, J.A.; Johansson, C.C.C.; Beck, E.M.; Gaunt, M.J. Oxidative Pd(II)-catalyzed C-H bond amination to carbazole at ambient temperature. J. Am. Chem. Soc. 2008, 130, 16184-16186. [CrossRef] [PubMed]

61. Zakrzewski, J.; Smalley, A.P.; Kabeshov, M.A.; Gaunt, M.J.; Lapkin, A.A. Continuous-Flow Synthesis and Derivatization of Aziridines through Palladium-Catalyzed C $\left(\mathrm{sp}^{3}\right)-\mathrm{H}$ Activation. Angew. Chem. Int. Ed. 2016, 55, 8878-8883. [CrossRef] [PubMed]

62. Yoshimura, A.; Zhdankin, V.V. Advances in Synthetic Applications of Hypervalent Iodine Compounds. Chem. Rev. 2016, 116, 3328-3435. [CrossRef] [PubMed]

63. Canty, A.J.; Rodemann, T.; Skelton, B.W.; White, A.H. Access to Alkynylpalladium(IV) and -Platinum(IV) Species, Including Triorgano(diphosphine)metal(IV) Complexes and the Structural Study of an

Alkynyl(pincer)platinum(IV) Complex, $\mathrm{Pt}\left(\mathrm{O}_{2} \mathrm{CArF}\right) \mathrm{I}\left(\mathrm{C}: \mathrm{CSiMe}_{3}\right)(\mathrm{NCN})\left(\mathrm{ArF}=4-\mathrm{CF}_{3} \mathrm{C}_{6} \mathrm{H}_{4}, \mathrm{NCN}=\right.$ [2,6-(dimethylaminomethyl)phenyl-N,C,N]-). Organometallics 2006, 23, 3466-3473.

64. Canty, A.J.; Patel, J.; Rodemann, T.; Ryan, J.H.; Skelton, B.W.; White, A.H. Reactivity of Diaryliodine(III) Triflates toward Palladium(II) and Platinum(II): Reactions of C( $\left.\mathrm{sp}^{2}\right)$-I Bonds to Form Arylmetal(IV) Complexes; Access to Dialkyl(aryl)metal(IV), 1,4-Benzenediyl-Bridged Platinum(IV), and Triphenylplatinum(IV) Species; and Structural Studies of Platinum(IV) Complexes. Organometallics 2004, 23, 3466-3473.

65. Bayler, A.; Canty, A.J.; Ryan, J.H.; Skelton, B.W.; White, A.H. Arylation of palladium(II) and platinum(II) by diphenyliodonium triflate to form metal(IV) species, and a structural analysis of an isomer of $\mathrm{PtIMe} 2 \mathrm{Ph}(\mathrm{bpy})$ (bpy = 2,2'-bipyridine). Inorg. Chem. Commun. 2000, 3, 575-578. [CrossRef]

66. Canty, A.J.; Rodemann, T. Entry to alkynylplatinum(IV) chemistry using hypervalent iodine(III) reagents, and the synthesis of triphenyl $\left\{4,4^{\prime}\right.$-bis(tert-butyl)-2,2'-bipyridine\}iodoplatinum(IV). Inorg. Chem. Commun. 2003, 6, 1382-1384. [CrossRef]

67. Kalyani, D.; Deprez, N.R.; Desai, L.V.; Sanford, M.S. Oxidative C-H activation/C-C bond forming reactions: Synthetic scope and mechanistic insights. J. Am. Chem. Soc. 2005, 127, 7330-7331. [CrossRef] [PubMed]

68. Wagner, A.M.; Sanford, M.S. Palladium-catalyzed C-H arylation of 2,5-substituted pyrroles. Org. Lett. 2011, 13, 288-291. [CrossRef] [PubMed]

69. Deprez, N.R.; Sanford, M.S. Synthetic and mechanistic studies of Pd-catalyzed C-H arylation with diaryliodonium salts: Evidence for a bimetallic high oxidation state Pd intermediate. J. Am. Chem. Soc. 2009, 131, 11234-11241. [CrossRef] [PubMed]

70. Canty, A.J.; Ariafard, A.; Sanford, M.S.; Yates, B.F. Mechanism of Pd-Catalyzed Ar-Ar Bond Formation Involving Ligand-Directed $\mathrm{C}-\mathrm{H}$ Arylation and Diaryliodonium Oxidants: Computational Studies of Orthopalladation at Binuclear Pd(II) Centers, Oxidation To Form Binuclear Palladium(III) Species, and

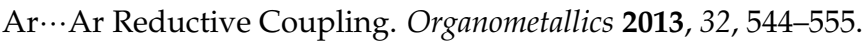

71. Deprez, N.R.; Kalyani, D.; Krause, A.; Sanford, M.S. Room temperature palladium-catalyzed 2-arylation of indoles. J. Am. Chem. Soc. 2006, 128, 4972-4973. [CrossRef] [PubMed] 
72. Hickman, A.J.; Sanford, M.S. Catalyst Control of Site Selectivity in the Pd II/IV-Catalyzed Direct Arylation of Naphthalene. ACS Catal. 2011, 1, 170-174. [CrossRef]

73. Tolnai, G.L.; Ganss, S.; Brand, J.P.; Waser, J. C2-Selective Direct Alkynylation of Indoles. Org. Lett. 2012, 15, 112-115. [CrossRef] [PubMed]

74. Cho, E.J.; Senecal, T.D.; Kinzel, T.; Zhang, Y.; Watson, D.A.; Buchwald, S.L. The Palladium-Catalyzed Trifluoromethylation of Aryl Chlorides. Science 2010, 328, 1679-1681. [CrossRef] [PubMed]

75. Grushin, V.V.; Marshall, W.J. Facile Ar- $\mathrm{CF}_{3}$ Bond Formation at Pd. Strikingly Different Outcomes of Reductive Elimination from $\left[\left(\mathrm{Ph}_{3} \mathrm{P}\right)_{2} \mathrm{Pd}\left(\mathrm{CF}_{3}\right) \mathrm{Ph}\right]$ and $\left[(\mathrm{Xantphos}) \mathrm{Pd}\left(\mathrm{CF}_{3}\right) \mathrm{Ph}\right]$. J. Am. Chem. Soc. 2006, 128, 12644-12645. [CrossRef] [PubMed]

76. Wang, X.; Truesdale, L.; Yu, J.-Q. Pd(II)-Catalyzed ortho-Trifluoromethylation of Arenes Using TFA as a Promoter. J. Am. Chem. Soc. 2010, 132, 3648-3649. [CrossRef] [PubMed]

77. Ball, N.D.; Kampf, J.W.; Sanford, M.S. Aryl-CF 3 Bond-Forming Reductive Elimination from Palladium(IV). J. Am. Chem. Soc. 2010, 132, 2878-2879. [CrossRef] [PubMed]

78. Ball, N.D.; Gary, J.B.; Ye, Y.; Sanford, M.S. Mechanistic and computational studies of oxidatively-induced aryl- $\mathrm{CF}_{3}$ bond-formation at Pd: Rational design of room temperature aryl trifluoromethylation. J. Am. Chem. Soc. 2011, 133, 7577-7584. [CrossRef] [PubMed]

79. $\mathrm{Mu}$, X.; Chen, S.; Zhen, X.; Liu, G. Palladium-Catalyzed Oxidative Trifluoromethylation of Indoles at Room Temperature. Chem. Eur. J. 2011, 17, 6039-6042. [CrossRef] [PubMed]

80. Powers, D.C.; Benitez, D.; Tkatchouk, E.; Goddard, W.A.; Ritter, T. Bimetallic reductive elimination from dinuclear Pd(III) complexes. J. Am. Chem. Soc. 2010, 132, 14092-14103. [CrossRef] [PubMed]

81. Ye, Y.; Ball, N.D.; Kampf, J.W.; Sanford, M.S. Oxidation of a cyclometalated Pd(II) dimer with " $\mathrm{CF}_{3}+$ ": Formation and reactivity of a catalytically competent monomeric $\mathrm{Pd}(\mathrm{IV})$ aquo complex. J. Am. Chem. Soc. 2010, 132, 14682-14687. [CrossRef] [PubMed]

82. Powers, D.C.; Lee, E.; Ariafard, A.; Sanford, M.S.; Yates, B.F.; Canty, A.J.; Ritter, T. Connecting binuclear $\mathrm{Pd}(\mathrm{III})$ and mononuclear Pd(IV) chemistry by Pd-Pd bond cleavage. J. Am. Chem. Soc. 2012, 134, 12002-12009. [CrossRef] [PubMed]

83. Cotton, F.A.; Gu, J.; Murillo, C.A.; Timmons, D.J. The First Dinuclear Complex of Palladium(III). J. Am. Chem. Soc. 1998, 120, 13280-13281. [CrossRef]

84. Cotton, F.A.; Koshevoy, I.O.; Lahuerta, P.; Murillo, C.A.; Sanaú, M.; Ubeda, M.A.; Zhao, Q. High Yield Syntheses of Stable, Singly Bonded $\mathrm{Pd}_{2}{ }^{6+}$ Compounds. J. Am. Chem. Soc. 2006, 128, 13674-13675. [CrossRef] [PubMed]

85. Powers, D.C.; Geibel, M.A.L.; Klein, J.E.M.N.; Ritter, T. Bimetallic palladium catalysis: Direct observation of Pd(III)-Pd(III) intermediates. J. Am. Chem. Soc. 2009, 131, 17050-17051. [CrossRef] [PubMed]

86. Gol'dshleger, N.F.; Eskova, V.V.; Shilov, A.E.; Shteinman, A.A. Alkane Reactions in Solutions of Chloride Complexes of Platinum. Zh. Fiz. Khim. 1972, 46, 1353.

87. Byers, P.K.; Canty, A.J.; Honeyman, T. Conformational studies in Palladium(IV) and Platinum(IV) chemistry. Crystal structure of the 1,1-bis(pyrazol-1-yl)-ethane complex fac-PtIMe $3\left[(\mathrm{pz})_{2} \mathrm{CHMe}-\mathrm{N}, \mathrm{N}^{\prime}\right]$. J. Orgmet. Chem. 1992, 433, 223-229. [CrossRef]

88. Canty, A.J. Organopalladium and platinum chemistry in oxidising milieu as models for organic synthesis involving the higher oxidation states of palladium. Dalton Trans. 2009, 10409-10417. [CrossRef] [PubMed]

89. Labinger, J.A. Platinum-Catalyzed C-H Functionalization. Chem. Rev. 2016. [CrossRef] [PubMed]

90. Dick, A.R.; Kampf, J.W.; Sanford, M.S. Platinum Model Studies for Palladium-Catalyzed Oxidative Functionalization of C-H Bonds. Organometallics 2005, 24, 482-485. [CrossRef]

91. Whitfield, S.R.; Sanford, M.S. Reactions of Platinum(II) Complexes with Chloride-Based Oxidants: Routes to Pt(III) and Pt(IV) Products. Organometallics 2008, 27, 1683-1689. [CrossRef]

92. Mamtora, J.; Crosby, S.H.; Newman, C.P.; Clarkson, G.J.; Rourke, J.P. Platinum(IV) Complexes: C-H Activation at Low Temperatures. Organometallics 2008, 27, 5559-5565. [CrossRef]

93. Corbo, R.; Georgiou, D.C.; Wilson, D.J.D.; Dutton, J.L. Reactions of [PhI(pyridine) $\left.{ }_{2}\right]^{2+}$ with model Pd and Pt II/IV redox couples. Inorg. Chem. 2014, 53, 1690-1698. [CrossRef] [PubMed]

94. Lanci, M.P.; Remy, M.S.; Lao, D.B.; Sanford, M.S.; Mayer, J.M. Modulating Sterics in Trimethylplatinum(IV) Diimine Complexes To Achieve C-C Bond-Forming Reductive Elimination. Organometallics 2011, 30, 3704-3707. [CrossRef] 
95. Mutule, I.; Suna, E.; Olofsson, K.; Pelcman, B. Catalytic direct acetoxylation of indoles. J. Org. Chem. 2009, 74, 7195-7198. [CrossRef] [PubMed]

96. Wagner, A.M.; Hickman, A.J.; Sanford, M.S. Platinum-catalyzed C-H arylation of simple arenes. J. Am. Chem. Soc. 2013, 135, 15710-15713. [CrossRef] [PubMed]

97. Hashmi, A.S.K. Gold-catalyzed organic reactions. Chem. Rev. 2007, 107, 3180-3211. [CrossRef]

98. Pflästerer, D.; Hashmi, A.S.K. Gold catalysis in total synthesis-Recent achievements. Chem. Soc. Rev. 2016, 45, 1331-1367. [CrossRef] [PubMed]

99. Fürstner, A.; Davies, P.W. Catalytic carbophilic activation: Catalysis by platinum and gold pi acids. Angew. Chem. Int. Ed. Engl. 2007, 46, 3410-3449. [CrossRef] [PubMed]

100. Wegner, H.A.; Auzias, M. Gold for C-C coupling reactions: A Swiss-Army-knife catalyst? Angew. Chem. Int. Ed. 2011, 50, 8236-8247. [CrossRef] [PubMed]

101. Komiya, S.; Kochi, J.K. Electrophilic Cleavage of Organogold Complexes with Acids. The Mechanism of the Reductive Elimination of Dialkyl(aniono)gold. J. Am. Chem. Soc. 1976, 98, 7599-7607. [CrossRef]

102. Hopkinson, M.N.; Gee, A.D.; Gouverneur, V. AuI/AuIII Catalysis: An Alternative Approach for C-C Oxidative Coupling. Chem. Eur. J. 2011, 17, 8248-8262. [CrossRef] [PubMed]

103. Wu, C.-Y.; Horibe, T.; Jacobsen, C.B.; Toste, F.D. Stable Gold(III) catalysts by oxidative addition of a carbon-carbon bond. Nature 2015, 517, 449-454. [CrossRef] [PubMed]

104. Wolf, W.J.; Winston, M.S.; Toste, F.D. Exceptionally fast carbon-carbon bond reductive elimination from Gold(III). Nat. Chem. 2014, 6, 159-164. [CrossRef] [PubMed]

105. Winston, M.S.; Wolf, W.J.; Toste, F.D. Halide-Dependent Mechanisms of Reductive Elimination from Gold(III). J. Am. Chem. Soc. 2015, 137, 7921-7928. [CrossRef] [PubMed]

106. Hashmi, A.S.K.; Blanco, M.C.; Fischer, D.; Bats, J.W. Gold Catalysis: Evidence for the In-situ Reduction of Gold(III) During the Cyclization of Allenyl Carbinols. Eur. J. Org. Chem. 2006, 2006, 1387-1389. [CrossRef]

107. Hashmi, A.S.K.; Ramamurthi, T.D.; Rominger, F. Synthesis, structure and reactivity of organogold compounds of relevance to homogeneous gold catalysis. J. Organomet. Chem. 2009, 694, 592-597. [CrossRef]

108. Bennett, M.A.; Hockless, D.C.R.; Rae, A.D.; Welling, L.; Willis, A.C. Carbon-Carbon Coupling in Dinuclear Cycloaurated Complexes Containing Bridging 2-(Diphenylphosphino)phenyl or 2-(Diethylphosphino)phenyl. Role of the Axial Ligand and the Fine Balance between Gold(II)-Gold(II) and Gold(I)-Gold(III). Organometallics 2000, 20, 79-87. [CrossRef]

109. Zamora, F.; Amo-Ochoa, P.; Fischer, B.; Schimanski, A.; Lippert, B. 5,5'-Diuracilyl Species from Uracil and. Angew. Chem. Int. Ed. 1999, 38, 2274-2275. [CrossRef]

110. Fuchita, Y.; Utsunomiya, Y.; Yasutake, M. Synthesis and reactivity of Arylgold(III) complexes from aromatic hydrocarbons via C-H bond activation. J. Chem. Soc. Dalton Trans. 2001, 2330-2334. [CrossRef]

111. Constable, E.C.; Sousa, L.R. Metal-ion dependent reactivity of 2-(2'-thienyl)pyridine (Hthpy). J. Organomet. Chem. 1992, 427, 125-139. [CrossRef]

112. Huynh, H.V.; Guo, S.; Wu, W. Detailed Structural, Spectroscopic, and Electrochemical Trends of Halido Mono- and Bis(NHC) Complexes of $\mathrm{Au}(\mathrm{I})$ and $\mathrm{Au}(\mathrm{III})$. Organometallics 2013, 32, 4591-4600. [CrossRef]

113. Pažický, M.; Loos, A.; Ferreira, M.J.; Serra, D.; Vinokurov, N.; Rominger, F.; Jäkel, C.; Hashmi, A.S.K.; Limbach, M. Synthesis, Reactivity, and Electrochemical Studies of Gold(I) and Gold(III) Complexes Supported by N-Heterocyclic Carbenes and Their Application in Catalysis. Organometallics 2010, 29, 4448-4458. [CrossRef]

114. Gaillard, S.; Nun, P.; Slawin, A.M.Z.; Nolan, S.P. Expeditious Synthesis of $[\mathrm{Au}(\mathrm{NHC})(\mathrm{L})]^{+}(\mathrm{NHC}=$ $\mathrm{N}$-Heterocyclic Carbene; L = Phosphine or NHC) Complexes. Organometallics 2010, 29, 5402-5408. [CrossRef]

115. Hofer, M.; Nevado, C. Unexpected Outcomes of the Oxidation of (Pentafluorophenyl) triphenylphosphanegold(I). Eur. J. Inorg. Chem. 2012, 2012, 1338-1341. [CrossRef]

116. Ghidiu, M.J.; Pistner, A.J.; Yap, G.P.A.; Lutterman, D.A.; Rosenthal, J. Thermal versus Photochemical Reductive Elimination of Aryl Chlorides from NHC-Gold Complexes. Organometallics 2013, 32, 5026-5029. [CrossRef]

117. Orbisaglia, S.; Jacques, B.; Braunstein, P.; Hueber, D.; Pale, P.; Blanc, A.; de Frémont, P. Synthesis, Characterization, and Catalytic Activity of Cationic NHC Gold(III) Pyridine Complexes. Organometallics 2013, 32, 4153-4164. [CrossRef]

118. Corbo, R.; Pell, T.P.; Stringer, B.D.; Hogan, C.F.; Wilson, D.J.D.; Barnard, P.J.; Dutton, J.L. Facile formation of homoleptic $\mathrm{Au}(\mathrm{III})$ trications via simultaneous oxidation and ligand delivery from $\left[\mathrm{PhI}(\text { pyridine })_{2}\right](2+)$. J. Am. Chem. Soc. 2014, 136, 12415-12421. [CrossRef] [PubMed] 
119. Roşca, D.-A.; Smith, D.A.; Bochmann, M. Cyclometallated Gold(III) hydroxides as versatile synthons for Au-N, Au-C complexes and luminescent compounds. Chem. Commun. (Camb.) 2012, 48, 7247-7249. [CrossRef] [PubMed]

120. Kar, A.; Mangu, N.; Kaiser, H.M.; Beller, M.; Tse, M.K. A general gold-catalyzed direct oxidative coupling of non-activated arenes. Chem. Commun. (Camb.) 2008, 106, 386-388. [CrossRef]

121. Kar, A.; Mangu, N.; Kaiser, H.M.; Tse, M.K. Gold-catalyzed direct oxidative coupling reactions of non-activated arenes. J. Organomet. Chem. 2009, 694, 524-537. [CrossRef]

122. Cambeiro, X.C.; Boorman, T.C.; Lu, P.; Larrosa, I. Redox-controlled selectivity of C-H activation in the oxidative cross-coupling of arenes. Angew. Chem. Int. Ed. 2013, 52, 1781-1784. [CrossRef] [PubMed]

123. Ball, L.T.; Lloyd-Jones, G.C.; Russell, C.A. Gold-catalyzed direct arylation. Science 2012, 337, $1644-1648$. [CrossRef] [PubMed]

124. Hofer, M.; Nevado, C. Cross-coupling of arene-Gold(III) complexes. Tetrahedron 2013, 69, 5751-5757. [CrossRef]

125. Haro, T.D.; Nevado, C. Gold-Catalyzed Ethynylation of Arenes. J. Am. Chem. Soc. 2010, 132, $1512-1513$. [CrossRef] [PubMed]

126. Brand, J.P.; Charpentier, J.; Waser, J. Direct alkynylation of indole and pyrrole heterocycles. Angew. Chem. Int. Ed. 2009, 48, 9346-9349. [CrossRef] [PubMed]

127. Brand, J.P.; Li, Y.; Waser, J. Gold-Catalyzed Alkynylation: Acetylene-Transfer instead of Functionalization. Isr. J. Chem. 2013, 53, 901-910. [CrossRef]

128. Brand, J.P.; Waser, J. Direct alkynylation of thiophenes: Cooperative activation of TIPS-EBX with gold and Brønsted acids. Angew. Chem. Int. Ed. 2010, 49, 7304-7307. [CrossRef] [PubMed]

129. Brand, J.P.; Waser, J. Para-Selective Gold-Catalyzed Direct Alkynylation of Anilines. Org. Lett. 2012, 14, 744-747. [CrossRef] [PubMed]

130. Li, Y.; Brand, J.P.; Waser, J. Gold-catalyzed regioselective synthesis of 2- and 3-alkynyl furans. Angew. Chem. Int. Ed. Engl. 2013, 52, 6743-6747. [CrossRef] [PubMed]

131. Iglesias, A.; Muñiz, K. Oxidative Interception of the Hydroamination Pathway: A Gold-Catalyzed Diamination of Alkenes. Chem. Eur. J. 2009, 15, 10563-10569. [CrossRef] [PubMed]

132. Zhang, D.-H.; Dai, L.-Z.; Shi, M. C( $\left.\mathrm{sp}^{3}\right)-\mathrm{C}\left(\mathrm{sp}^{3}\right)$ Bond Breaking in Methylenecyclopropanes Involving a AuI/ AuIII Catalytic Cycle. Eur. J. Org. Chem. 2010, 2010, 5454-5459. [CrossRef]

133. Ananikov, V.P. Nickel: The "Spirited Horse" of Transition Metal Catalysis. ACS Catal. 2015, 5, $1964-1971$. [CrossRef]

134. Klein, H.-F.; Bickelhaupt, A.; Jung, T.; Cordier, G. Syntheses and Properties of the First Octahedral Diorganonickel(IV) Compounds. Organometallics 1994, 13, 2557-2559. [CrossRef]

135. Shimada, S.; Rao, M.; Tanaka, M. Reaction of 1,2-Disilylbenzene with Bis[1,2-bis(dimethylphosphino) ethane]nickel(0). Isolation and Characterization of the First Silylnickel(IV) Complex-Organometallics (ACS Publications). Organometallics 1999, 18, 291-293. [CrossRef]

136. Dimitrov, V.; Linden, A. A pseudotetrahedral, high-oxidation-state organonickel compound: Synthesis and structure of bromotris(1-norbornyl)nickel(IV). Angew. Chem. Int. Ed. Engl. 2003, 42, 2631-2633. [CrossRef] [PubMed]

137. Carnes, M.; Buccella, D.; Chen, J.Y.-C.; Ramirez, A.P.; Turro, N.J.; Nuckolls, C.; Steigerwald, M. A stable tetraalkyl complex of nickel(IV). Angew. Chem. Int. Ed. 2009, 48, 290-294. [CrossRef] [PubMed]

138. Higgs, A.T.; Zinn, P.J.; Simmons, S.J.; Sanford, M.S. Oxidatively Induced Carbon-Halogen Bond-Forming Reactions at Nickel. Organometallics 2009, 28, 6142-6144. [CrossRef]

139. Higgs, A.T.; Zinn, P.J.; Sanford, M.S. Synthesis and Reactivity of NiII(Phpy) 2 (Phpy = 2-Phenylpyridine). Organometallics 2010, 29, 5446-5449. [CrossRef]

140. Camasso, N.M.; Sanford, M.S. Design, synthesis, and carbon-heteroatom coupling reactions of organometallic Nickel(IV) complexes. Science 2015, 347, 1218-1220. [CrossRef] [PubMed]

141. Bour, J.R.; Camasso, N.M.; Sanford, M.S. Oxidation of Ni(II) to Ni(IV) with Aryl Electrophiles Enables Ni-Mediated Aryl-CF 3 Coupling. J. Am. Chem. Soc. 2015, 137, 8034-8037. [CrossRef] [PubMed]

142. Meucci, E.A.; Camasso, N.M.; Sanford, M.S. An Organometalllic Ni(IV) Complex That Participates in Competing Transmetalation and $\mathrm{C}\left(\mathrm{sp}^{2}\right)-\mathrm{O}$ Bond-Forming Reductive Elimination Reactions. Organometallics 2017, 36, 247-250. [CrossRef]

143. Martinez, G.E.; Ocampo, C.; Park, Y.J.; Fout, A.R. Accessing Pincer Bis(carbene) Ni(IV) Complexes from Ni(II) via Halogen and Halogen Surrogates. J. Am. Chem. Soc. 2016, 138, 4290-4293. [CrossRef] [PubMed] 
144. Hwang, S.J.; Powers, D.C.; Maher, A.G.; Anderson, B.L.; Hadt, R.G.; Zheng, S.-L.; Chen, Y.-S.; Nocera, D.G. Trap-Free Halogen Photoelimination from Mononuclear Ni(III) Complexes. J. Am. Chem. Soc. 2015, 137, 6472-6475. [CrossRef] [PubMed]

145. Yokota, A.; Aihara, Y.; Chatani, N. Nickel(II)-Catalyzed Direct Arylation of C-H Bonds in Aromatic Amides Containing an 8-Aminoquinoline Moiety as a Directing Group. J. Org Chem. 2014, 79, 11922-11932. [CrossRef] [PubMed]

146. Lee, E.; Hooker, J.M.; Ritter, T. Nickel-Mediated Oxidative Fluorination for PET with Aqueous [18F] Fluoride. J. Am. Chem. Soc. 2012, 134, 17456-17458. [CrossRef] [PubMed]

147. Willert-Porada, M.A.; Burton, D.J.; Baenziger, N.C. Synthesis and X-ray structure of bis(trifluoromethyl)(N, $\mathrm{N}$-diethyldithiocarbamato)-copper; a remarkably stable perfluoroalkylcopper(III) complex. J. Chem. Soc. Chem. Commun. 1989, 1633-1634. [CrossRef]

148. Furuta, H.; Maeda, H.; Osuka, A. Doubly N-Confused Porphyrin: A New Complexing Agent Capable of Stabilizing Higher Oxidation States. J. Am. Chem. Soc. 2000, 122, 803-807. [CrossRef]

149. Santo, R.; Miyamoto, R.; Tanaka, R.; Nishioka, T.; Sato, K.; Toyota, K.; Obata, M.; Yano, S.; Kinoshita, I.; Ichimura, A.; et al. Diamagnetic-paramagnetic conversion of tris(2-pyridylthio)methylcopper(III) through a structural change from trigonal bipyramidal to octahedral. Angew. Chem. Int. Ed. Engl. 2006, 45, 7611-7614. [CrossRef] [PubMed]

150. Phipps, R.J.; Gaunt, M.J. A meta-selective copper-catalyzed C-H bond arylation. Science 2009, 323, $1593-1597$. [CrossRef] [PubMed]

151. Phipps, R.J.; Grimster, N.P.; Gaunt, M.J. Cu(II)-catalyzed direct and site-selective arylation of indoles under mild conditions. J. Am. Chem. Soc. 2008, 130, 8172-8174. [CrossRef] [PubMed]

152. Parsons, A.T.; Buchwald, S.L. Copper-Catalyzed Trifluoromethylation of Unactivated Olefins. Angew. Chem. Int. Ed. 2011, 50, 9120-9123. [CrossRef] [PubMed]

153. Filippou, A.C.; Winter, J.G.; Kociok-Köhn, G.; Troll, C. Electron-Rich Trichlorogermyl Complexes of Molybdenum and Tungsten Bearing a Cyclopentadienyl Ligand: Synthesis, Crystal Structures, and Cyclic Voltammetric Studies. Organometallics 1999, 18, 2649-2659. [CrossRef]

154. Hayton, T.W.; Legzdins, P.; Patrick, B.O. Differing reactivities of (trimpsi)M(CO)(2)(NO) complexes $[\mathrm{M}=$ $\mathrm{V}, \mathrm{Nb}, \mathrm{Ta}$; trimpsi $\left.\left.=(t) \mathrm{BuSi}\left(\mathrm{CH}_{2}\right) \mathrm{PMe}(2)\right)(3)\right]$ with halogens and halogen sources. Inorg. Chem. 2002, 41, 5388-5396. [CrossRef] [PubMed]

155. Dröse, P.; Crozier, A.R.; Lashkari, S.; Gottfriedsen, J.; Blaurock, S.; Hrib, C.G.; Maichle-Mössmer, C.; Schädle, C.; Anwander, R.; Edelmann, F.T. Facile access to tetravalent cerium compounds: One-electron oxidation using iodine(III) reagents. J. Am. Chem. Soc. 2010, 132, 14046-14047. [CrossRef] [PubMed]

156. Crispini, A.; Ghedini, M.; Neve, F. Synthesis and structure of the dimer $\left.\operatorname{Ir}_{2} \mathrm{Cl}_{2} \mathrm{I}_{2}(\mathrm{CO})_{2}(\mu \text {-dppm })_{2}\right]$. Inorg. Chim. Acta 1993, 209, 235-237. [CrossRef]

157. Teets, T.S.; Nocera, D.G. Oxygen reduction reactions of monometallic rhodium hydride complexes. Inorg. Chem. 2012, 51, 7192-7201. [CrossRef] [PubMed]

158. Young, K.J.H.; Mironov, O.A.; Periana, R.A. Stoichiometric Oxy Functionalization and CH Activation Studies of Cyclometalated Iridium(III) 6-Phenyl-2,2'-Bipyridine Hydrocarbyl Complexes. Organometallics 2007, 26, 2137-2140. [CrossRef]

159. Li, Z. Oxidation of hydrocarbons with iodobenzene diacetate catalyzed by manganese(III) porphyrins in a room temperature ionic liquid. J. Mol. Catal. A Chem. 2004, 214, 95-101. [CrossRef]

160. Karimipour, G.R.; Shadegan, H.A.; Ahmadpour, R. Clean and highly selective oxidation of alcohols by the $\mathrm{PhI}(\mathrm{OAc})_{2} / \mathrm{Mn}(\mathrm{TPP}) \mathrm{CN} / \mathrm{Im}$ catalytic system. J. Chem. Res. 2007, 2007, 252-256. [CrossRef]

161. In, J.-H.; Park, S.-E.; Song, R.; Nam, W. Iodobenzene diacetate as an efficient terminal oxidant in Iron(III) porphyrin complex-catalyzed oxygenation reactions. Inorg. Chim. Acta 2003, 343, 373-376. [CrossRef]

162. Fumagalli, G.; Boyd, S.; Greaney, M.F. Oxyarylation and aminoarylation of styrenes using photoredox catalysis. Org. Lett. 2013, 15, 4398-4401. [CrossRef] [PubMed]

163. Lu, M.-Z.; Loh, T.-P. Iron-catalyzed cascade carbochloromethylation of activated alkenes: Highly efficient access to chloro-containing oxindoles. Org. Lett. 2014, 16, 4698-4701. [CrossRef] [PubMed]

(C) 2017 by the authors. Licensee MDPI, Basel, Switzerland. This article is an open access article distributed under the terms and conditions of the Creative Commons Attribution (CC BY) license (http://creativecommons.org/licenses/by/4.0/). 